Portland State University

PDXScholar

$1-1-1986$

\title{
Fuzzy multiobjective mathematical programming in economic systems analysis: design and method
}

Li Da Xu

Portland State University

Follow this and additional works at: https://pdxscholar.library.pdx.edu/open_access_etds Let us know how access to this document benefits you.

\section{Recommended Citation}

$\mathrm{Xu}, \mathrm{Li} \mathrm{Da}$, "Fuzzy multiobjective mathematical programming in economic systems analysis: design and method" (1986). Dissertations and Theses. Paper 471.

https://doi.org/10.15760/etd.471

This Dissertation is brought to you for free and open access. It has been accepted for inclusion in Dissertations and Theses by an authorized administrator of PDXScholar. Please contact us if we can make this document more accessible: pdxscholar@pdx.edu. 


\title{
FUZZY MULTIOBJECTIVE MATHEMATICAL PROGRAMMING \\ IN ECONOMIC SYSTEMS ANALYSIS \\ DESIGN AND METHOD
}

by

LI DA XU

A dissertation submitted in partial fulfilment of the requirements for the degree of

\section{DOCTOR OF PHILOSOPHY \\ in \\ SYSTEMS SCIENCE}

\author{
Portland State University
} 1986 
TO THE OFFICE DF GRADUATE STUDIES AND RESEARCH:

The members of the Committee approve the dissertation

of Li Da Xu presented August 14, 1986.

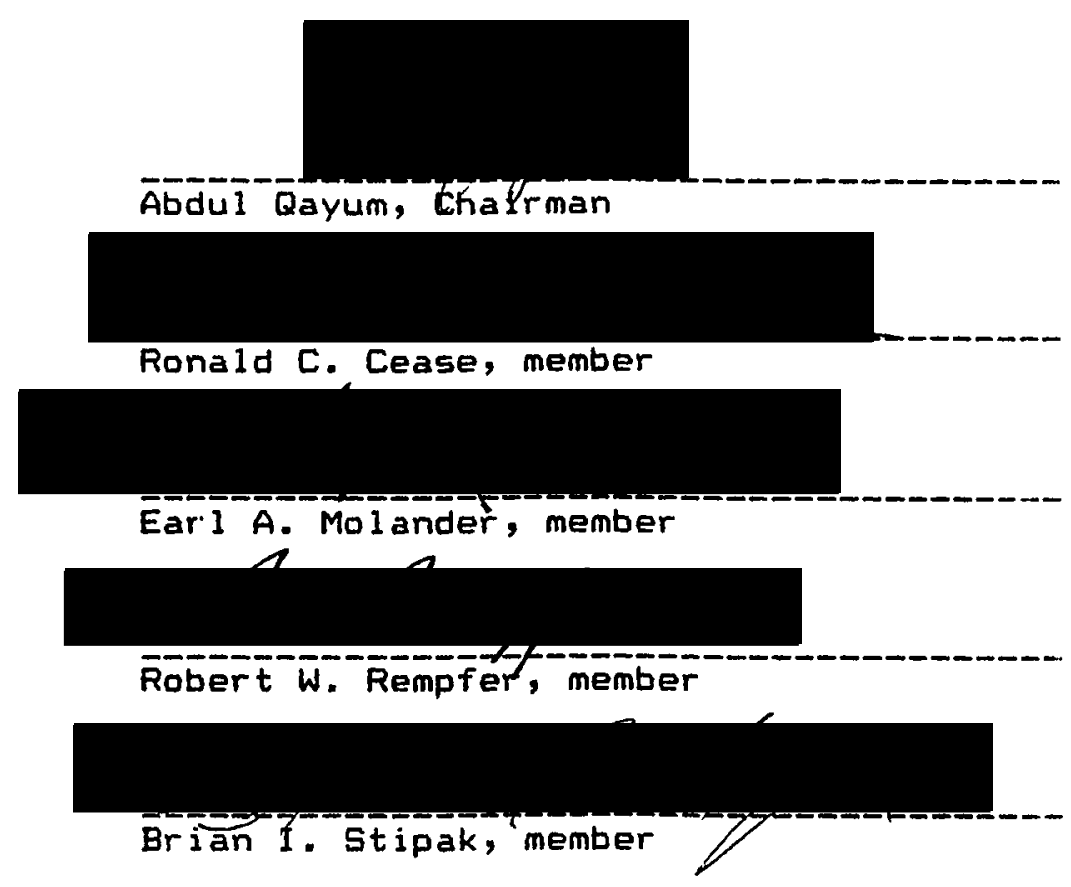

APPROVED:

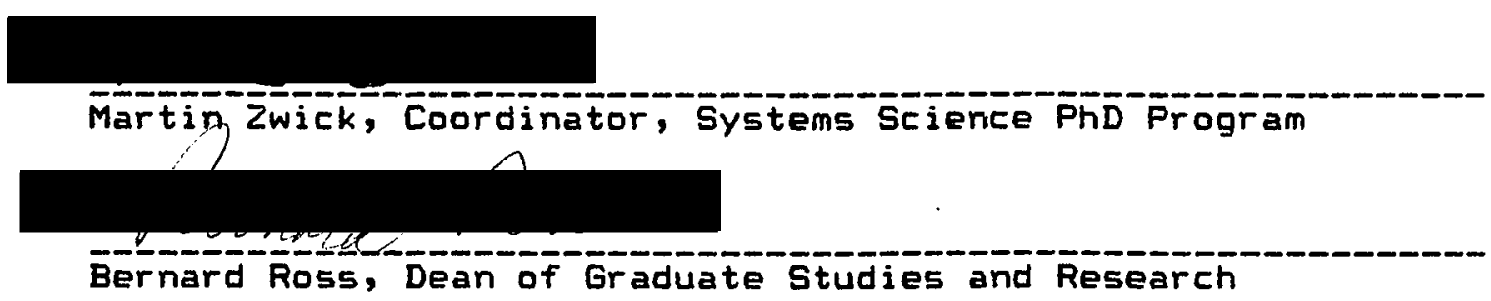


AN ABSTRACT OF THE DISSERTATION OF $\mathrm{Li}$ Da $X_{u}$ for the Doctor of Philosophy in Systems Science presented August 14, 1986.

Title: Fuzzy Multiobjective Mathematical Programming in Ecunomic Systems Analysis--Design and Method

APPROVED BY MEMBERS OF THE DISSERTATION COMMITTEE:

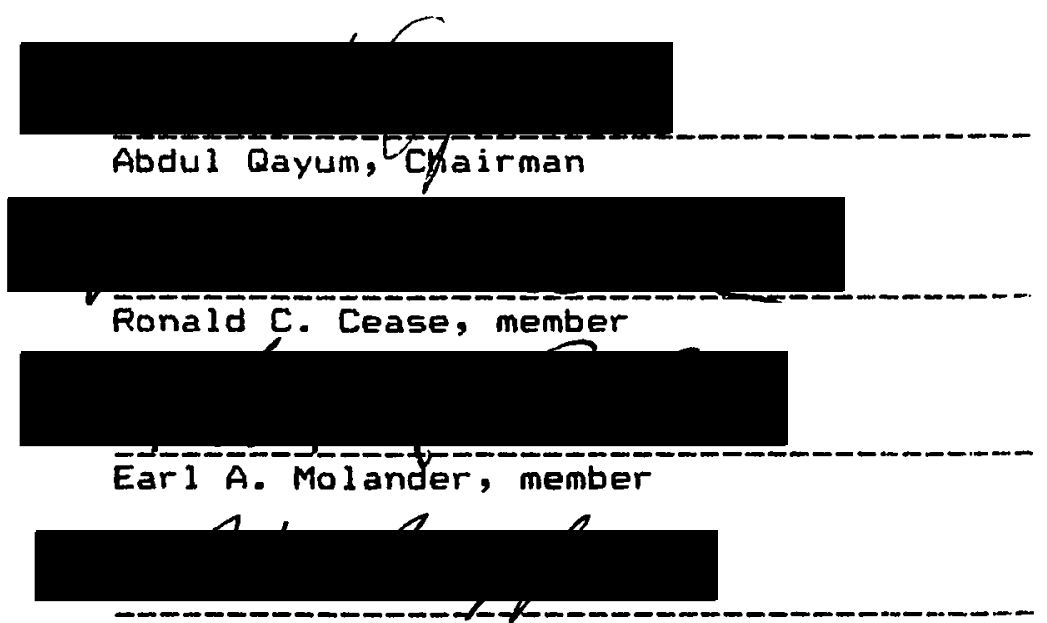
Robert W. Rempfer, member

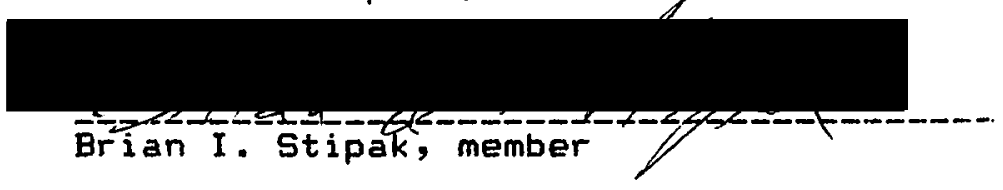

Economic systems analysis is a systems analysis technique of setting out the factors that have to be taken into account in making economic systems decisions. The inquiring and operational systems of the technique are almost exclusively designed for well-structured systems. In review of economic 
systems analysis against systems thinking, there is a growing tendency to discard the analytical approach as inappropriate for dealing with an ill-structured issue. Therefore, economic systems analysis needs both the inquiring and operational systems which are appropriate for ill-structured systems.

The foregoing leads to the introduction of an extensive methodology. Mainly, the weakness of economic systems analysis methodology can be traced to the philosophical paradigm upon which the technique is based. In this study, four main aspects of both the inquiring and operational systems of economic systems analysis are being explored:

1. A new philosophical paradigm is proposed as the foundation of general methodology in place of the traditional Newtonian-Kantian inquiring system.

2. The new philosophical paradigm needs new problem formulation and analysis space; therefore, a multidimensional, synergetic, and autopoietic model is proposed for systems synthesis and systems analysis.

3. The new philosophical paradigm is characterized as a Singerian inquiry, and as a result, Marglin's multiobjective analysis is replaced by a singerian multiobjective analysis.

4. Markov communication theory and fuzzy sets theory are proposed as tools for handling complexity. Markov 
communication theory and fuzzy sets theory are introduced for systems design and multiple objective analysis.

The first three aspects serve as a basis for introducing fuzzy multiobjective mathematical analyses, i.e., the fourth aspect. These refinements in methodology promise to aid in solving current problems not only in economic systems analysis, but also in the related fields of fuzzy multiobjective mathematical programming and systems theory.

This study reports on the first application of a Singerian fuzzy multiobjective mathematical algorithm in economic systems analysis, concluding that fuzzy systems theory, especially Markov communication theory, can realize approximate reasoning in economic systems analysis. Fuzzy modeling offers a deeper understanding of complexity and a means of expressing the insights that result from that understanding; moreover, it provides a means of incorporating subjectivity and adaptation. Therefore, fuzzy modeling increases the validity of the systems approach for dealing with ill-structured systems. The proposed method represents an important theoretical improvement of Marglin's approach. The results, however, also hold practical importance, for they are of practical interest to systems analysts who would improve systems design and multiobjective analysis. 


\section{ACKNOWLEDGEMENTS}

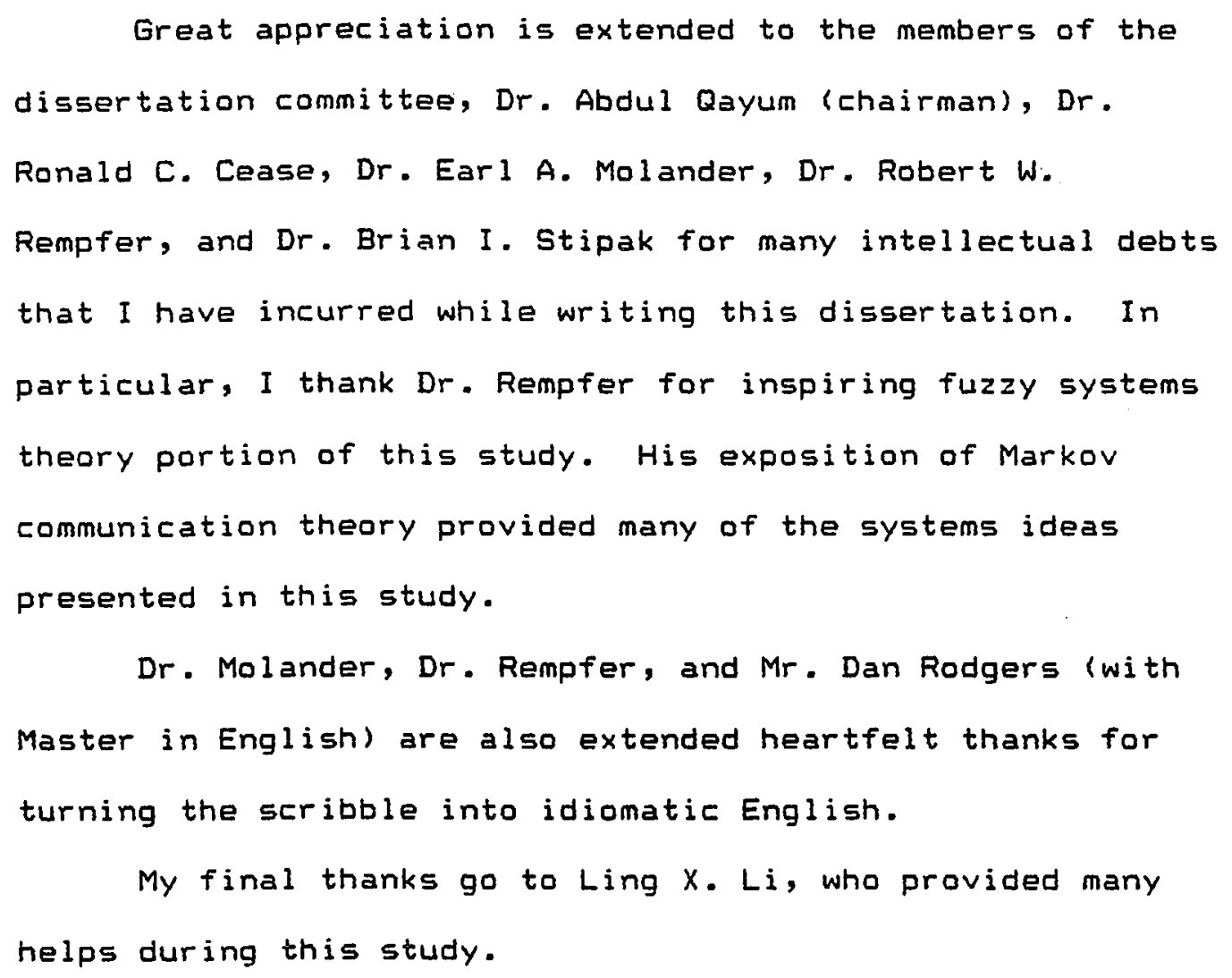

Portland, Oregon

August 1986 
TABLE OF CONTENTS

PAGE

ACKNOWLEDGEMENTS.......................... i i i

LIST OF TABLES.......................... vi

LIST OF FIGURES......................... vi

CHAPTER

1 INTRODUCTION

1.1 Statement of The Problem............ 1

Classical Economic Systems Analysis

Distinquishing Features of Classical

Economic Systems Analysis

Two Schools: Systems Analysis Vs. Poliey

Analysis

Crux of The Problem

1.2 Siqnificance of The Studv........... 8

1.3 Orqanization of the Study............ q

2 SYNERGETIC PHILOSOPHICAL PARADIGM IN ECONOMIC SYSTEMS ANALYSIS

2.1 Synerqetic Philosophical Paradigm........ 11

2.2 Proposed Paradigm Vs Conventional Paradigm 14

2.3 Prospect For Methodoloqy............ 25 
3 SYSTEMS DESIGN IN ECONOMIC SYSTEMS ANALYSIS

3.1 Multidimensional Frames.............. 31

3.2 Multidimensional Structural Analysis.... 33

General Interaction Process

Order Parameter, Critical Point, And Phase Transition

Decision-Prone Area--Boundary

Energy And Information

Systems Dynamics

Three-Dimensional System

3.3 The Implications To Systems Desiqn In Economic Systems Analysis........... 57

Systems Analysis And Purposeful Formulation

Control Feedback And Iterative Desian

FUZZY MULTIOBJECTIVE PROGRAMMING AND MARKOV COMMUNICATION THEORY IN ECONOMIC SYSTEMS ANALYSIS

4.1 Introduction................... 62 Resolution Level

Singerian Multiobjective Analysis Vs. Marqlin's Multiob.jective Analysis Characteristics of Adaptation 4.2 Truthfulness, Randomness, And Fuzziness.. 66 4.3 Introduction To Fuzzy Systems Theory..... 70 


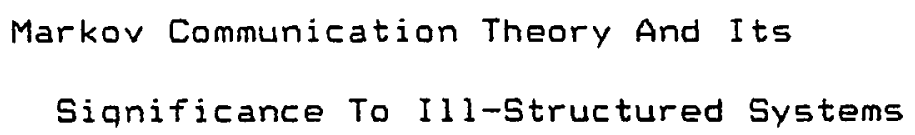

A LIST OF SYMBOLS...................... 127 


\section{LIST OF TABLES}

TABLE

PAGE

I Multidimensional Characteristics in Economic

Systems Decisionmakinq................. 15

II The Major Characteristics of Economic Systems

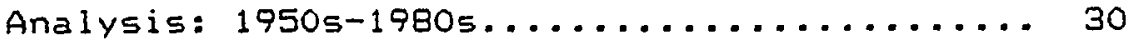

II Empirical Data for Initial Distribution of

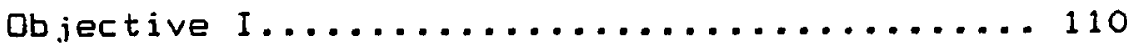

IV Simulation Results for Initial Distribution of

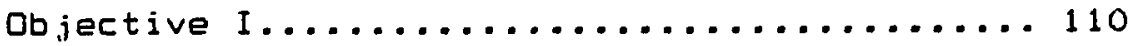

$\checkmark$ Empirical Data for State Transition of Objective

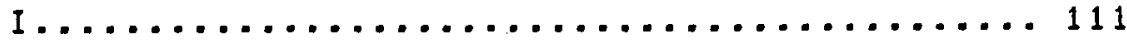

VI Simulation Results for State Transition of

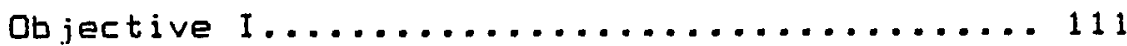

VIi Empirical Data for State Transition of objective

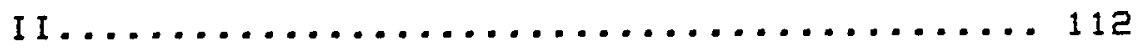

VIII Simulation Results for State Transition of

objective II...................... 112 


\section{LIST OF FIGURES}

FIGURE PAGE

1. Fuzzy Contral Systems..................46

2. Hierarchical Structure of Economic Systems

Analysis....................... 59 


\section{CHAPTER 1}

\section{INTRODUCTION}

But the existing scientific concepts cover always only a very limited part of reality, and the other part that has not yet been understood is infinite.

W. Heisenberg $[1$, P.201]

\subsection{Statement of The Problem}

1.1.1. Classical Economic Systems Analysis

Economic systems analysis is a systems analysis technique of setting out the factors that have to be taken into account in making economic systems decision, with the aim of maximizing the value of all benefits minus that of all costs, subject to given constraints. In fact, Paul Samuelson [2], a Nobel laureate in economics, defines economics as a subject for analyzing the costs and benefits of alternative patterns of resource allocation. Thus, economic systems analysis in many ways reflects the essence of economics.

Economic systems analysis may date back as far as the 1780 s when Bentham told briefly what his major work was and its significance [3]. It began to flourish in the early 1950s. Over the next two decades, works such as Mckean's Efficiency in Government through Systems Analysis, Hitch and 
McKean's The Economics of Defense in the Nuclear Age,

Quade's Systems Analysis and Policy Planning, Seiler's Introduction to Systems Cost Effectiveness, and Fisher's

Cost Considerations in Systems Analysis $[4,5,6,7,8]$

became representative of the discipline.

Many modern scholars have come to view economic

systems analysis as a sophisticated and well-founded

technique that examines all prospective consequences of a

proposed alternative in economic terms $[9,10]$. The

technique systematically enumerates all benefits and costs

of a particular economic alternative, whether external or

internal, tanqible or intanqible, quantifiable or

qualitative, that will accrue to the society.

According to Stokey [9], in brief, the procedure of

economic systems analysis consists of the following steps:

1. Definition of the project to be analyzed.

2. Determination of all relevant effects, internal or external.

3. Conversion of all effects into economic terms.

4. Calculation and comparison of benefits and costs.

5. Selection of optimal alternative.

According to Sage [11], similar steps are performed

for economic systems analysis:

1. Formulation of the problem. This is qenerally

accomplished by using tectiniques suitable for problem

formulation, including the identification of objectives, 
boundaries, constraints, and a value system. The outcome of the formulation mainly consists of alternatives.

2. Identification of the costs and benefits of each alternative. Costs and benefits of each alternative are enumerated. Measures for different kinds of costs and benefits are desiqnated. Economic conversion factors are considered.

3. Collection of data concerning costs and benefits. Information concerning the costs and benefits of each alternative is collected from sources that may include modeling, simulation, and optimization. When similar alternatives differ only in a set of parameter values. it is possible to build a model that ranks the alternatives on a performance scale. The model embraces an optimization procedure that indicates a set of parameter values, yielding the optimal performance.

4. Economic quantitative analysis of costs and benefits. Quantified costs and benefits are expressed in economic units. Market prices or shadow prices are introduced. Discounting is used to convert casts and benefits at different times to present values, allowing comparison.

5. Analysis of qualitative aspects. This analysis usually includes indirect effects such as social, cultural, esthetic, leqal, and environmental factors.

6. Communication of results, ordinarily in the form of 
a numerical report.

1.1.2. Distinquisting Features of Classical Economic Systems Analysis

In classical economic systems analysis, the traditional systems analysis tools are often considered to be sufficient and appropriate. Distinquishing features of classical economic systems analysis are as follows:

1. We11-structured systems assumption. a. The number of attributes necessary to characterize a system is 1 imited; b. System is static and does not evolve in time; $c$. The laws relating the properties of the attributes to the behavior of the system are generally deterministic; d. The behavioral factors do not contribute significantly to systems performance.

2. Objectivity. In accordance with the Newtonian inquiring system, economic systems analysis sets out to describe facts, and then to deduce results from that description. Both the analyst and the decisionmaker are seen as unbiased observers who are likely to define systems objective outside the system. Therefore, it is assumed that the decisionmaker acts rationally in the public interest. The aolden rule of allocative efficiency and the utility maximization rule of decision theory are siqnificant examples based on assumptions of objectivity.

3. Abstraction. The study of a system is in terms of 
a limited number of attributes and the relationships among them. This approach adopts the Kantian inquiring system, according to which truth is synthetic, i.e., the data and any analytical models based on the reduction are inseparable. Once the essential features of an observation have been reduced to a model, the resultant model can be adapted to realities. Radical abstraction tends to banish the detailed picture which may be described by qualitative analysis.

Conventional systems analysis technique to modeling aims at capturing the aggregate logic of an issue, which is taken to represent the essence of the issue. Aggregation, a technique of economic systems analysis, considers all relevant effects associated with a project during a given time frame, and then determines benefits and costs. Meanwhile, a discount rate is assumed, and the time streams of benefits and costs are discounted to present values. Theoretically, economic systems analysis can associate all the effects with each alternative, and then condense the effects into a single figure, for the purpose of comparing and ranking alternatives.

4. Linear time frame. Economic systems analysis uses a discount rate applied to future benefits minus costs to determine present values.

5. Optimal solution exploration. Economic systems analysis is widely known for its exploration for the 
optimum.

6. Problem-solving view. It is assumed that the solution is available for the system being explored.

1.1.3. Two Schools: Systems Analysis Vs. Policy Analysis From a classical perspective, as summarized by Anderson [12], the purpose of economic systems analysis is primarily to study economic efficiency. Applied systems analysis, too, discusses economic systems analysis in economic terms [11]. Beginning in 1965, a new school represented by Prest and Turvey [13], advocated economic systems analysis as a technique of decisionmaking within a framework which related to political, social, and other non-economic considerations. Prest and Turvey considered it unduly restrictive to define economic systems analysis as a continuation of operations research or systems analysis. Williams [14] points out that non-economic considerations intertwine so inextricably with economic factors, so that economic systems analysis can and must incorporate them, developing beyond mere operations research and systems analysis. These two schools, systems analysis represented by Anderson [12] and policy analysis represented by Prest, Turvey, and Williams [13, 14], have coexisted since the 19605 .

1.1.4. Crux of The Problem

Economic systems analysis has been successful in 
assessing well-structured projects since the 1950s. Since the early 1970s, growing numbers of analysts have criticized economic systems analysis for failing to cope with illstructured issues that involve broader considerations. Most analyses of ill-structured systems leave many questions unanswered. Indeed, this dearth of solutions to socioeconomic issues is inherent in the conventional methodology. However, economic systems analysis is still applied to illstructured issues, and the result is inappropriate policy. In fact, most of the characteristics of conventicnal economic systems analysis are incompatible with the reality represented by il1-structured systems (see 1.1.2.). The characteristics of economic systems analysis account larqely for the rise of the school of policy analysis.

The function of economic systems analysis, per se, is directly related to its inquiring and operational systems. However, these inquiring and operational systems are almost exclusively designed for well-structured systems. There is a growing inclination to dismiss the analytical approach as improper for dealing with ill-structured issues, arguing that the conventional methodology is insufficient to describe the approximate mechanism of a complex system, and shifting the emphasis of the method from analytical thinking to the approximate description in order to achieve approximate reasoning and meet the challenge raised by illstructured systems. 
Because economic systems analysis lacks both inquiring and operational systems for solving problems in illstructured systems, the quest for appropriate inquiring and operational systems becomes a paramount methodological issue. This search is the major purpose of the research.

\subsection{Significance of The Study}

In the course of time, the characteristics of the theories accepted by science are determined by philosophical paradigms. The Newtonian-Kantian inquiring system has been the methodological core of economic systems analysis for a long time. However, this model does not describe the actual process of economic systems decisionmaking. As a substitute, this study develops a synergetic philosophical paradigm as the foundation of general methodology, accompanied by an appropriate operational system that includes corresponding systems design and optimization. The study, a response to current trends in economic systems analysis, is the first to develop an inquiring system and corresponding operational system designed for il1-structured issues in economic systems analysis. Its results, therefore, have both theoretical and practical impor tance.

The major contribution of the study is to the methodological basis and the operational system of economic systems analysis. Furthermore, since economic systems 
analysis is one of the most important analytical functions in decision support systems, the study also contributes to the problem processing and artificial intelliqence phases of decision support systems, especially self-learning and model updating.

\subsection{Orqanization of The Study}

Inquiring systems and operational systems exist in an inseparable symbiosis. This study focuses on four principal aspects of both the inquiring and operational systems with the fol!owing objectives:

1. A new philosophical paradigm will be proposed as the foundation of general methodology in place of the Newtonian-Kantian inquiring system.

2. Because the new philosophical paradigm needs specific problem formulation and analysis space; therefore, a multidimensional, synergetic, and autopoietic model will be proposed for systems synthesis and systems analysis.

3. Because the new philosophical paradigm is characterized as a Sinqerian inquiry [15], Marqlin's multiob.jective analysis [16] will be replaced by a singerian multiobjective analysis.

4. Fuzzy systems theory, especially Markov communication theory [17], will be introduced for systems design and multiobjective mathematical analysis. The first three aspects provide a solid basis for 
introducing fuzzy formulation. The new philosophical paradiam creates multidimensional analysis and a Singerian multiobjective analysis replaces a Newtonian-Kantian multiobjective analysis such as the Marglin approach; then, the introduction of randomness and fuzziness becomes necessary. In short, the first three phases clarify the randomness and fuzziness in economic systems decisionmaking. The last--the fuzzy alqorithm--demonstrates how to deal with the fuzziness in economic systems issues that are eharacterized by multiobiectives. 
CHAPTER 2

SYNERGETIC PHILOSOPHICAL PARADIGM IN

ECONOMIC SYSTEMS ANALYSIS

\author{
But in fact, we know nothing from having seen it; \\ for the truth is hidden in the deep. \\ Democritus [18, p.166]
}

\author{
2.1. Synerqetic Philosophical Paradiqm \\ As a seientific inquiry, economic systems analysis \\ reflects or mirrors various science-oriented theories. This \\ general framework basically is the deep structure of \\ scientific theories. \\ The proposed philosophical paradigm claims the \\ functional characteristics of a general theoretical \\ framework of economic systems analysis but is basically \\ antagonistic: to the aforementioned features of economic \\ systems analysis in the following way: \\ Subjectivity \\ The process of economic systems analysis is \\ fundamentally a process of human activity. Therefore, \\ economic systems analysis is developing along with the \\ subjective activity of human beings. The statement that the \\ trace of subjectivity is indelible in scientific practice \\ [1] seems to hold true for economic systems analysis. The
}


recognition of Heisenberg's celebrated "Principle of Indeterminacy" [1] heralded a new era of scientific thought. As Popper [19, p.6] points out "seientifie method holds a somewhat peculiar position in being even less existent than some other non-existent subjects," the ideal and objective principles have been surrendered. The pattern that has been brought to light by economic systems analysis is only a partial one which can be probed by subjective practice under certain spacial and temporal conditions. The probe directly relates to the sțructure of subjective practice.

Wider Systems, Systems, And Subsystems This is a conceptual system that allows the economic systems issues to be studied as a complex whole. In performing its functions, a system depends on the input it receives from subsystems to generate useful outputs. The output of one subsystem becomes the required input for another subsystem. This interdependence is important in system functioning. A project can be approached as a system in which an economic subsystem is interdependent with other subsystems in a wider context. Multiple Reference Frames

Economic systems analysis is no longer a framework consisting of points that form a surface. Rather it is the whole of various reference frames, and the product of certain practice-cognition frames. 
Multidimensional Structure

A multidimensional structure is the end product of multiple reference frames. Economic systems analysis, instead of being viewed as a linear system, is now described as a system consisting of composites and autopoietic structure. The bistochastic assumption accepts that a socio-economic system contains multiple realities. Integrity

Econcmic systems analysis cannot eliminate societal intervention. Scientific analysis and value judgment become a whole through mediation.

Openness

Economic systems analysis is now characterized as an open system. Its theory is subject to further modification and reconstruction with the advent of new evidence that is incompatible with its basic assumptions. Therefore, it is continually being fed with new inputs that can be so incisive as to shatter the conventional picture. The progress of economic systems analysis is an unending process, and the structure of the framework itself is a dynamic pattern in continuous change. We observe that the above paradigm with which we are concerned here, in fact, has been accepted in reality. Based on the above characteristics, the evidence, which will be discussed in the following section, points to the fact that the existing concepts fit reality only inaccurately, 
and that the proposed paradigm complements the conventional paradigm in an appropriate way.

\subsection{Proposed Paradigm Vs. Conventional Paradigm}

Moving beyond the limitations of the Newtonian-Kantian

system will allow us to expand our rational thinking to a

deeper level. A systems approach is suggested here as an alternative to conventional method because systems thinking

has shown that ill-structured issues are more efficiently handled holistically than analytically. As an extension to the Newtonian-Kantian system, the proposed philosophical

view makes it possible to appreciate external and internal perspectives along with the analytical perspective in order to understand a socio-economic system fully. The point is that the well-1ill-structured systems dimensions have to be converted into a multidimensional system which describes the essential features of real world decisionmaking. The main characteristics of the multidimensional perspectives are described in Table I.

As Table I shows, the factors affecting the decisionmaking can be classified as analytical, external, and internal. The record of external and internal factors can be traced back to ancient times. External factors are a system's numerous determinants external to the decisionmakers that affect decisionmaking. Internal factors are the totality of the makeup of an individual, including 
Table I. Multidimensional Characteristics in Economic Systems Decisionmakinc

\begin{tabular}{|c|c|c|c|}
\hline & $\begin{array}{l}\text { Analytical } \\
\text { Perspective }\end{array}$ & $\begin{array}{l}\text { External } \\
\text { Perspective }\end{array}$ & $\begin{array}{c}\text { Internal } \\
\text { Perspective }\end{array}$ \\
\hline $\begin{array}{l}\text { Systems } \\
\text { definition }\end{array}$ & well-structured & i11-structured & il1-structured \\
\hline $\begin{array}{l}\text { Inquiring } \\
\text { system }\end{array}$ & Newtonian-Kantian & Singerian & Sinoerian \\
\hline $\begin{array}{l}\text { Subiect vs. } \\
\text { object }\end{array}$ & objectivity & subjectivity & sub jectivity \\
\hline Goal & $\begin{array}{l}\text { optimization of } \\
\text { resource allo- } \\
\text { cation, economic } \\
\text { feasibility }\end{array}$ & $\begin{array}{l}\text { orqanizational } \\
\text { or social } \\
\text { concern/ } \\
\text { acceptance }\end{array}$ & $\begin{array}{l}\text { preference, } \\
\text { needs }\end{array}$ \\
\hline $\begin{array}{l}\text { Value } \\
\text { system }\end{array}$ & $\begin{array}{l}\text { secondary value } \\
\text { [20] }\end{array}$ & $\begin{array}{l}\text { primary value } \\
\text { [20] }\end{array}$ & $\begin{array}{l}\text { primary vaiue } \\
\text { [20] }\end{array}$ \\
\hline $\begin{array}{l}\text { Abstrac- } \\
\text { tjon }\end{array}$ & $\begin{array}{l}\text { reductive } \\
\text { quantification }\end{array}$ & $\begin{array}{l}\text { intrinsic im- } \\
\text { possibility }\end{array}$ & $\begin{array}{l}\text { intrinsic im- } \\
\text { possibility }\end{array}$ \\
\hline Mechanism & cause-effect & interaction & interaction \\
\hline Time frame & I inear & nonl inear & nonl inear \\
\hline Measure & market-price & $\begin{array}{c}\text { non-market } \\
\text { price }\end{array}$ & $\begin{array}{c}\text { non-market } \\
\text { price }\end{array}$ \\
\hline $\begin{array}{l}\text { Decision } \\
\text { criterion }\end{array}$ & optimal & quasi-optimal & quasi-optimal \\
\hline $\begin{array}{l}\text { Observabi- } \\
\text { lity }\end{array}$ & $\begin{array}{l}\text { objective ana- } \\
\text { lyst \& } \\
\text { decisionmaker }\end{array}$ & $\begin{array}{l}\text { interest qroup } \\
\text { [21], goal } \\
\text { displacement } \\
\text { [22] }\end{array}$ & $\begin{array}{c}\text { coqnitive } \\
\text { tunnel }\end{array}$ \\
\hline Process & problem-5olving & $\begin{array}{l}\text { problem- } \\
\text { shifting }\end{array}$ & $\begin{array}{l}\text { problem- } \\
\text { shifting }\end{array}$ \\
\hline
\end{tabular}


beliefs, values, motivations, and behavioral modes;

obviously, they influence how a decisionmaker perceives, imagines, thinks, wills, and acts. The definition of external and internal factors here is broader than that suggested by authors such as Stokey, Andersen, and Linstone [9, 23, 24]. It is difficult to discover the laws that govern external and internal behavior. Human beings act in ways that can either conform to or disprove proposed behavioral laws. The ignorance of human behavioral mechanisms raises the possibility of rejecting any economic or engineering optimization. In describing both external and internal factors in economic systems analysis, analytical tools prove inadequate in modeling since many of the determinants of behavior are random and fuzzy. The aim of the following discussion is to illustrate and compare the new paradigm and the Newtonian-Kantian system (see 1.1.2. and 2.1.). I11-Structured System vs. Well-Structured System Most projects emerge from processes joined with complex structures that combine human and their environment with different artifacts of human, society, economy, and technology. The objectives and constraints surrounding projects differ in many important aspects from those prevailing in a well-structured system in terms of dimensionality and randomness. In the public sector, there are signs of ill-structured problems everywhere. 
In many cases, intuitive judgment must rule.

Subjectivity vs. Dbjectivity

The inconsistency shown by decisionmaker in decision space indicates that a decisionmaker does not always behave in accordance with an unique, objective preference function. A construction of an observed system is constrained by the perceptions and values of the observer. Even if such a construction distinguishes the system, it is still relatively close to its own limits. Foerster [25] indicates that the perception of a system is a part of the system, not external to it. Boulding [26] stresses that the formation of a new image is a function of the structure of existent images. The reality is being computed continuously and its eigenvalue is only a fuzzy representation.

Therefore, observation is a function of the observer plus the observed. In view of this inescapable subjectivity, the analyst is one of a number of important inputs, rather than a static, objective observer. In this sense, economic systems analysis cannot be objective. Analytical results are unlikely to be replicated by different analysts, because the value judgments-an uncontrollable variable-are indispensable and unavoidable elements in the analytical process. Here analytical results can be reasonably considered as the function of a fuzzy image.

The implication to the economic systems analysis is 
that the human cognitive system is largely subjective.

Subjectivity is not necessarily in the best public interest. Bias can be introduced by the analysts as well as the decisionmakers. Both the analyst and the decisionmaker must be mindful of the risks posed by their subjectivity. A self referential system requires an ethical feedback system to adjust the biases involved in the analytical process. Systems Concepts vs. Economic Feasibility

There is little sign of a serious quest for a reappraisal of the systems as a whole. However, the proposed paradigm emphasizes the systems concepts. The study of a project in isolation from its systems framework does not yield essential insight. In a general characterization of the immediate determinants of project decisionmaking, an abstract concept such as "benefits maximization" is less useful than the concept of systems-not because the latter is less abstract, but because it is less restrictive and closer to reality in the formulation and solution of practical issues.

It may be reasonable to disregard the known causal factors for the purposes of simplifying mathematical calculation. However, there is no warrant for ignoring the systems concepts in a statement of the theory of economic systems analysis. The initial estimated cost of a project may be substantially higher than its full cost, while the initial estimated benefits may be substantially lower than 
the real benefits. An alternative, if implemented, may have many consequences caused by the motion of subsystems which can be positive, neutral, or negative to system objectives. A basic contradiction residing in economic systems analysis is that no matter how rational it is from an economic point of view, the economic systems issue is a systems decision issue, therefore, economic analysis is, at best, a part of the complete analysis.

The systematic thesis claims that only with a systems view is it possible to find real objectives and constraints. Therefore, the interactions among subsystems, systems, and wider systems is of great importance in exploring the real decision process. A project ought to be studied as a system open to such interactions.

Multiple Reality vs. Optimization of Resource Allocation Optimization of resource allocation is the main criterion of economic feasibility. However, multiple realities exist. Kneese [27] provides an example which exposes the contradiction between resource allocation optimization and public appeal. Economic systems analysis, in fact, is an evaluation effort that has been developed to deal with complex, ill-structured issues. Holling [28] emphasized that most complicated systems seek resilience instead of efficiency. Efforts taken to determine an unique optimal solution to an economic systems issue which consists of a great number of variables are probably doomed to 
failure. Optimal solutions by multiple returns methods, or benefit-cost ratios may cause bifurcation in problem solving, i.e., the analytical perspective tends to conflict with external and/or internal factors.

The issue being modeled is ill-structured, such that a beautiful mathematical model is limited despite its elegance. Obviously, the optimization of a project can only be obtained if the subsystem state matches the system state; otherwise, an optimization, at best, is only a quasioptimization. Multiple Reference Frames vs. Abstraction

A common criterion for evaluating projects is that a meaningful comparison of all effects is possible only when all inputs and outputs can be expressed in terms of a common unit at a certain point in time and this criterion is strongly supported by abstraction. In practice, to quantify all effects and convert them into an economic measure is beyond the capability of conventional methodology.

The aggregate approach has serious deprivations. First, reduction erases considerable information and the details have to be de-intensified, for instance, when undesirable distributional effects cannot be corrected by transfer payments. Second, a single economic measure depends on the value assigned to effects when they are perceived and on the assumptions by which commensurate units are ascertained. The judgment and assumption are fuzzy and 
may lead to a value system which only slightly relates to the reality. Moreover, the reduced figure is dependent on several measurements, each is subject to error, and therefore, the final figure necessarily incorporates a combination of these errors. Third, serious theoretical and practical problems arise when there are multiple decisionmakers. Finally, a single objective function is often used to approximate essentially multiobjective situations. Accordingly, objects cannot be meaningfully reduced to terms which will allow precise quantification, and reductive modeling only reflects partial reality.

In a project, the inputs are from all interrelevant sources; the outputs are a compound substance of the inputs. The after effects continue beyond the project life, such as higher order effects, resilience, and intergeneration discounting. In most cases, one common unit is insufficient for expressing all inputs and outputs. A solution to an economic systems issue that is simplified and possibly made amenable to calculation by aggregation may not be an appropriate solution to the original problem. Rourke [29] indicates that many public programs proved resistant to quantification. Dasqupta [30] recognizes that there are serious limitations for ignoring externality in economic systems analysis. Hoos [31] lists two economic systems analyses of education and health programs in which the traditional reductive modeling led to "suboptimization" 
and "piecemeal fraqmentation". Self [32] indicates the unrealistic and even artificial deqree of precision in the evaluation of an airport.

As Table I shows, a systematic view leads us to focus on more complex factors.

Multiple Reference Frames vs. Market Value

The expression that all the items of input and output can be expressed in terms of market value remains an ideal solution. Many items of input and output certainly cannot be expressed in terms of market value. Non-divisibility is one characteristic of environmental goods that makes it difficult to obtain economic value directly. Even if the price is available, it may not perfectly reflect value. If the emphasis is to be placed on external and/or internal considerations, market prices are just not reliable as a basis for developing value estimates of the consequences of decisions. For many large-scale projects, even when it is claimed that the market price is available, caution is to be exercised in using it as a basis for estimating money expenditure implications, since it involves various considerations other than monetary eriteria. Therefore, the application of the principle of market price is complicated.

Multiple Reference Frames vs. Discounting Rate

In analytical perspective, all the items of input and output can be stated in terms of equivalent values at any 
particular discount or interest rate discounting backward or compounding forward. An economic system is subiect to inflation, recession, and depression. It is a complex system consisting of many different elements which are constantly changing. Many factors should be viewed not as static, but as dynamic, with some units being continually created, and some others being phased out. The dynamic time frame sugqests a nonlinear perception of time. The function may have continuous partial derivatives. However, the rationale for keeping other independent variables constant is lack of sufficient grounds. Even the existence of these partial derivatives is not enough to quarantee the continuity of the function.

Besides, different decisionmakers may have different time preferences, and some have a negative discount rate. The attainment of present objectives can be juxtaposed to potential future objectives, and these may not be conveniently expressed through a simplified discount rate. In addition to the deficiency of an analytical perspective, the weights put on the rational analysis by decisionmakers are always insiqnificant $[33,34,35]$. The final decision may not be based on analytical criteria, the more important consideration may be embedded atmosphere. Common "Weltanschauung", moral standard, and value system unify all forces under the universal philosophy and direction, and finally a prevailing view is created. 


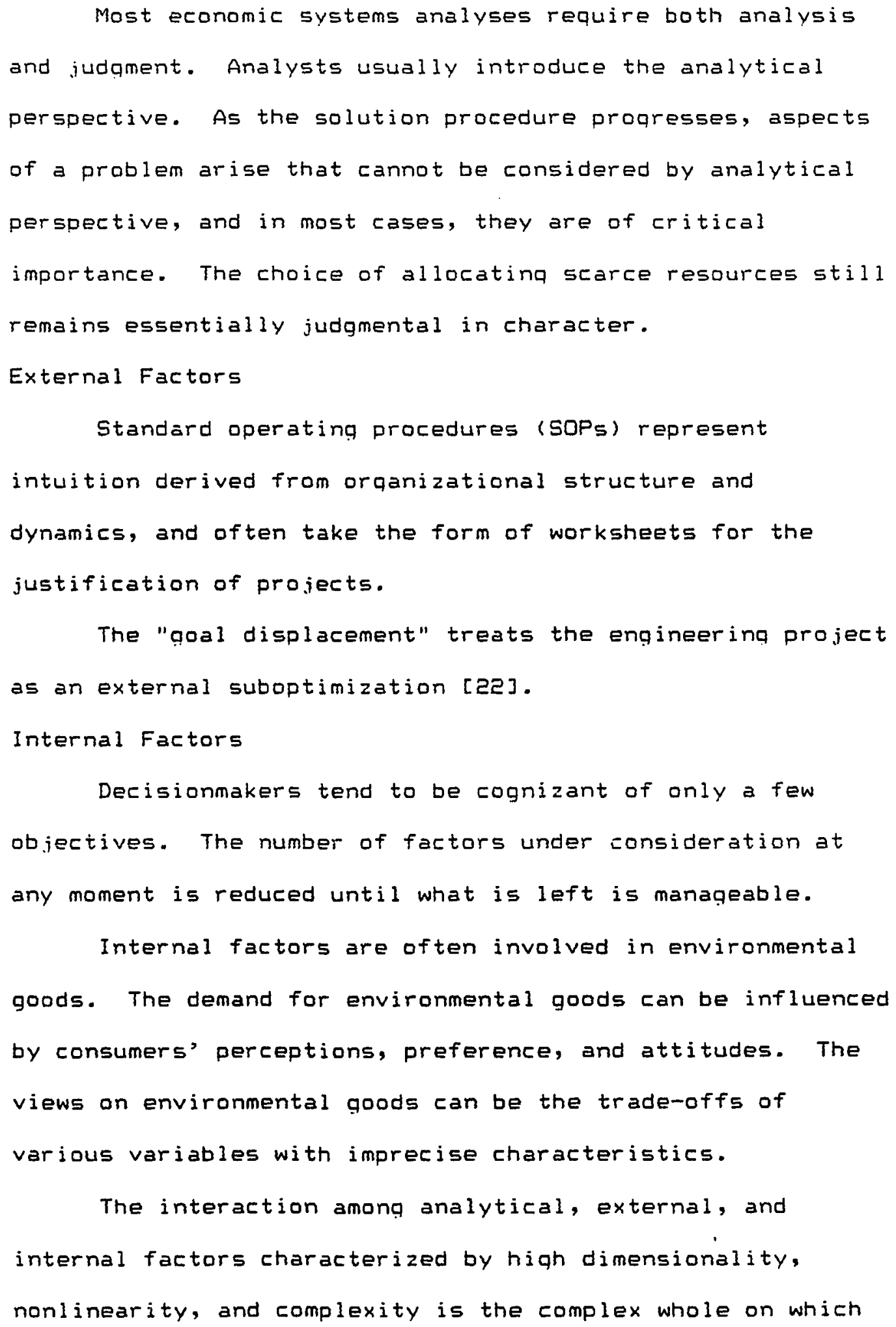


economic systems analvsis is based. The choice made by the decisionmaker is influenced by many factors and various Datterns of interaction. The triadic model suggested by some authors omits the function of the interaction. The tetrahedron is the unique symmetrical set of minimum interrelationships in the choice of a model. In this interaction, the behavior of a whole cannot be predicted by the characteristics of any of the subsystems' separate parts $($ see 3.2 .1$.

The above exposition demonstrates the need to use analytical, external, and internal perspectives in conjunction, and to avoid the exclusive use of one or the other.

\subsection{Prospect For Methodology}

Economic systems analysis is not only a systems analysis technique, but also a way of revealing complex reality. The traditional analytical modeling fails when it is applied to ill-structured systems since it is little more than an appreciative system, a mechanism which maintains well-structured relationships and eludes ill-structured ones. It tends to design the total system at the level of an economic subsystem. Though many authors provide valuable contributions to the field, the conventional methodology can be criticized for not being adequate to deal with the difficulties posed by ill-structured issues. 
The main idea of the general systems approach is to develop a methodology capable of explaining the composite picture, consisting of various subsystems. Economic systems analysis leaves no room for a systems approach from the Newtonian-Kantian inquiring system. Therefore, a systems approach is invoked to represent systematic methods which differ from pure Newtonian-Kantian inquiry. We attempt to make economic systems analysis more applicable to the problems in the real world, where external and internal factors are both complex and obscure. As a result, economic systems analysis needs to be broadened and shifted from the conventional systems analysis to policy analysis. The proposed systematic methodology is based on the philosophical paradigm described previously and has the following characteristics:

1. Pragmatic view. Systems engineering is referred to as an element of organized, creative technology. Economic systems analysis is an organized, constructive activity: organized in that there is a pattern of analysis; constructive in that it constructs a system to meet a realistic need. Economic systems analysis and reality exist in an inseparable symbiosis. In economic systems analysis, the goal is to construct models that are closer and closer approximations of reality. The ultimate objective of economic systems analysis is not just to discover economic efficiency, but also to get the project accepted and 
implemented. The objective is to search for an appropriate course of action instead of proposing solutions which may turn out to be not only inadequate but possibly inimical to the system.

2. Systems characteristics. The focus here is a deeper understanding of economic systems issue as a socioeconomic issue. The emphasis is on a holographic, panoramic description. The analysis should be related to systems framework. It is necessary to eliminate the inferior alternatives evaluated in multidimensional analysis; however, these alternatives may rank very high on an economic scale. The decision to adopt a project depends both on analytical properties and systems characteristics. 3. Learning, adaptation, and quasi-optimization. The emphasis here is on learning, adaptation, and quasioptimization, which improve the efficiency of decisionmaking and bridge the gaps among multidimensional perspectives. On one hand, the process uses systematic thinking to understand and intervene in real-world complexity; on the other the process itself is implemented as a participative, interactive, and iterative one. Such a system has the following characteristics: a. It is a non-linear system with time-varying parameters, therefore, it offers the possibility of substantially increased systems performance when inputs are time varying; $b$. It is a complicated adaptive system that adapts in the face of changing wider 
systems.

4. Quantitative vs. qualitative. Both quantitative and qualitative concerns come into the analysis. The analysis provides insights into the nature of the issues by using Markov communication theory and fuzzy sets theory as a response to "neglect of the subjective elements" [31]. The fuzzy description allows the complexity of the issues to be appreciated. There are many occasions in economic systems analysis when random and fuzzy data are available. It is possible to manage the complexity of the issue to an approximate form both quantitatively and qualitatively.

5. Systematic feedback. The method itself is a learning, adaptation, and quasi-optimization system, and within the system it maintains multiple reference frames. It asserts at same time that such models are the representation of partial reality, i.e., an incomplete picture of various ways of perceiving the reality. For existing systems approach relies in the end upon finite systems which, however synthesized, can not be free of the cunstraints of finiteness.

Economic systems analysis is defined here as a structure of self-interstabilization in terms of a complex of perspectives operative in multiple degrees of freedom in resource allocation.

Economic systems issue is a socio-economic' issue. The proper way of facing it is to seek an appropriate 


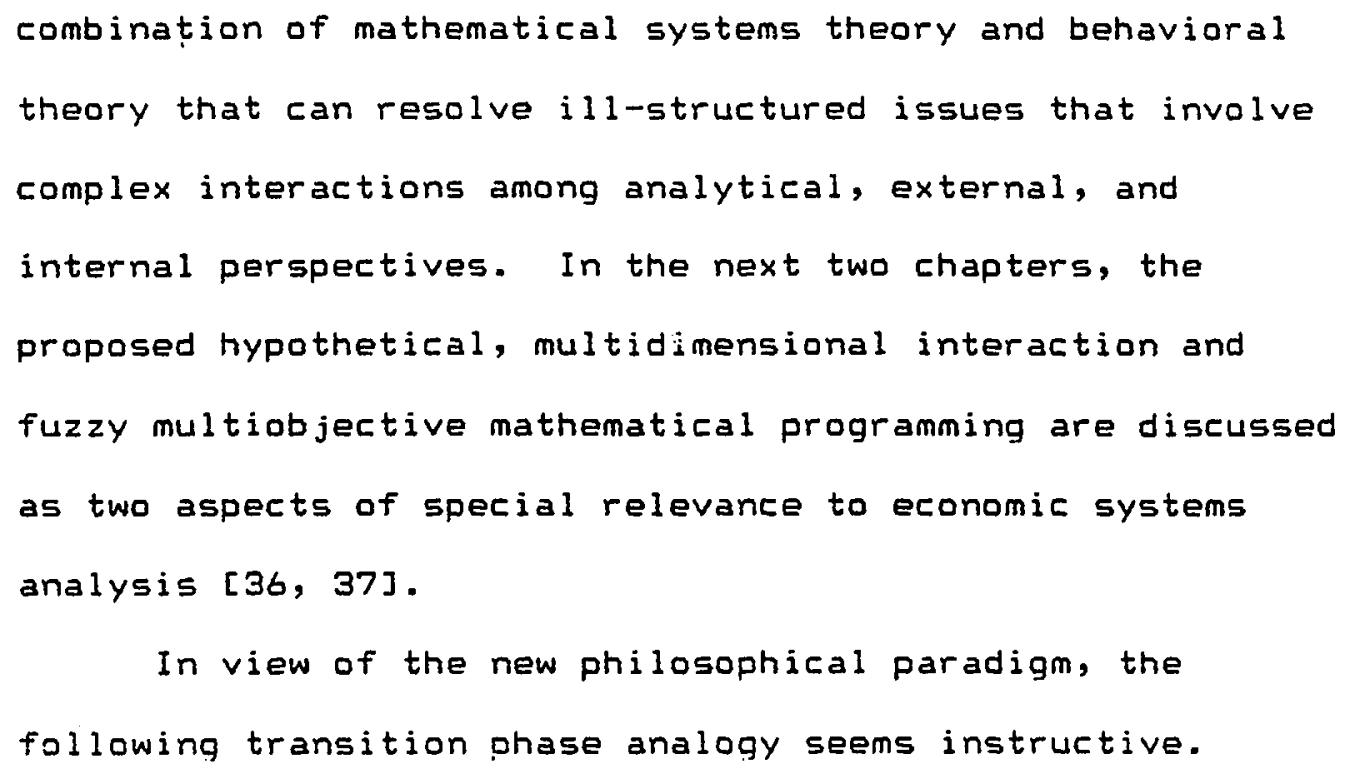


Table II. The Major Characteristics of Economic Systems Analysis: 1950s-1980s

\begin{tabular}{|c|c|}
\hline $\begin{array}{c}\text { Conventional } \\
\text { Method } \\
1950 \text { s-1980s }\end{array}$ & $\begin{array}{l}\text { Proposed } \\
\text { Method } \\
1980 \text { s- }^{-}\end{array}$ \\
\hline economic system & socio-economic system \\
\hline subsystem & whole \\
\hline optimization & $\begin{array}{l}\text { learning, adaptation, } \\
\text { and quasi-optimization }\end{array}$ \\
\hline points and surface & functiona] space $[3 B]$ \\
\hline partial reality & $\begin{array}{l}\text { partial reality towards } \\
\text { integrity }\end{array}$ \\
\hline fixed framework & progressive activity \\
\hline analytical mathematics & $\begin{array}{l}\text { imprecise \& analytical } \\
\text { mathematics }\end{array}$ \\
\hline two-valued logic & bistochastic process [17] \\
\hline objectivity & subjectivity \\
\hline reductive & holographic \\
\hline doctrine & way of thinking \\
\hline final rule & infinite inquiry \\
\hline
\end{tabular}


CHAPTER 3

SYSTEMS DESIGN IN ECONOMIC SYSTEMS ANALYSIS

The interaction is the ultimate cause of the event. Friedrich Engels [39, p.574]

\subsection{Multidimensional Frames}

The pluri-model and hierarchical holographic model have already been developed [40]. This chapter proposes a multidimensional, synergetic, and autopoietical model. "Synergetics" was first coined by Haken [41] in the 19705 to describe physics, but here it is, for the first time, applied to economic systems analysis. In addition to synergetics and related concepts, such as order parameter, critical point, and phase transition, original concepts are introduced, such as general interaction, free energy, higher order substance, the transit of information, boundary, and systems dynamics in ill-structured systems decisionmaking. Applications of the proposed model to economic systems analysis are also suggested. "Autopoiesis" was first coined by Maturana [42] in the 1970 s to describe the process of self-renewal and self-maintenance characteristic of living orqanisms. Here the term is introduced in a new context to describe the self-sustaining characteristics of multidimensional system. 
Economic systems analysts long have been searching for a problem space of incorrect dimensionality, with an inadequate list of elements in the state vector defining the system. The economic optimization pertains to only part of system, so the analytical perspective is 1 imited in number. The proposed paradigm permits various perspectives. Suboptimization of any frame, moreover, can diminish the system's effectiveness because the objectives and criteria for subsystems can so easily be chosen in ways inconsistent with those of the system. Economic systems analysis designed to pursue an economic optimum often conflicts with other subsystems. In this sense, it is pointless to expect sound analysis based on economic criteria alone. There is, however, a possibility of finding the truth at a different position [1]. It is the whole that exhibits systems behavior; the parts only exhibit functions that contribute to the purpose of the whole. The parts have perspectives of their own, but the perspective of the whole is unique and subsumes that of the parts.

In economic systems analysis, all relevant reference frames need to be incorporated and taken seriously in a formulation framework. There will be no exact, two-valued logic description in multiple reference frames. A typical economic systems analysis takes the form of finding the quasi-optimal decision with respect to a multidimensional 
system. As an example of quasi-optimization, in the fuzzy multiobjective algorithm (see Chapter 4), the objective and constraint can be revised within the context of the state of system so long as the decisionmaker believes it is effective in systems perspective. The further analysis is pursued by fuzzily comparing alternatives. The purpose of comparison is to discover the approximate range of trade-offs which will be acceptable for systems effectiveness.

The multidimensional approach which explicitly recognizes the importance of both external and internal perspectives is more realistic than the economic optimization model. Evaluations can partially rely on mathematical models, but subjective judgment is a pivotal input. The breadth and depth of the analysis encourages us to move beyond mathematical economics and convert from maximizing subsystems objectives to optimizing systems ob jectives.

\subsection{Multidimensional Structural Analysis}

\subsubsection{General Interaction Process}

Since the theory has been developed in naturalartificial systems interaction, therefore, a general explanation of the interaction between human systems is indispensable. In the structural representation, a new perspective is advanced for shifting the view from simple cause effect relationships to multiple interaction. 
Comprehending the interaction of perspectives in decisionmaking is the aim.

A multidimensional perspective system consists of subsystems that are in interaction, in transit from disorder to order or vice versa. It is a living system in constant motion whereby energy and information are processed.

In this complex system, a. the causal connections among recent inputs and ongoing outputs, i.e., higher order relationships, are too fast to establish in terms of Mesarovic's definition [43]; $b$. the properties of the dimensionality cannot be explained by a superposition of the actions of subsystems; c. multiple configurations of rea]ity are available [17].

In a sense, multidimensional frame is an intricate, evolving game with a variable number of players [38], each of whom possesses free energy and draws an unique confiquration of numerous attributes. They are organized into various subsystems, all relating to the dynamic processes. In reality, the game is played in a system of extreme complexity. The mechanism, therefore, must have sufficient energy available to provide the driving force, and in order to move the perspectives, forces should act on the frames. The formation of a mosaic of perspectives in relative motion with respect to one another is a consequence of these forces. The subsystems are continuously in kinetics. Under the influence of continuously supplied 
energy, one or more reaction processes are superior to others. Those favourable processes then reinforce each other more and more, growing continuously. Eventually, they run over the other forms of motion. Those new processes of motion thus imprint a macrostructure on the system. The new state thus achieved by the system is of a higher order. The dynamic principle is that the kinetics depends on the substitute process of the subsystems. Those of the highest substitution rates that take the superior positions usually determine the macrostructure. The different rates of substitution of individual motion result in the structure that prevails, implying a constant substitution among the complex mations.

In the interaction, any object in one subsystem probably affects objects in another subsystem. In the system theory, interaction is assumed to occur between entities. But in reality, interactions can occur among interactions as wel1. These complex, higher order interactions are generally ignored since the existing systems approach is incapable of coping with higher order relationships. However, a general interaction explanation is necessary for macrostructure theoretical development. In order to understand the behavior of the system, the concept of interaction is explained here by a mathematical model. The hypothetical explanation leads to a topological and 
kinetic understanding of the final outcome in a decision process.

The economic systems issue, in which many factors interact in many ways, is extremely complex. Costs and benefits are much more than the influx and outflow of physical resources, for both may be the autcomes of interaction among all relevant factors. Most decisionmaking processes in economic systems can be attributed to the interaction of perspectives. Analytical, external, and internal perspectives all create a final outcome through their relative motion and interaction. Many well-known historical facts are available to support this point of view. Zhang Wentian, former leader of Chinese Communist Party wrote that Mao Zhedong's personality and some personal random events always affected significant economic policymaking [44]. A comparison of the Carter Administration's attitude to the 56-inch natural gas pipeline project, and that of the Reagan Administration is another striking example [45].

Since the decision systems are in constant interaction, it is impossible to define an appropriate systems objective without knowing a great deal about the system dynamics. This knowledge can be derived only from a multidimensional, synergetic analysis, which encourages full understanding of the decisionmaking process. In a synergetic analysis, objectives, constraints, and value 
systems are scrutinized in a synergetic way. An alternative solution which may first seem acceptable in the analysis, on further exploration can lead nowhere or prove counterproductive. The original systems components may be substituted by new ones.

In summary, the purpose of this chapter is to explore the economic systems issue at a depth sufficient to give both the analyst and decisionmaker an idea of multiple dimensions and synergetic structure, and identify the possible scope of objectives and alternatives. Multidimensional, synergetic analysis provides a framework for decisionmaking that admits the dynamical contribution of relevant aspects. It is in this system that both quantitative and qualitative data are collected and analyzed, and the final decision begins to take shape: the initial order is ereated.

Parts of the literature on multidimensional

perspectives deal with ill-structured systems, but the majority concentrates on static rather than dynamic properties. In fact, the multidimensional motion is a dynamic process (see pp. 31-37). Synergetic Information Processing Process Information processing in decisionmaking can be represented in the following way:

Set $E$ as a set of implicitly defined formal objects, 


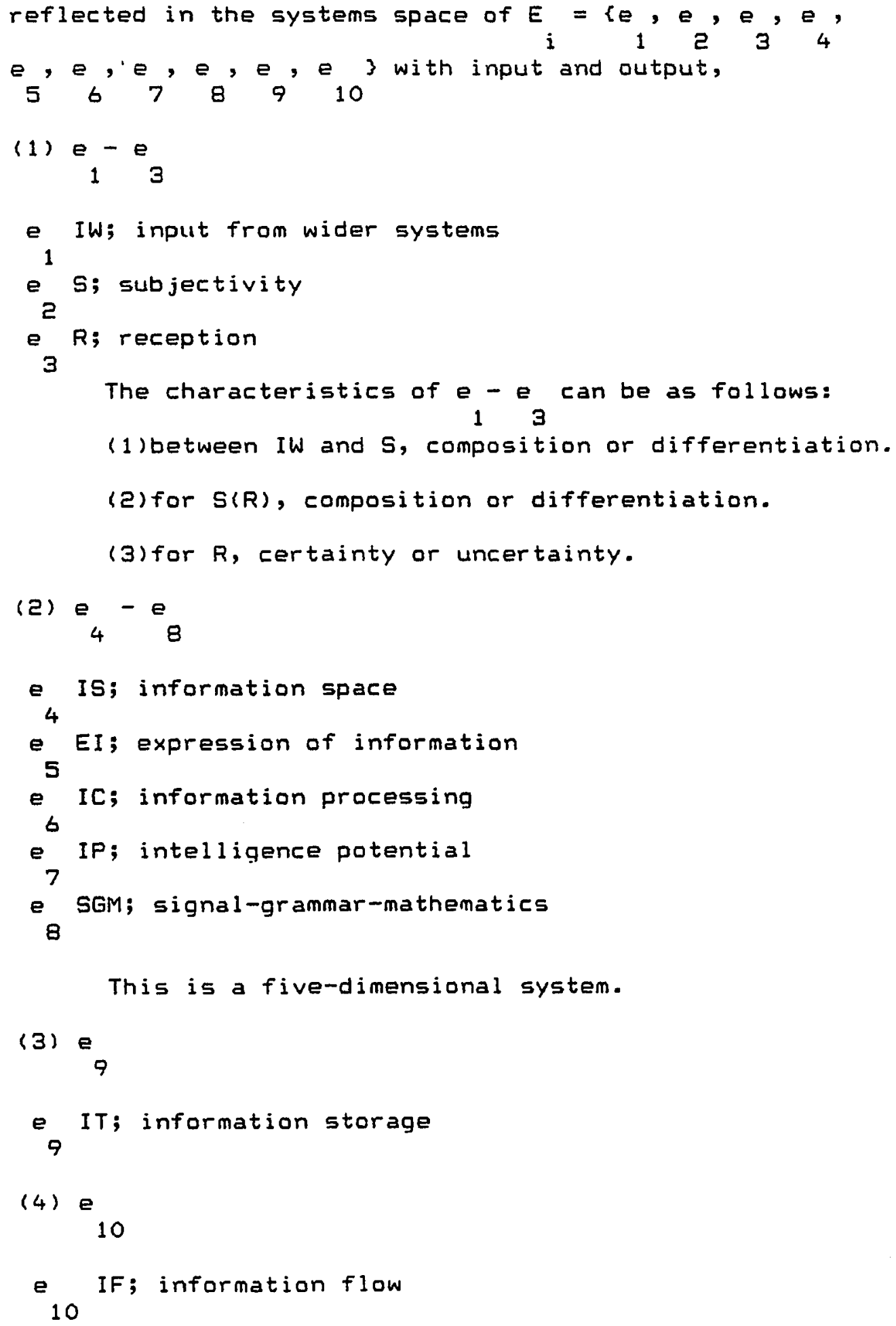

The following system expresses the key elements of 
information processing:

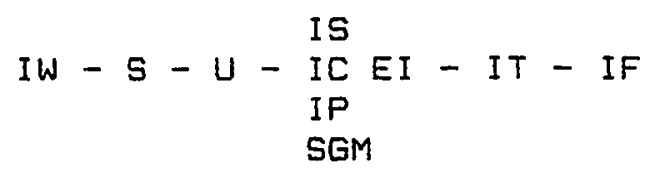

The significant kinetic features of the interaction mechanism are as follows:

The interaction (I) is the set of transformation. The synergetic effect provides the rule for forming new forms in terms of interaction. The statements indicating initial forms of the objects are described in the expressions of $(3.2)$ and $(3.3)$.

Set the objects, i.e., If in the system as, (1) (2) $E^{(m)}$ products of interaction as $c^{(1)}, c^{(2)}$ $E,{ }_{(n)}, \ldots, E$, products of interaction as

$\ldots, C, a_{i j}$ as coefficients of $E$ in $C$, then

$C^{(1)}=E_{a 11}^{(1)} E_{a 12}^{(2)} \ldots \ldots E_{a 1 m}^{(m)}$,

$C^{(2)}=E_{a 21}^{(1)} E_{a 22}^{(2)} \ldots E_{a 2 m}^{(m)}$,

$C^{(n)}=E_{a n 1}^{(1)} E_{a n 2^{(2)}} \cdots E_{a n m}^{(m)}$. 
(i)

Set $b(j=1,2, \ldots, m)$ as coefficients of $E$, and $\times(i=1,2, \ldots, n)$ as coefficients of $c^{(i)}$ in the interaction, i then,

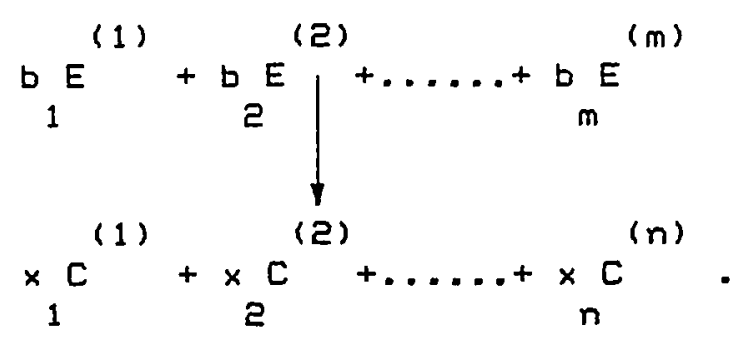

In the system,

$f(x)=$ free energy of the products of interaction i i

$f(x) \varepsilon[0,1]$

i i

The free energy of the system is,

$\Phi\left(x_{1}, x_{2}, \ldots, x_{n}\right)=f\left(x_{1}, x_{2}, \ldots, x_{n}\right)+\ldots+f\left(x_{n}, x_{2}, \ldots, x_{n}\right)$

(3.1)

$\Phi\left(x_{1}, x_{2}, \ldots, x_{n}\right) \varepsilon[0,1]$

$x$ is nonnegative,

i

$x \geqslant 0, i=1,2, \ldots, n$,

assume conservative law exists,

$$
\sum_{i=1}^{n} a_{i j} x_{i}=b, j=1,2, \ldots, m
$$


$H$ is denoted as a hiqher order substance, which can be obtained in terms of the following formula:

$$
H=C^{(i)}-\sum_{i=0}^{m} E^{(i)}+\Delta x,
$$

(i) (i)

E is denoted as $E$ which loses part-whole relations, and $\sim$ (i)

$\Delta x$ is the fuzziness of $E$ without losing part-whole

relations. The general problem can be summarized as, an optimal solution: find the minimum of ( $x, x, \ldots, x)$ that satisfies the conditions of $(3.2)$ and $(3.3)$; a quasioptimal solution: find the quasi-optimal solution.

For a one dimensional system, in which $x$ is the input, $y$ is the output, the differential equation for deseribing systems characteristics is as follows:

$$
\begin{aligned}
& y^{(n)}+a y^{(n-1)}+a y^{(n-2)}+\ldots+a y^{(1)}+a y^{(1)} \\
& =b x^{(m)}+b x^{(m-1)}+\ldots+b{ }_{m-1} x^{(1)}+b x^{(3.5)}
\end{aligned}
$$

For the interaction processes, the corresponding differential equations must include all known and unknown variables. However, because of the tremendous number of factors, it is extremely difficult to list all variables and to solve all of these equations. $E^{(i)}$ tends to move in a complex manner throughout the interaction process. Every (i)

E at any specific time is in a stochastic state. 
In fact, we are not interested in the motion of (i)

individual $E$; more important is the general state

derived from general interaction which involves all relevant (i) E.

In accordance with interaction, it is possible to generate a wide range of possible products symbolically represented by free energy. Therefore, one can express the system in terms of this symbolism.

The instantaneous characteristics can be depicted approximately. Assume free energy as a symbolism, then, set $x=\left\{x_{1}, x_{2}, \ldots, x_{n}\right\}, y=\left\{y, y_{2}, \ldots, y_{m}\right\}, 0 \leqslant L \leqslant 1$.

Theorem 3.1: Set $R=\left(r \underset{i j i n \times n}{\text {, } n}, R=\stackrel{n}{V}_{R=1}^{P}\right.$. Theorem 3.2: Set $R=(r)_{i j n \times n}$ satisfies self-reciprocity

and symmetry, then

$$
R=R^{n-1}
$$

In a fuzzy matrix,

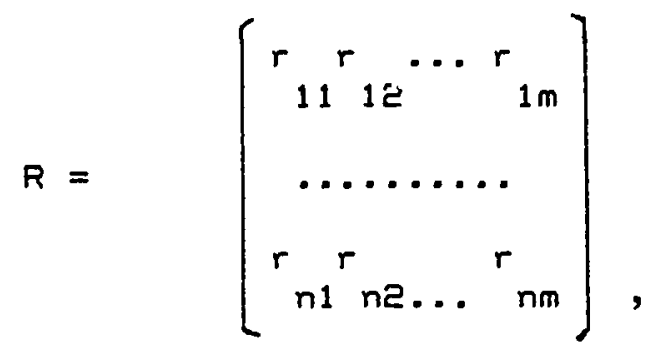

$r=R(x, y), i \leqslant n, j \leqslant m$. Specically, $R: X \times Y+[0,1]$, it i j i j belongs to $F$ matrix $[46]$. 
The general form of the fuzzy matrix is,

$$
A=\left(\begin{array}{ccc}
a & a & a \\
11 & 12 \ldots & 1 n \\
a & a & a \\
21 & 22 \ldots & 2 n \\
\ldots \ldots & \ldots & \ldots \\
a & a & a \\
m 1 & m 2 & m n
\end{array}\right),
$$

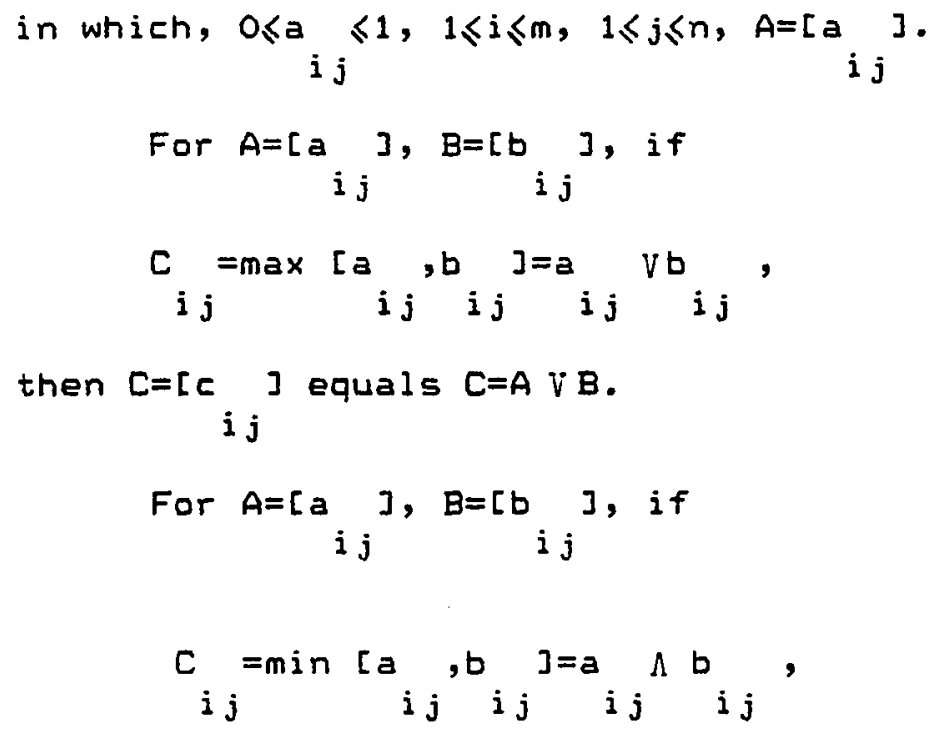


then,

$$
r_{i j}= \begin{cases}1 & \text { if } r \geqslant \lambda \\ 0 & \text { if } r_{i j}<\lambda,\end{cases}
$$

$R_{\lambda}=\left(\lambda_{i j}^{r}\right.$ ) is called $\lambda$-cut matrix of $R$, and defined by

1. $(A \vee B) \lambda=A \lambda \vee B \lambda$.

2. $(A \Lambda B) \lambda=A \lambda \Lambda B \lambda$.

3. If $\lambda, \mu \varepsilon[0,1], \lambda<\mu$, then $A_{\lambda} \supseteq A_{\mu}$.

The useful insight is that the analyst can know the (n)

extent of free energy in $C$ in relation to quasi-optimal solution.

The process of interaction can be expressed approximately in terms of fuzzy control systems, as figure 1 shows. The fuzzy conditional statements can be described as,

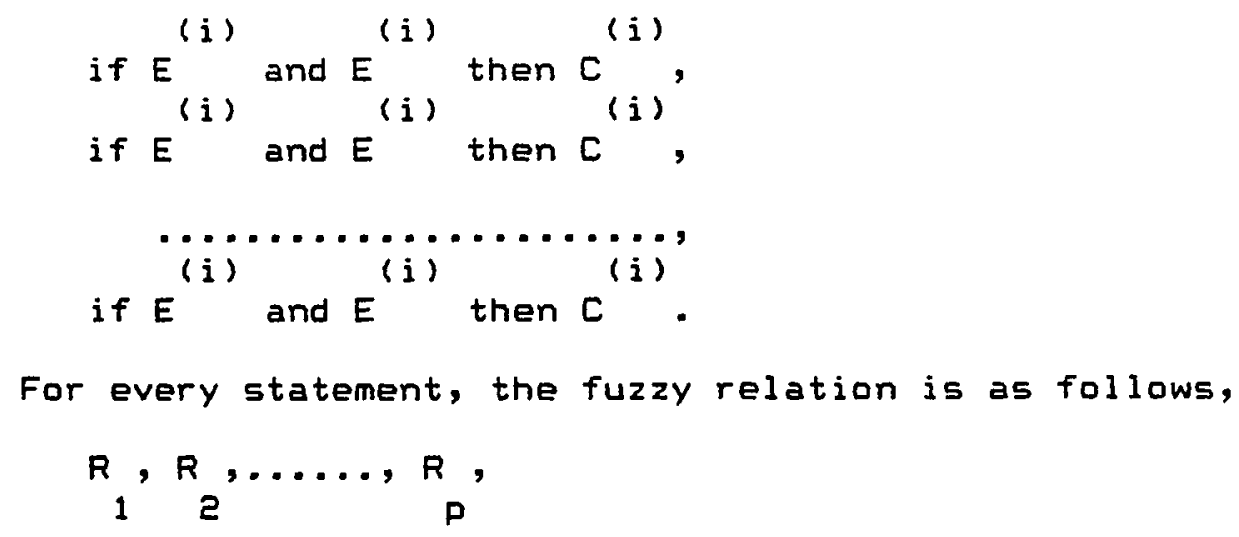

the $R$ for the system is, 


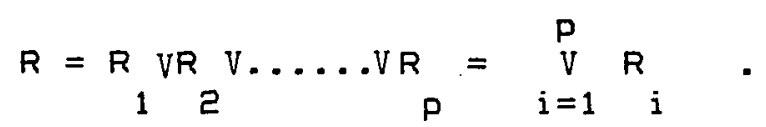

Suppose $A$ and $B$ are inputs, $C$ is output, and $D=A \times$

$B$,

then,

$$
R=D^{T} \times C
$$

Suppose $A$ is input, $B$ is output. If $A$ is known, $B=$ $A \times R, R=A \times B$.

1

It must be acknowledged that the necessary framework of concepts for this highly complicated nonlinear process is still under development. Although we are deeply and inescapably aware of the vast range of unexploited details, we must not allow such preoccupations to obscure our approximate understanding of the generalized mechanism operated by decisionmaking in a synergetic interaction. The notion of mechanism here does not simply mean the dimensionality, but actually embraces the structures of affectors and effectors.

The model is a generalization; the form is a special case. This study's interest is to introduce the general structure of a multidimensional process and suggest its implications for the system synthesis of economic systems analysis. Since one cannot construct a program of all programs, for a specific system, the task is to single out systems factors as relevant to the problem 


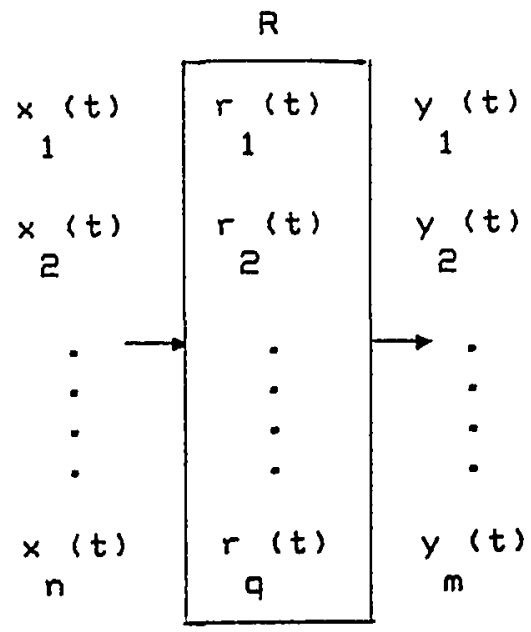

(a) multidimensional systems

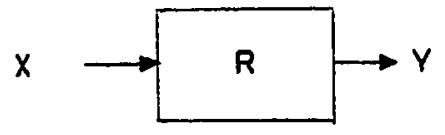

(b) one-dimensional system

Figure 1. Fuzzy Control Systems 
under consideration, to approximate the siqnificant relationships among these factors, and to formulate hypotheses regarding the interaction process.

\subsubsection{Order Parameter, Critical Point, And Phase} Transition

Multidimensional analysis further consists of both multidimensional perspectives and interaction system. In the interaction system, a variety of perspectives is in relative motion and moves into an orderly imaqe of the events concerned. The event tends to bring order out of perspectives, and results from the change of interrelationships. No subsystem is immune to substitution; in another word, no aspect of a system is precluded from kinetics. The order parameters are the long-lived systems that prevail over the short-lived ones, i.e., certain states of order grow continuously until they eventually supplant all other parts of of a system. A higher order state is both the cause and effect of substitution. A system displays a higher order state that may hold over a relatively short run. Over the long run, the relationships are altered by the structural effects. The implication is that the perspective from which a system is viewed depends on particular circumstances at the time. It is possible to predict the new states of order in a well-structured 
system, but is extremely difficult to do so in a purely illstructured system. In an ill-structured system, the Markov transition matrix may not be apparent because the matrix is not time-invariant. Having passed the critical point, the transition matrix may be revealed in some cases. However, in some other cases, the solutions to the various equations may, at a particular critical point, offer more than one possible solution [47]. There might be, in a complicated system far from equilibrium, a whole series of bifurcations, as long as the transition matrix is random. In this system, the 1 ist of variables in the state vector may not be constant; new variables may emerge, old ones disappear; and the transition probabilities may alter from time to time, causing some transitional probabilities to fall to zero, and others to become non-zero, but with no change in the elements in the state vector. The establishment of the states also depends on random events, and without them the new state would not be finally determined. The same set of interaction may lead to different orders under different randomness. Rempfer [17] has proved this hypothesis mathematically.

Possibly a complicated fluctuation determines the final choice between equivalent states of order. Numerous phenomena present a certain instability because initial symmetry disappears. In the process of transformation, a substituent may arise from fluctuation in the systems' 
structure. Then, a hiqher order state is established.

A system can be governed not only by one but by several order parameters. Three order parameters can be represented by perspectives that include an equilateral triangle. In the phase of chaotic motion of three objects, three order parameters enter into an interaction, thereby undulating the system to and fro among its various states of motion. For a certain time, one order parameter prevails over the two others. After a short while, however, it may lose its dominant position to another order parameter, and the sequence is repeated. Sometimes the perspectives are in conflict, sometimes they cooperate, or shift from conflict to cooperation. This change of domination is totally irregular. Chaotic motion might lead to the assumption that the order parameters have lost their power to control. The macroproperty of the multidimensional system can be described either by cooperation or by substitution among equivalent forces, creating a new pattern.

A well-ordered structure can be created from chaos and maintained with a constant supply of energy and information. The cooperation of subsystems can result in order. The overall context is sustained by the order parameters, which become most significant whenever the macrostructure of the system changes.

In project evaluation, the decisionmaker should look squarely at multidimensional system and its order parameter. 
A concrete example helps show that in most cases the decision is not based on economic criteria, but on systems characteristics related to the formation of order parameters.

In the Himalayas of Tibet near the border between India and China exists perhaps the world's greatest potential hydroelectric resource. A major river--the Tsangpo-Brahmaputra--drops 10,000 feet between two points only forty miles apart. A tunnel connecting the upper $r$ iver (Tsangpo) with the lower river (Brahmaputra) could provide enough hydroelectric power to meet a significant portion of the energy needs of Tibet, India, and Bandladesh. In addition to being an important renewable energy source, such a dam could partially control the catastrophic floods that now ravage Bangladesh. The project would, however, require close political and economic cooperation between China and India, since the dam would have to be in Tibet, whereas the generating plant would be across the border in India. Due to the order parameter, i.e., the political instability in southern Asia, at present, the dam will not be built. The totality of all possible states is described as the phase space of the system. The phase transition, an inevitable element of irrationality, means a transition from disorder to order or vice versa [1]. In disorderly state, the multidimensional system, which can point in all directions, is in a symmetrical state, with no dominant 
direction. However, having entered the interaction step, directions are selected and the original symmetry of the directions ends. The different phases result from the substitution effect among different perspectives, the substitutive behavior of collective type of motion. This motion plays an important role in forming an order parameter, as previously described, directing the motion of the subsystems. Once such motion has been established in subsystems, some subsystems may be suppressed by the order parameters. When the state of motion is unstable, even a very minor fluctuation often affects the phase transition. Whenever a new state of order begins, nature again leaves the system a choice of several possibilities. At the point of instability, the system tests new possibilities of an orderly macrostate; the new collective form of motion will prop̣ressingly become energetic, and finally gain superiority over all others. Once the choice has been made, all subsystems accept it.

The collective motion is complicated. Instability may shift from the subsystem to the system or from the system to the subsystem. This interrelation between the subsystem and system may result in the subsystem being deprived of its freedom that may produce instability according to systems measure. In other words, a' great deal of freedom for the subsystem means an increasing 
possibility of conflict in the system, as the proposed interaction model shows.

3.2.3. Decision-Prone Area--Boundary

Decisionmaking is associated with the perspectives' interactions at the phase boundaries, and a significant fraction of any decision occurs at such boundaries. The substitutional driving mechanism provides a general framework for understanding the pattern of decisionmaking on the border.

Decisionmaking is associated with displacements on the borders, which occur when the stress across the border builds up to a sufficient level to cause transition. When a border is in a coherent state, elastic energy accumulates in the perspectives around the border. When stress reaches a critical value, the border slips and a transition is made. The elastic energy stored in the adjacent perspectives partially dissipates on the border and partially radiates away as energy. The relative motions of the perspectives are often accommodated on major borders.

\subsubsection{Energy And Information}

Within a multidimensional system, flows of energy result in flows of information. The transition of interactions (energy) in an orderly structure forms the information, which can be recognized in terms of macroscopic hierarchical struetures. 
The basic mechanism of decisionmaking provides the energy. A sufficient energy must be supplied to produce a positive substitute rate. By using an energy function, the stability of the system can be determined, as well as the causes of instability. At a certain level of enerqy supply and interaction, the perspectives appear and disappear, and macro-changes of the system take place.

In order to understand the energy in decisionmaking process, it is essential to introduce the concept of stress and strain distribution. The creep on the boundary, in response to forces, leads to fuzzy, fluid-like behavior in the elements on the border. The fluid-like behavior of decisionmaking is thus explained by the ereep process. In many cases, the final decisionmaking can be attributed to substitutional activated creep processes. The creep relaxes elastic stress, and the pressure solution creep can account for the decisionmaking. The process involves the dissolution of elements in regions of high pressure and their precipitation in regions of low pressure. At low stress levels, the dominant creep process exists. The diffusion relieves an applied stress and results in strain. At first, the elastic behavior of a perspective arises from the internal forces that maintain each element in its position, resisting any attempt to move elements further apart or closer together. If the perspectives are compressed, the internal force resists the compression. The 
strain rate is proportional to the stress. At a hiqher stress level, the creep results from the movement of dislocations through the multidimensional system. In the process of deformation, an elastic element will exhibit linear, elastic behavior until a yield stress is reached. The element can then be deformed plastically at this stress. The multidimensional system can be deformed, and result in folding. Strain or deformation at the surface of the system often stems from perspective substitution motion. Thus, the measurement of surface strain can provide important information on the dynamic process of decisionmaking.

Obviously, if deformation occurs on boundary, high stress levels can be expected. The interaction of perspectives is an important source of stress. The state of stress results from all relevant contributions.

Although there is no comprehensive understanding of the motion, most likely decisionmaking is the result of complex interactions among perspectives, and the multiplicity of perspectives can deform the entire process. Therefore, the driving mechanism provides an approximate framework for understanding the orientation of decisionmaking.

\subsubsection{Systems Dynamics}

Making an economic systems decision is a dynamic process of perspective interactions. However, the structure 
of a decision system used to be regarded as static. We ought to be aware that a decision directed against one perspective is not based on a certain perspective against another. It is the certain collective modes of behavior that lead to a certain result. System behavior exists when subsystems act as if by prearrangment. Actually, every subsystem is in relative motion. Any equilibrium is subject to dynamic processes rather than artificial intentions. In the language of autopoiesis, the interaction gives rise to the system structure in a self-organizing form. Structures form, substitute, coexist, or result in higher order structures, powered by spontaneous forces.

\subsubsection{Three-Dimensional System}

Multiple forces, exerted on the analytical, external, and internal aspects of decisionmaking, confront almost all economic systems issues. These pressures result in stresses, which are inherent in the increased complexity of the issue and the increased scale of the systems. Three Dimensional Stress

Here we provide a quantitative model of the different types of collision, in terms of the relative magnitude of the principal stresses, assuming that the stress in $x, y$, and $z$ directions are the principal stresses. In three dimensions, there are nine components of stress: include $s_{x x}, S_{y y}$, and $s$, normal stresses; and $s_{x y}, s_{y x}, s_{x z}$, 
5 , $5 x$, and 5 , shear stresses. Supposing that the parallelepiped is not to rotate about any of its axes, tion $s_{x y}=S_{y x}, s_{x z}=S_{z x}$, and $s_{y z}=s_{z y}$, and $s i x$ of the stress components are independent. In the principal axes, three orthogonal axes can be expressed, with the result that all shear stresses equal zero. By convention, they are maximum principal stress, intermediate principal stress and minimum principal stress. The $5 \mathrm{ix}$ independent stresses, the orientation of the principal axes and the values of the principal stresses provide information about the state of stress at a point.

In the perspective cooperation case, the three principal stresses are equal, identified as $5=5=S_{1}$. When the three principal stresses are inequal, the pressure is defined as their means. The pressure is invariant to the choice of coordinate system. It is equal to the mean of the normal stresses in any coordinate system, such as

$$
p=1 / 3(S+5+5) .
$$

Triple Perspectives Intersection

In accordance with interaction theory, a perspective always ends by intersecting another perspective. Three perspectives result in an intersection as a triple intersection. In principle, there are numerous triple intersections, though some cannot, in fact, exist. The required condition for the existence of a triple 
intersection is that the three vector velocities defining relative motions between perspective pairs at a triple intersection must form a closed triangle. For many types of triple junctions this condition requires a particular orientation of the perspective boundary. Assuming $P$ represents a perspective, the velocity condition for all triple intersections requires that,

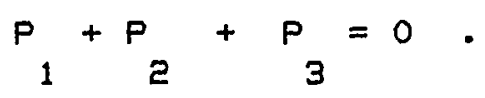

The purpose of describing the mathematical aspects of a decisionmaking process is to explain the dynamic process of decisionmaking. Detailed mathematical analysis of the decisionmaking process is not the major purpose of this study.

3.3. The Implications To Systems Design In Economic Systems Analysis

\subsubsection{Systems Analysis And Purposeful Formulation}

Multidimensional perspectives are an inexhaustible source of mystery to ws through the abundance of their patterns and the delicacy of their structures in which the subsystems interact with each other. Interest is increasingly turning to the questions of how these structures originate and what mechanisms are at work. The expression of dimensionality has basically answered the 
first question. The second are partially answered by the basic mechanisms discussed in this chapter and by omnidimensional structures to be explored in the future research of the decisionmaking process.

Figure 2 shows the hierarchical structure of economic systems analysis. In this analysis, the multidimensional system consists of the diverse subsystems. In systematic methodology, significant effort should be devoted to systems design, including the understanding of the interactions among multidimensional perspectives and the determination of purposeful alternatives. The analysis points to the degree of motion in systems between the purposes of subsystems, systems, and wider systems. The conventional method tends to overlook such motion, believing that the analysts can ascertain the real objectives. All perspectives, from a single perspective to the multidimensional system, interact in a complex manner. The subsystems that engage each other directly or indirectly make the system complex. The collective behavior of subsystems directly determines the state through substitution or cooperation. A final outcome will be formed depending on relative motion, critical point, higher order states, and systems structure. This picture of objects becomes a picture of structures and orders, subject to a bistochastic process. Every construction seems to make sense, as it provides an autopoietic view. The most important implications for 


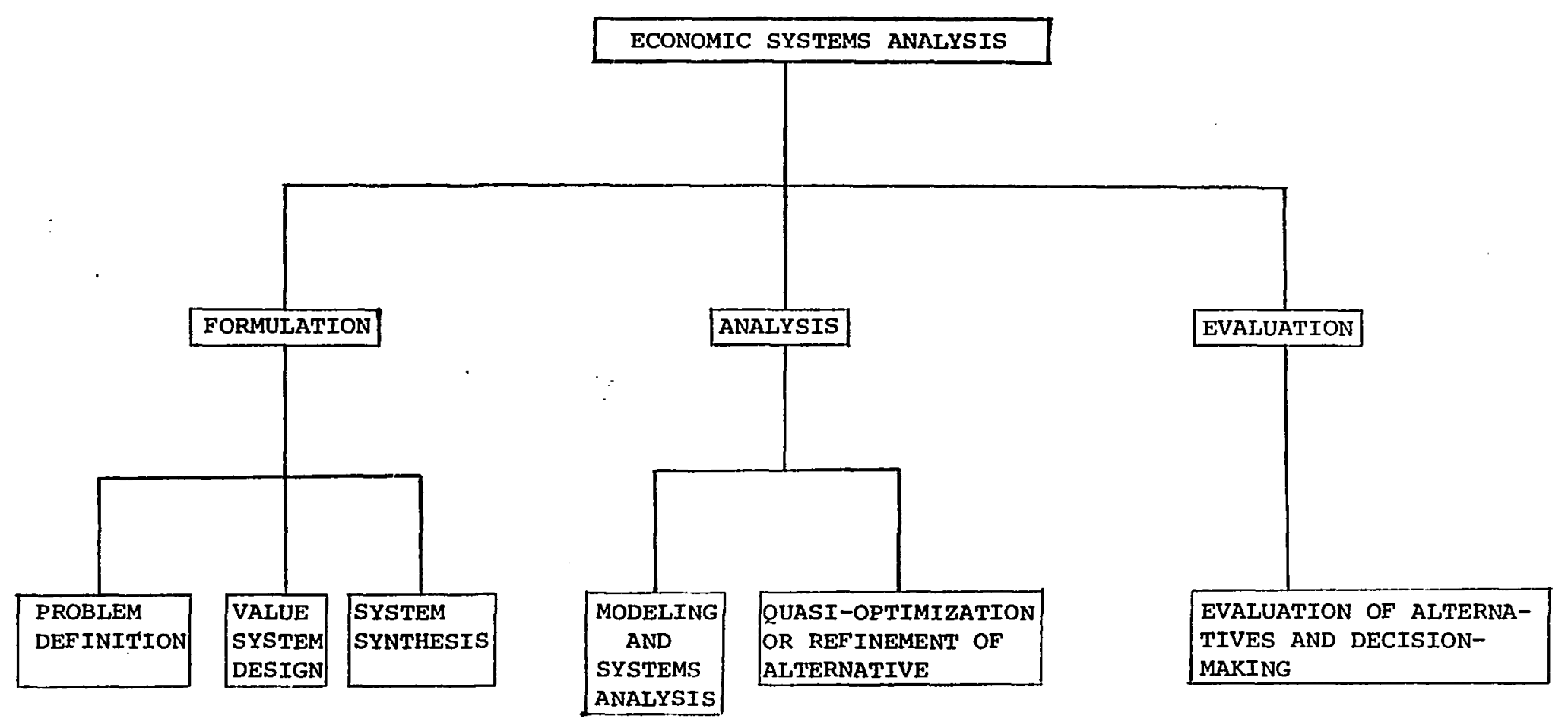

FIGURE 2. HIERARCHICAL STRUCTURE OF ECONOMIC SYSTEMS ANALYSIS 
economic systems analysis are that:

1. The elements in the designed system are considered and evaluated as related to the purpose of systems.

2. The system is self-regulating through the dynamic interactions among subsystems.

3. The system is autopoietic and spontaneous, i.e., (a). a higher order structure must result in its specific function, and it is represented by high order substance $H$, and (b). the motion of subsystems is reversible while the motion of systems is irreversible.

4. The existence of an interaction between a growing understanding of what is involved with what is known at the start.

Therefore, constant redefinition is essential and relatively less effort is needed for the optimization effort. This step constitutes one of the main watersheds between conventional methodology and systems methodology $[36,48,49,50,51,52,53,54,55]$. An H-type merger of multidimensional perspectives of real-world concerns increases the probability of posing the right problem in terms of a systematic view and significantly improves the likelihood of implementation. The systems process is supposed to encompass multidimensional perspectives, and synthesize them into an H-type system.

This view of synergetic multidimensional decision systems was shared by Heisenberg [1, P.205] to some extent: 
... Remembering our experience in modern physics it is easy to see that there must always be a fundamental complementarity between deliberation and decision. In the practical decisions of 1 ife it will scarcely ever be possible to go through all the arguments in favor of or against one possible decision, and one will therefore always have to act on insufficient evidence. The decision finally takes place by pushing away all the arguments-both those that have been understood and others that might come up through further deliberationand by cutting off all pondering. The decision may be the result of deliberation, but it is at the same time complementary to deliberation; it excludes deliberation. Even the most important decisions in 1 ife must always contain this inevitable element of irrationality.

\subsubsection{Controlled Feedback And Iterative Design}

An important implication of the foregoing analysis is that the errors associated with the data and modeling process, such as computative illusory, time and angle distortions of perspectives, and deceptive sensing of information, create a need in the synthesizing system to send feedback to the previous steps. This points to the need to search for alternatives which might fill in missing parts of the system. The formulation process may not even be fulfilled because the information space (see interaction model) is too limited to hold the information necessary to perceive the structure of the system. This function, selfadjusting through the availability of feedback, is an important part of the view suggested in Chapter 2 . We have a system: $y=c x+w, y$ is the measured output, $c$ is a constant, $x$ is the part of the state we want to requlate, and $w$ is the noise. The purpose is to insulate the output $y$ from $w$. 


\title{
CHAPTER 4
}

FUZZY MULTIOBJECTIVE PROGRAMMING AND MARKOV

COMMUNICATION THEORY IN ECONOMIC

SYSTEMS ANALYSIS

\author{
Never aim at more precision than is required by the \\ problem in hand.
}

K. Popper $[19, p .7]$

4.1. Introduction

4.1.1. Resolution Level

Analyzing an economic system characterized by multidimensionality involves two levels of description: one an analysis of the multidimensional system, and the other a discussion of its behavior in terms of macrostructure. After the multidimensional analysis, the resolution level is reached. The fuzzy objective reformulation for the system and its sub-systems cannot be established until complexities have been scrutinized. At this level, a quasi-quantitative description of the interacting perspectives becomes possible. We can again choose between either a classical mathematical framework or a fuzzy framework. In this study, imprecision is dealt with from a fuzzy mathematical point of view, representing a step toward rapprochement between the 
precision of classical mathematics and the pervasive imprecision of economic systems analysis.

4.1.2. Singerian Multiobjective Analysis Vs. Marglin's Multiobjective Analysis

The analysis of multiobjective problems has evolved rapidly over the last three decades. The economists' first concern that could be characterized as multiobjective was the efficient allocation of resources. In 1962, Marglin [16] introduced multiobjective analysis as an alternative to conventional economic systems analysis, using a method founded on the Newtonian-Kantian system.

Multiobjective analysis closely relates to the proposed philosophical paradigm and the fuzzy resolution level of multidimensional structure. Therefore, the appropriate multiobjective analysis is a Singerian analysis that encompasses all modes of inquiry to the extent they prove useful.

In response to the appeal made by Pierskalla, Mintzberg, Sage, and Luft $[35,56,57,58]$ for searching an appropriate analytical method for ill-structured systems, a practical, interactive, and iterative fuzzy programming method for solving a quasi-optimization problem under constraints involving a multiple objective function is proposed; its basic characteristic has been discussed in Chapter 2. The principal aim is to seareh for a quasi- 
optimization, and reproduce the real decisionmaking process. The algorithm begins with a fuzzy formulation in the steps of systems synthesis and analysis. Then, learning by trial and error is initiated, which comprises learning from systematic observation as well as from chance observation. In the process of analysis, a fuzzified preferred solution becomes the current solution, and, based on that, a new search starts. Then, another fuzzified preferred solution replaces the current solution. This is a repetitive process, the search continuing until no improvement can be found. Most solutions will fall within the efficient boundary, though since the boundaries are fuzzified, the solutions may be moved on or beyond the efficient boundary of the feasible region. In the case of an efficient solution within the feasible region, various alternatives among the current solutions are tested in order to choose a solution that is, momentarily, preferable to the current one.

\subsubsection{Characteristics of Adaptation}

The proposed adaptive economic systems analysis is a study of economic systems analysis incorporating an adapted space produced by flows of energy and information. An adaptive systen's structure can be adjusted so that its performance improves through contact with its environment. The adaptation can begin with a division of reality into two 
parts, one representing the behavior of a part of the system, i.e., the decisionmaker, the other representing the parts of wider systems, i.e., system. The adaptive economic systems analysis is a collection of perspectives that react and adapt to each other and to the system. In such a system, both reaction and adaptation occur throughout. The linkage communicates information among the system and subsystems. Emphasizing the perspective adaptation creates a practical way of thinking which allows decisionmakers to respond to the system and modify their behavior. Interaction allows the changing of actions from one mode to another in accordance with the systems state. The decisionmaker survives only if the generates an admissible decision under a certain system.

The elemental decomposition of an adaptive decisionmaker is into two constituent parts, that which receives and processes information about the system and that which responds reactively. It has a similar structure to that of a servomechanism. The first subsystem's function may be broken down into ohservation, measurement, processing, and storage (see interaction model). The second's function is into adaptive reaction. This distinction recognizes that a socio-economic system can be realized comprehensively only with great difficulty, and that the decisionmaker must therefore adapt to the system. Adaptation is fuzzy by nature. In a two-valued logic 
system, the adaptation seems mechanical, but actually, the adaptation exhibits an extremely broad range of fuzzy behavior. Adaptive decisionmaking can be described by a vector of characteristic variables, the values of which must lie in a fuzzy set to ensure the acceptability of the resulting decision. The value of each characteristic variable is determined by the systems state and the decisionmaker's decision. The search for rules of analytical adaptation that exhibit homeostasis appears to be necessary.

\subsection{Truthfulness, Randomness, And Fuzziness}

At the outset of systems analysis, in the 1940s, systems analysts accepted that there could be no absolutely accurate measurement. Complex relationships, plus the instability of precise logic in dealing with the vagueness inherent in economic systems analysis, made it difficult to define clear borders. In economic systems analysis, the varieties of complexity do not lead to easily analyzable models; hence, the essence of conventional methodology is to treat what is vague as if it were precise. Even for pure economic evaluation of alternatives, true complexity arises when simple systems are combined into numerous, complex assemblages. In systems analysis, system theory is, in fact, fuzzy systems theory with distinguishing characteristics for dealing with key aspects of the 
humanistic system [59]. In order to achieve a meaninofu] representation we have to compromise on exactness.

The human perception of reality is ambiquous. In most cases, a decisionmaker is assumed to choose a value between two-valued loqic representations in accordance with momentary judgment. Referring to the decisionmaker's picture of the system as fuzzy means that though his description of a system's structure is likely to be exact, his estimate of parameters, constraints or even the system itself is ambiguous. The eigenvalue links limited inputs with those imprinted in mind. A decisionmaker may make a sequence of choices inconsistent with fixed functions.

In economic systems analysis, solutions are rarely clear-cut; usually, several similar ones often exist. These alternatives are intimately connected with the interlinked modes of a fuzzy system. Having decided upon the objectives, and accepting that different alternatives will achieve the various objectives to differing degrees, we may then explore the degree of approximation appropriate to the economic systems issue by using fuzzy linguistic variables that result from decisionmakers' reliance on judgment, intuition, and experience. One way to handle subjective assessment of the attainment of the objective is to assign a fuzzy membership function to each alternative to represent the best estimates as to its range of effectiveness in attaining the objective under consideration. Heisenberg 
[1, p.201] indicated that,

We know that any understanding must be based finally upon the natural lanquage because it is only there that we can be certain to touch reality, and hence we must be skeptical about any skepticism with reaard to this natural lanquage and its essential concepts.

The lack of precise data from which the measures of the systems can be developed, and the lack of an adequate method from which the imprecise measure can be approached, support the application of Markov communication theory and fuzzy sets theory in the following ways:

Classification of costs and benefits. Due to complexity, it is hard to classify every effect as being either a cost or a benefit. In military economic systems analysis, many costs measured in dollars or human lives are actually estimates made on a speculative basis [31].

Distributional effects. There is no exact way to represent or explain distributional effects.

Measurement. Measures can be partially quantitatively determined and partially judgmental. The description of side-effects, externalities, social cost, social interest, future cost, noncommensurate units, and higher order effects are highly qualitative rather than quantitative, and no market price is available. Judgment and speculation guide the analyst more than economic calculations. Analysts tend to dismiss costs that cannot be measured quantitatively as non-cost considerations or qualitative factors. In sum, all costs and benefits measurements are approximations. 
Multiple objectives. Numerous examples of multiobjective trade-offs are available in the literature [20, 21, 22, 27, 30, 60]. In the public sector, objectives are seldom entirely agreed upon, and tend instead to be stated in broad, imprecise terms. Public policy objectives are typically ill-structured, multiple, conflicting, vague, approximate, and noncommensurate. Optimization is never the real aim.

Ranking. Due to 1 imited cognitive capability, and the imperfect information about the possible states of nature and transition probability, it may not be possible for both analysts and decisionmakers to prepare an unambiguous ranking of all alternatives.

Strategic bias. Anticipation of a contracting agent's willingness to pay for a study may lead to an attempt to influence the outcome or result by responding untruthfully. Information bias. This further imprecision results from the respondent's lack of complete information for willingness to pay.

In sum, the conventional technique is rigid in the sense that it demands precise data and functional relationships of the problem. In practice, however, we rarely have precise measurements. In short, science = truthfulness + randomness + fuzziness. The alternative is to consider Markov communication theory and fuzzy sets theory. A fuzzy formulation would consider the imprecise 
objectives and constraints. By focusing on this imprecision, approximation can be introduced into the system, and an adaptive progression achieved.

In the analysis, the role played by analysts includes:

1. Helping the decisionmaker to develop all of the relevant objectives during the multidimensional analysis by recognizing synergetic effects.

2. Searching for the possible ways to attain these approximate objectives during the search process.

4.3. Introduction To Fuzzy Systems Theory

4.3.1. Markov Communication Theory And Its Significance To I1]-Structured Systems

The basic axioms about propositions in symbolic logic are that,

1. A statement is either true or false;

2. A statement cannot be simultaneously true and false.

This absolute mode of thought has long existed. However, it has been found that the imprecise concepts lead to contradictions in a two-valued logic. Russell indicated that not all propositional truth can be organized by the theory of truth functions. Russell's Paradox, Cantor's Well-Ordering Principle, and Zermelo's Axiom of Choice all challenged the reliance on two-valued logic as a basis for inquiry. As another school of thought, the term "fuzzy" was 
introduced in 1962 by Zadeh in a paper about the transition from circuit theory to systems theory in which he called for a "mathematics of fuzzy or cloudy quantities which are not described in terms of probability distribution" [61, p.856]. This paper was followed in 1965 by the proposing of an imprecise mathematics termed as fuzzy sets theory [62].

In fuzzy sets theory, let $x$ be a classical set of objects, called the universe, whose generic elements are denoted $x$. Membership in a classical subset $A$ of $x$ is often $v$ iewed as a characteristic function $u$ from $X$ to $[0,1]$. Bellman and Zadeh [63, p.B141] give an abstract classification of imprecision in terms of "classes in which there is no sharp transicion from membership to non-membership." Rempfer defined an F-set as a function $u(x)$ with value $0 \leqslant u(x) \leqslant 1$ for each $x$. The power of an F-set is $\varepsilon u(x)=v$. A special case: the F-sets $u(x), i \varepsilon 1,2$, ...,r are said to be a partition if $\Sigma u(x)=1$ for each $x$. Rempfer illustrates that "partition-conserving mappings belong to the class of Markov chains. To be partitionconserving, they are necessarily bistochastic Markov chains" $[17, p .1]$. As indicated in previous chapters, a stochastical process is the major characteristic of an illstructured system. Rempfer's definition makes it possible to propose a stochastical process in an ill-structured system using a mathematical proof. The Markov communication process explains fuzzy behavior in an ill-structured system 


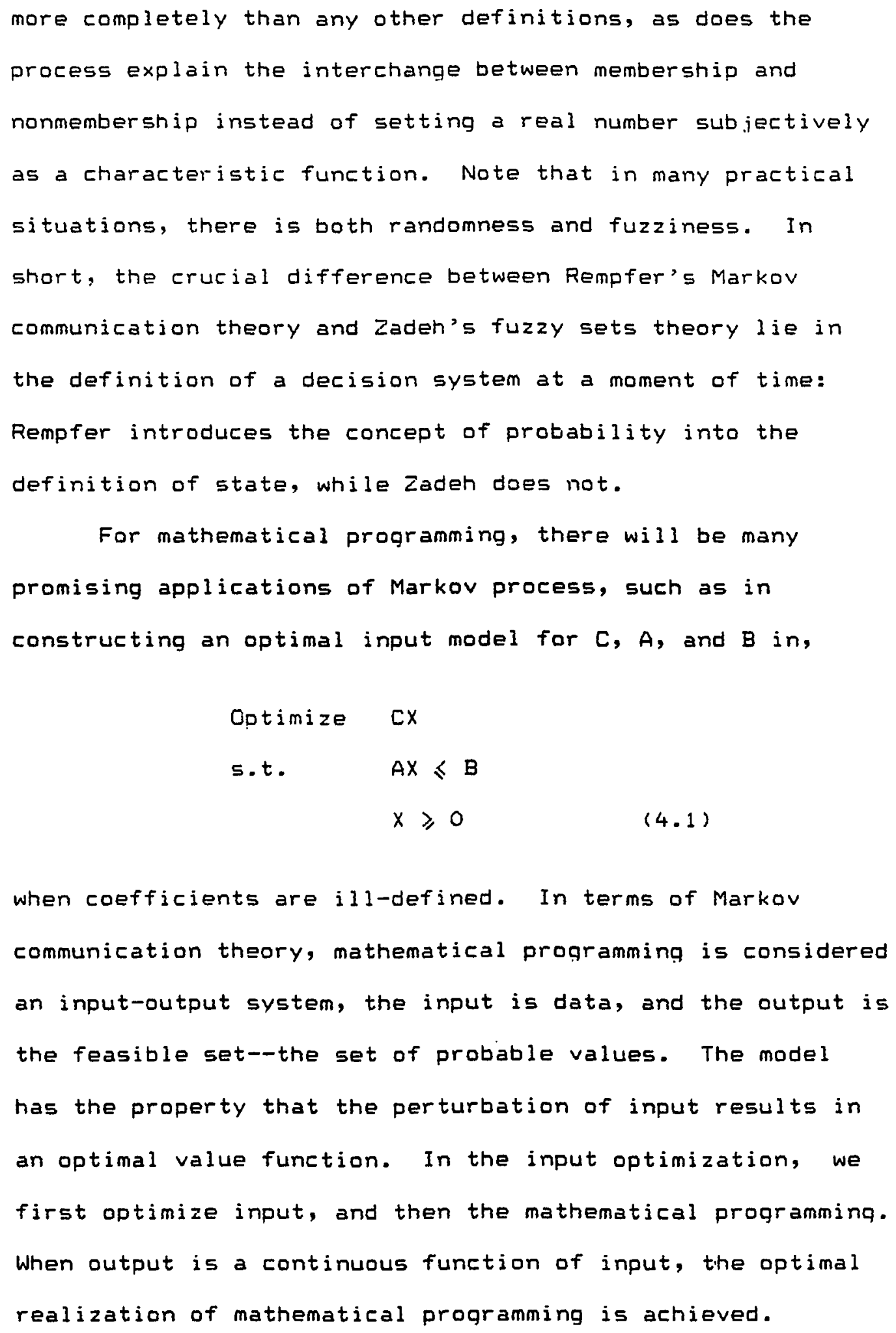




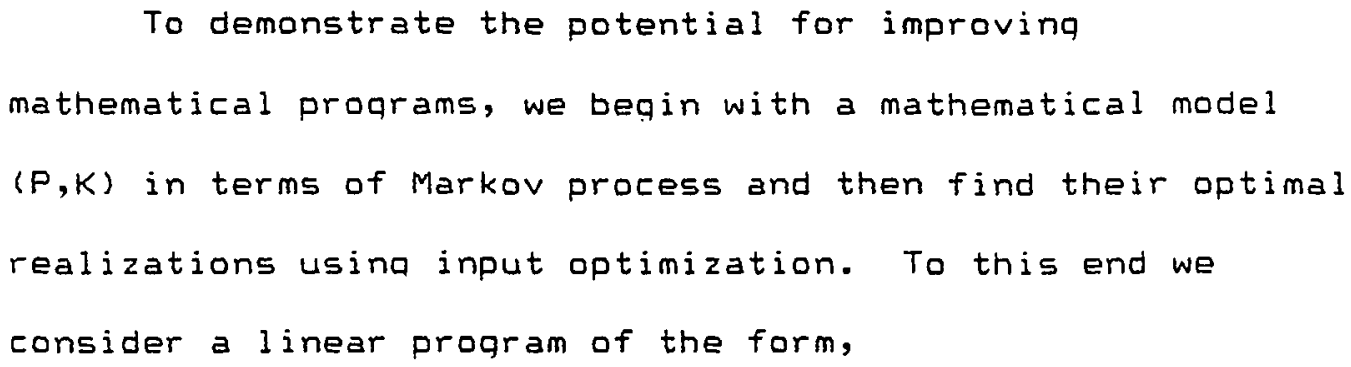


system, with the input $k$ and the output: $F(k), f(k),\{x \mid$

$b(K) 3$. The problem $(P, K)$ is an input optimization model. The crucial step in the design of a problem which is to be solved by fuzzy sets methods is to determine the membership functions of the sets. An important question is now, and from what kind of data can membership functions actually be derived? Most analysts recognize that determining the membership functions is vital in a practical application of fuzzy sets theory, but the problem has rot been systematically studied in the literature [46]. The methods used in the past have often been heuristically based. Rempfer proposes a theory which offers a more riqorous method of defining statistically-based membership functions. This result forms a firmer theoretical ground for a class of membership functions which has been previously proposed.

This study explores the application of the Rempfer theory in deriving a membership function, i.e., the problem of identifying an input $k * E I$, which optimizes the optimal value function $f$ over the set $I$. Such a random optimal input determines the optimal value $f(k *)$. If $k^{*}$ is an optimal input obtained by a Markov analysis of $K$, the $(P, K *)$ is an optimal realization of $(P, K)$. Clearly, the value of the program $(P, K *)$ can only improve the value of $(P, K)$. Therefore, the random optimal input $k$ * can be regarded as a 
most probable function in formulation instead of subjective fuzzy linguistic approximation.

If the fuzziness of coefficients is decreased by using information about the coefficients, we can expect

a more realistic solution than could be obtained without information: the less the fuzziness of coefficients becomes, the more realistic is the solution obtained. Basically, in input random optimization, we randomly optimize the model. We assume that the model is convex. The procedure for random input consists of, a. analysis of the existing input $k$ and its regions of stability, and $b$. analysis of the random optimal input $k^{*}$, i.e., determination of a random optimal value in accordance with Rempfer theory. The main objective is, by reducing fuzziness, to get a less fuzzy objective function, and convert fuzzy constraints into less fuzzy ones. We can expect to obtain a more satisfactory solution than without conversion.

By using the property of a doubly stochastic matrix, a simulated Markov process can be represented. Assume a Markov chain $\{Z\}$ is homogeneous, with transition probability $P=(\hat{n}), i,, j=0,1,2, \ldots$, and with initial distribution $\{p\}, i=0,1,2, \ldots$ Set $z$ as a discrete random variable: $p\{Z=a\}=p$, in which $p \geqslant 0 \leqslant 1, \sum p=1$. $i$ i $i$ Then we create random samples on the computer with $x, x, x, \ldots$, being uniformly, randomly devia'tes on 123 $[0,1]$, let 


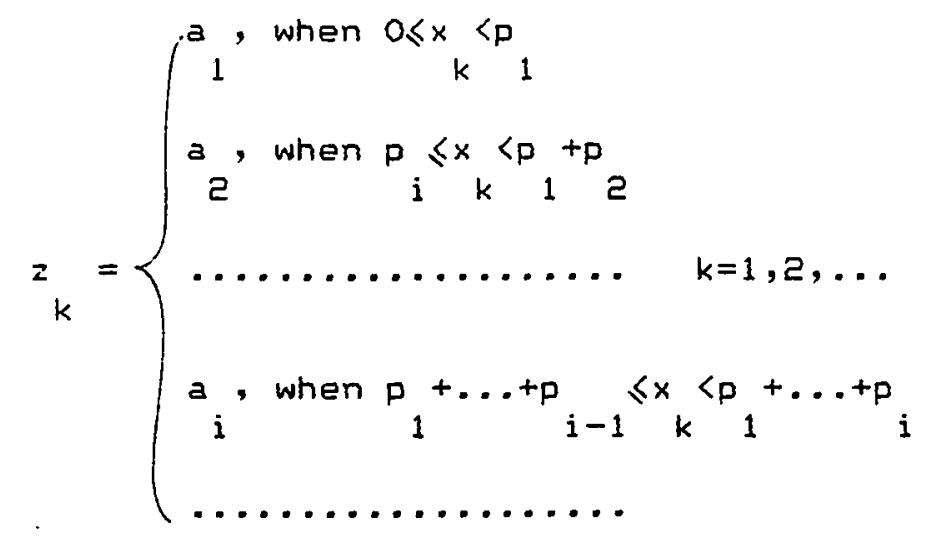

with $z, z, z, \ldots$ as random samples of $z$. We then have,

$$
\begin{aligned}
& 1 \geq z_{k}=a \\
& i
\end{aligned}=p\left\{p_{1}+\ldots p_{i-1} \leqslant x<p_{1}+\ldots+p_{i}\right\}
$$

Since we assume that $x$ uniformly distributes on $[0,1]$, the right-hand side becomes,

$$
\left(p+\ldots+p_{i}\right)-\left(p_{1}+\ldots+p_{i-1}\right)=p_{i}
$$

therefore,

$$
P\{z=a\}=p
$$

Now, we have a random variable $Z$ with $\{p\}$ as the distribution, set the sample value as $z$, then

$$
\{p z, j\}, j=0,1,2, \ldots
$$

0

as the probability distribution on $j$. We also can create 


$$
\{p z, i\}, \quad i=0,1,2, \ldots
$$

as the probability distribution on i. Finally, we consider the $P=\{p \quad\}$ with i j

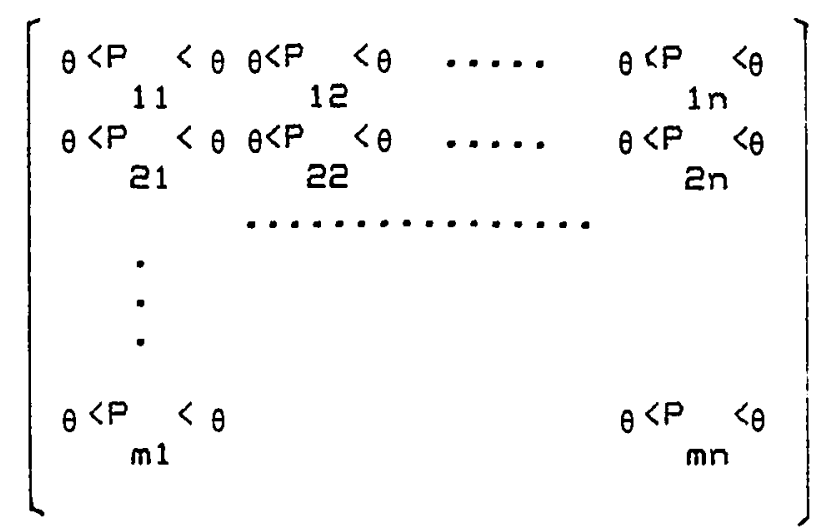

in which, $P=P+\theta P, \theta$ is a fuzzy interval, $0 \leqslant \theta \leqslant 1$.

This is the reality of a homogeneous, bistochastic Markov chain, with $\theta\langle\{p\}\rangle \theta$ as initial distribution, $\theta<\{P \quad\}<\theta$ as transition matrix. $i j$ In Markov based sets there is also reason to believe that the membership function relates to the physical properties of the set, as indicated by Rempfer, e.g., a communication system in which the signals received are noise contaminated. In the presence of a transmitted signal, the energy of the received signals will be the sum of the energies of the transmitted signals and the noise. The received signal is between 0 and 1 . A fuzzy membership function may be explained in terms of the received signals when a transmitted signal exists. The defining feature of 
the elements of this set is their energy. The problem can be considered again as (see 3.3.2.),

$$
y=c x+w
$$

where $c$ is constant, $x$ and $y$ are random numbers, $x$ is considered as signal, and $w$ is noise. The mean and variance of $x$ and $w$ can be calculated in terms of 1 inear estimation theory, which in turn provides information for constructing membership functions just as Markov analysis does.

4.3.2. An Alqorithm

Consider the following linear programming problem again:

$\begin{array}{ll}\text { Maximize } & C X \\ \text { s.t. } & A X \leqslant B \\ & x \geqslant 0 \quad(4.1)\end{array}$

where $A, B$, and $C$ have appropriate dimensions. This model can be fuzzified to a greater extent if instead of making $A$, $B$, and $C$ exact numbers, fuzziness is introduced. This expression is analoqous to Bellman and Zadeh's expression " $x$ is in the neighbourhood of $x$ " [63, P.8141]. In rea]ity, $A, B$, and $C$ can be fuzzified, $i . e$. , coefficients of the decision problem are considered to have fuzziness. The fuzziness of $A, B$, and $C$ affect the solution of any linear programming problem. 
$\zeta$ (A) in the equation of an ellipsoid is exposed here as an example of fuzziness. From calculus [64], the equation of an ellipsoid with center at the origin can be represented as

$$
1,2 X^{\top} A X=C
$$

$A$ is an $n \times n$ matrix, and $c>0$.

At the point $x$ of this ellipsoid, normal direction is, $T$ $1 / 2 \nabla(X A X)=A X$

If the normal direction is parallel to $x$,

$$
A X=\lambda X
$$

this direction is the direction of major axis, and $\|x\|$ is the length of semi axis. Then, substitute $A X_{i}=$

$$
\begin{aligned}
& { }_{i}^{\lambda} x_{i} \text { into }(4.3), \\
& \quad x_{i}^{T} \quad A x=\lambda_{i}=x_{i}^{\top} x_{i}=2 c
\end{aligned}
$$

then,

$$
\left\|x_{i}\right\|^{2}=\underset{i}{2 c / \lambda_{i}} i=1,2, \ldots, n
$$

Assuming that

$$
0<\lambda_{1} \leqslant \lambda_{2} \leqslant \ldots \leqslant \lambda_{n}
$$

the longest and shortest semiaxes are,

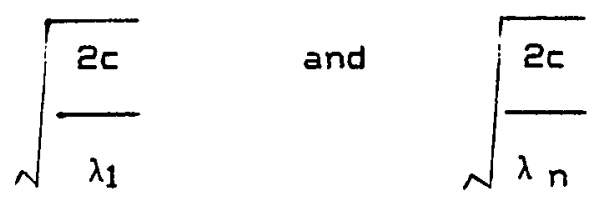

(A) has the fuzzy range, 


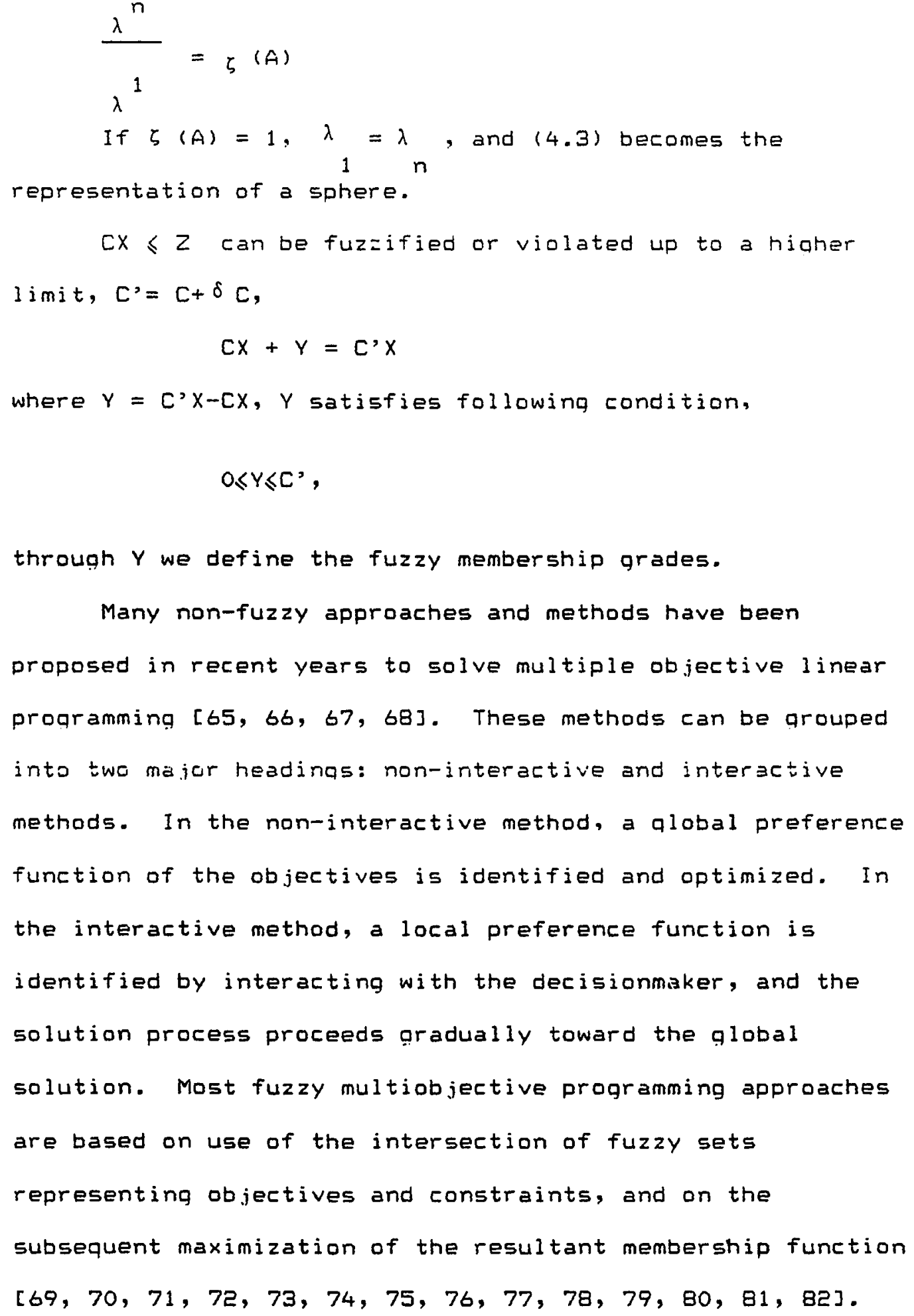


Here we present an approach based on interactive, iterative fuzzy evalution, which can be used to determine an imprecise solution to a multiobjective problem, especially in economic systems analysis.

The general multiobjective optimization problem with $n$ decision variables, $m$ constraints and $p$ objectives is as follows:

$$
\begin{aligned}
\text { Optimize } C\left(x_{1}, x_{2}, \ldots, x_{n}\right)= & {\left[c_{1}\left(x_{1}, x_{2}, \ldots, x_{n}\right),\right.} \\
& c_{2}\left(x_{1}, x_{2}, \ldots, x_{n}\right), \ldots, \\
& \left.c\left(x_{1}, x_{2}, \ldots, x_{n}\right)\right] \\
& p(4.6)
\end{aligned}
$$$$
\text { s.t } \quad g_{i}\left(x_{1}, x_{2}, \ldots, x\right) \leqslant 0 \quad i=1,2, \ldots, m
$$$$
x \geqslant 0 \quad j=1,2, \ldots, n
$$$$
\text { j }
$$

The general purpose is to find optimal solution of the following problem:

$$
\begin{array}{ll}
\text { Optimize } & u v(c(x)) \\
\text { s.t. } & x \in x \\
& u \in[0,1]
\end{array}
$$

In the iterative process, $v(c(x))$ is known fuzzily from the beginning to the moment immediately before the decision is made. The possibility exists, furthermore, that new order may form right after the phase transition. In order to adapt to the decisionmaking in the real world, an 
interactive, iterative procedure is developed to be practical for decisionmaking. The method has the following features, based on those deseribed in 2.3.:

1. It does not strive for predetermined objectives, but adapts to the dynamics of the decisionmaking process.

2. The interactive procedure helps include relevant factors for consideration, such as critical point, phase transition, and other factors. During the process of analysis, the decisionmaker can provide iniormation which is crucial to the acceptability of the analysis.

3. Iteration: The iterative concept, which has roots in cybernetics and control theory, is quite useful in economic systems analysis. It examines economic systems analysis as a dynamic rather than a static process, with systematic iteration as an important characteristic. In a deterministic system, with a fixed, known coefficient and no stochastic element to the laws of motion, deterministic optimization can be used; but as soon as a stochastic element is introduced into the laws of motion, as it must be in economic systems analysis, then a different rule is needed. Information from the performance in earlier periods must be fed back into the system in order that the quasioptimal path can be followed. An important task is to determine the decisionmaker's ultimate objective. The ultimate objective may be fuzzy, but many immediate objectives that lead toward it are fuzzier and include trial 
and error. The iterative re-aiming algorithm [83] demostrates this idea vividly.

4. Learning: The concept of learning can be combined with a fuzzy algorithm. If actual outcomes violate the expectations of the decisionmaker, then presumably the decisionmaker will learn from the discrepancies and modify expectations. In attempting to develop theoretical models that explicitly incorporate the idea that decisionmakers respond differently through time as they gradually learn about the system, one is increasingly forced to emphasize learning, an essentially fuzzy process with parameters for variables subject to change as a result of learning [84, 85].

The basic assumptions are as follows:

1. Let $C X=\{C i . x, i=1,2, \ldots, p, x \in X\}$. Assuming that decisionmaker's preference over solutions satisfies the following necessary and sufficient conditions:

(1). $v\left(c\left(x^{1}\right)\right) \geqslant v\left(c\left(x^{2}\right)\right), c\left(x^{1}\right)$ is preferred to $c\left(x^{2}\right)$; (2). $v\left(c\left(x^{1}\right)\right)=v\left(c\left(x^{2}\right)\right), c\left(x^{1}\right)$ and $c\left(x^{2}\right)$ are equally desired.

2. $v(c(x))$ is concave, differentiable with continuous first partial derivatives in $x$.

3. $X$ is convex, i.e., all points on a straight line segment joining any two points of the set belong to the set.

4. The overall value function is assumed to be 
fuzzily known, a fuzzy linear function with the possibility of modification.

5. The objective function coefficients are linearly independent.

6. The algorithm requires the decisionmaker to adjust the aspiration level linguistically.

7. Solution is not an extreme point of the constraint set $[66]$.

The algorithm is as follows:

1. Starting from suboptimization, determine $x^{i}$, $i=1,2, \ldots, n, n$ initial feasible solutions are created.

2. Determine the optimal solution of the multiobjective system as a whole.

3. Conduct fuzzy systematic evaluation of both subsystem and system.

4. Starting a subsystem-system search. A pattern of improving solutions is established for either a system solution vs. subsystems solution, or a subsystems solution vs. system solution.

5. Let $x^{x}$ be the optimal solution to the last step. If it is a basic solution preferred by the decisionmaker, go to step 6. Otherwise, determine the decisionmaker's preferred solution in the direction of trade-offs among the objectives offered by nonbasic variables at $x$ if they are preferred. If no non-basic variable at $x$ offer's desirable trade-offs among the objectives, go to step 6 . If the non- 


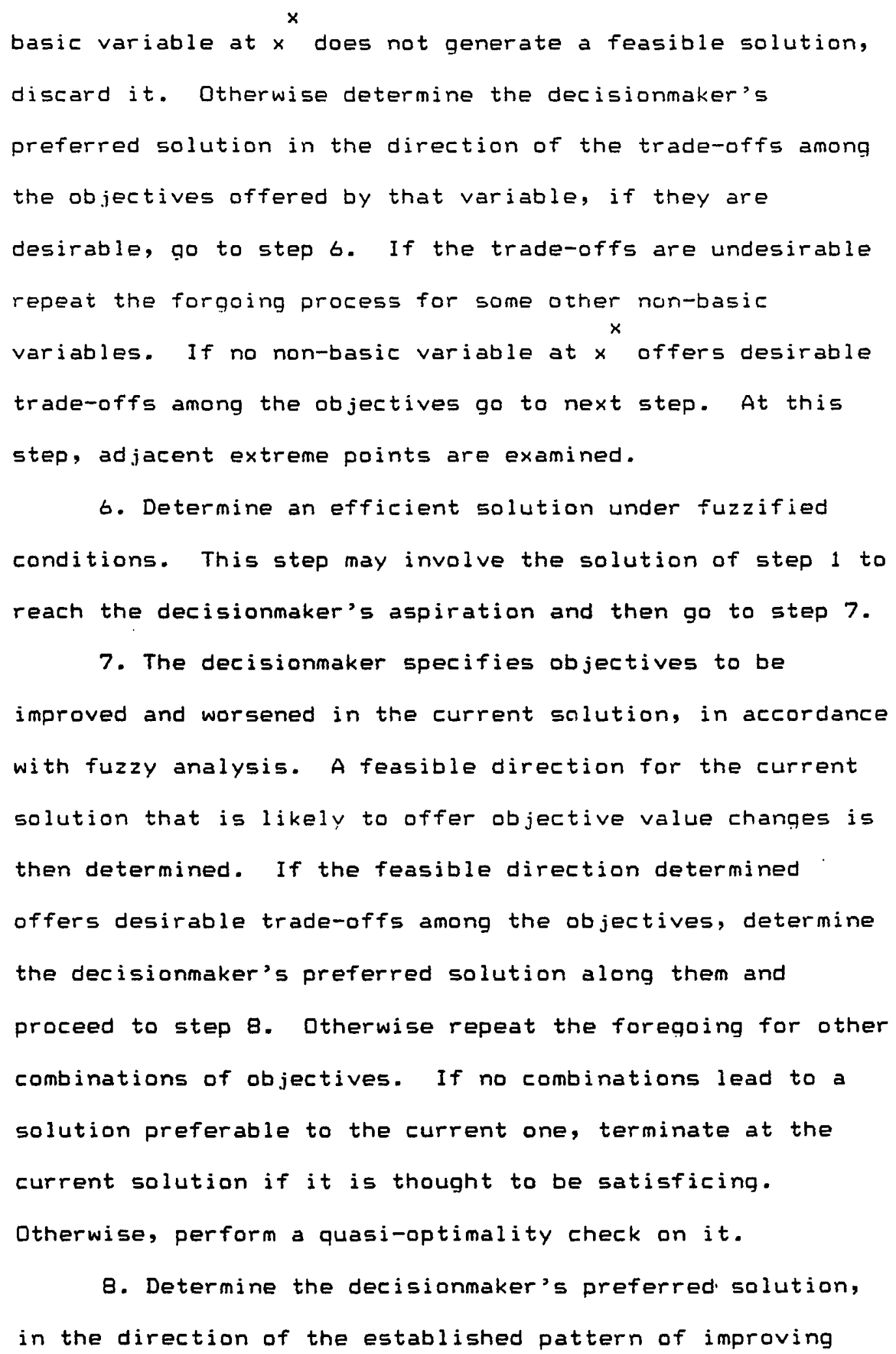


solutions until satisficing solution is found. If the pattern of improving solutions changes, go back to step 7 . 9. Determine, if an efficient solution that dominates the current one exist. If the determined solution is the same as or similar to the current one but is not satisficing, go back to step 7 , and then go to step 8 until a momentary satisficing solution is obtained.

Detailed Description of Steps

Step 1

Set $f$ as a real-valued function whose domain is a set W. $f(u)$ is assumed to be bounded from below by $m$ and from above by $M$. Then $0 \leqslant u(u) \leqslant 1$, $A$ is a fuzzy set on $U$.

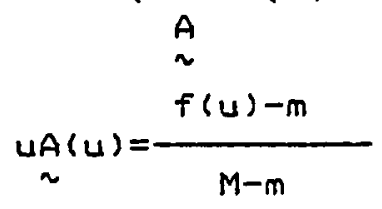

Set $A \varepsilon F(U)(i=1,2, \ldots, n)$ as fuzzy objectives, $B \in F(U)$ $(j=1,2, \ldots, m)$ as fuzzy constraints. Let

$$
D=A \Lambda \text { B }
$$

the membership function is,

$$
U \sim \sim \sim \sim \sim \sim \sim \sim \sim \sim(u)
$$

finding the maximum on $B_{\varepsilon} P(U)$ is equivalent to find $u^{*}$, and make $\underset{\sim}{u D\left(U^{*}\right)=}=\sup u D(u)$.

Definition 4.1: $U * U$ is called the element for maximizing $f$ on $B \varepsilon F(U)$, if

$$
\begin{aligned}
& U D(U *)=\max U D(U) \\
& \sim \in U \sim
\end{aligned}
$$


Now suppose both $C$ and $B$ in linear programming problems can be fuzzified, i.e., both objectives and constraints have inequal importance, and membership functions can be weighted by $A$ and $B$-dependent coefficients $a$ and $b$ such that, the $i \quad j$ ith individually optimal solution, denoted $x$, is obtained as the optimal solution to the following problem,

$$
\begin{aligned}
& \underset{\sim}{U D}(u)=\underset{\sim_{i}}{A}(u)+b \underset{\sim_{j}}{B}(u) \\
& a+b=1 \\
& a, b \geqslant 0
\end{aligned}
$$

membership functions can be weighted for fulfilling a third possibility or slack behavior [1, 86] through fuzzy evaluation. The concept of general optimization in a fuzzy environment was originally proposed by Bellman and Zadeh [63].

The importance of 1 inguistic input to the alqorithm has been indicated by Mushkat [87]. The idea for using linguistic input expressed in this study is shared by Zeleny $[88, p .169]:$

The task of a multiattribute weighting is complicated by a fuzzy logic employed by the decision maker when facing a not fully comprehensible problem. .... The newly developing theory of fuzzy set is intended to formalize such language.

Fuzzy linguistic input and linguistic hedqe have also been introduced in evaluating membership functions.

The solutions in this step are the efficient solutions at which the ith objective takes a fuzzy optimal value over 
$x$. It is advantageous if $a$ and $b$ can be chosen as close to the decisionmaker's preference, although it is subject to every change in decision systems. One fuzzy suboptimization solution to the problem is used as the first current solution. The ambiguity at issue here derives from fuzziness associated with the lack of a sharp transition from membership to nonmembership. According to Rempfer [17], this ambiguity stems from the randomness of a bistochastical process. The object can be the formulation of a fuzzy program to obtain a reasonable solution, given the ambiguity of the parameters. The fuzzy numbers can be regarded as a model of decisions in which human estimation. along with time, is significant.

Step 2

The optimization in a multiobjective system with $n$ objectives and $m$ constraints, and equal importance to objectives and constraints, is obtained as the solution to the following problem,

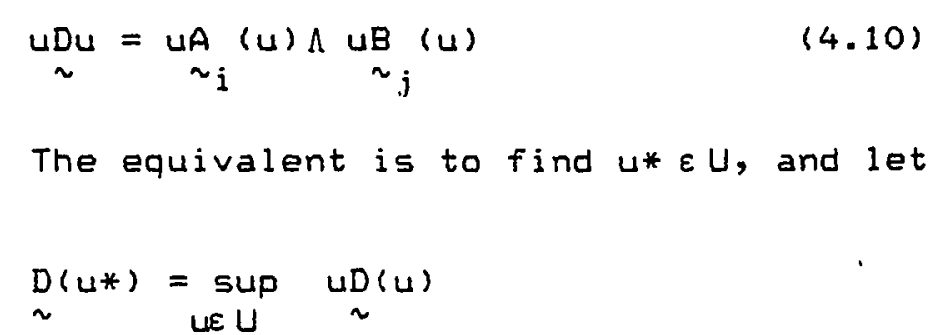


Step 3

1. Set $x=\{x, x, \ldots, x\}$ as a set of objects;

2. Set $y=\left\{y^{1}, y^{2}, \ldots, y^{n}\right\}$ as a set of criteria;

3. Set fuzzy relation from ${ }^{1} X$ to $Y$,

$f: X \rightarrow F(Y)$

$x_{i} \rightarrow r_{i 1} / y_{1}+r_{i 2} / y+\ldots+r$ im $/ y$

$0 \leqslant r \quad \leqslant 1, i=1,2, \ldots, \pi ; j=1,2, \ldots, m$

$i j$

From $f$, the fuzzy relation $R_{f}$ is introduced in terms of the fuzzy matrix,

$$
R=\left[\begin{array}{cccc}
r & r & \ldots & r_{1 m} \\
r_{11} & r_{12} & \ldots & r_{2 m} \\
21 & 22 & & 2 m \\
& \ldots & \ldots & \\
r & r & \ldots & r_{n m}
\end{array}\right]
$$

The vector of $\left.x_{i} R\right|_{i}=\left(r_{i 1}, r_{i 2}, \ldots, r_{i m}\right) \varepsilon[0,1]^{m}$;

4. Set the evaluation function $f:[0,1]^{m} \rightarrow R$, as

$$
E=f\left(z_{1}, z_{2}, \ldots, z_{m}\right)
$$

5. Calculate an evaluation index: $E\left(x_{i}\right)=f\left(r \underset{i 1}{ }, r_{i 2}\right.$, $\left.\ldots, r_{i m}\right), i \leqslant m$.

The triple $(X, Y, R)$ is called an evaluation space.

For $f$, the following conditions are satisfied:

1. regularity: $f(0,0, \ldots, 0)=0$; 
2. monotonicity: when $z \leqslant z, f(z, z, \ldots, z)$ $\leqslant f(z,, z, \ldots, z, i, i \leqslant m$;

$12 m$

3. continuity: $\lim f\left(z, z, \ldots, z_{m}\right)=f(z, \ldots, z)$. z $\underset{i}{z}$ io

In the proof, other conditions will be specified.

Lemma 4.1: Set monotonic function $\zeta:[0,1] \rightarrow R$,

$$
\zeta(x+y)=\zeta(x)+\zeta(y),(\forall x, y, x+y \in[0,1])
$$$$
\zeta(x)=a x, a=\zeta(1) \geqslant 0 \text {. }
$$

1

Proof: $\zeta(0+0)=\zeta(0)+\zeta(0), \zeta(0)=0$, for natural number $n,-\varepsilon[0,1]$,

$n$

$$
\zeta(1)=\left(\frac{1}{n} * n\right)=n\left(\frac{1}{n}\right)
$$

let $\zeta(1)=a, \zeta(-)=a * \frac{1}{-}$, for $\stackrel{m}{-} \varepsilon[0,1], n, m$ are natural numbers, $n \geqslant m$,

$$
\underset{\zeta(-)}{n}=\underset{\zeta}{(-*} m)=\underset{n}{n}\left(\frac{1}{n}\right)=a * \frac{m}{n}
$$

therefore, if $r \varepsilon[0,1]$ is a rational, $\zeta(r)=a * r$.

Then set $\xi a s$ any real number between $[0,1]$, take $a$, $b$, let $a<\xi<b$. From monotonity, $a a<\xi \xi<a b, i \rightarrow \infty$, $a^{n} \xi \zeta(\xi)<a \xi$. Therefore, for $\forall \times \varepsilon[0,1], \zeta(x)=a x, \zeta a=(1)$ $\geqslant 0$. 
m

Theorem 4.1: $f:[0,1] \rightarrow R$ satisfies reqularity, monotonicity, and

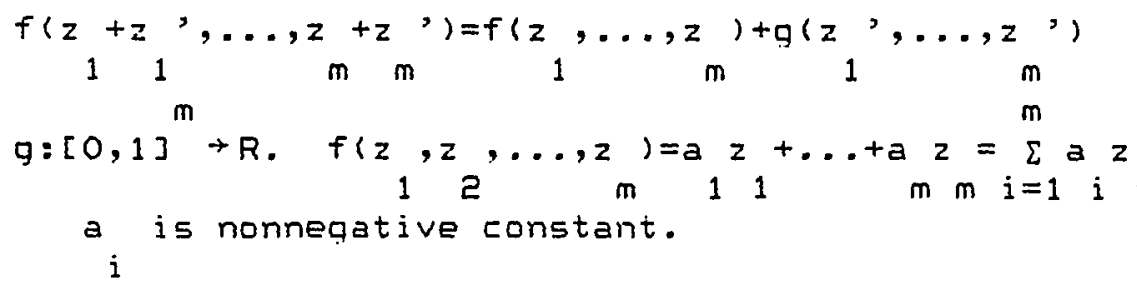

Proof: according to regularity,

$$
\begin{aligned}
& f\left(z_{1}{ }^{\prime}, z_{2}{ }^{\prime}, z_{m}^{\prime}\right)=f(0,0, \ldots, 0)+g\left(z_{1}^{\prime}, z^{\prime}, \ldots, z_{m}^{\prime}\right) \\
& =g_{1}\left(z_{2}, z^{2}, \ldots, z_{m}^{\circ}\right)
\end{aligned}
$$

then, $f\left(z+z_{1}, \ldots, z+z_{m},\right)=f(z, \ldots, z)+f\left(z, \ldots, z_{m}, \ldots\right)$

let $f(z)=f(z, 0, \ldots, 0), f(z)=f(0, z, 0, \ldots, 0)$

$$
\begin{array}{llllll}
1 & 1 & 1 & &
\end{array}
$$

$f(z)=f(0, \ldots, z, 0, \ldots, 0), i \leqslant m$, using the result from lemma i $i$

$1, f(z)=a z, a \geqslant 0$, i $6 m$, then

i $i$ i $i$ i

$$
\begin{aligned}
f(z, \ldots, z) & =f(z, 0, \ldots, 0)+f(0, z, 0, \ldots, 0)+\ldots+f(0, \ldots, 0, z) \\
& =\sum_{i=1}^{m} f_{i}(z)
\end{aligned}
$$

since $f(z)=a z, \sum^{m} f(z) \sum^{m} a z$. This linear homogeneous $i \quad i \quad i$ i $i=1$ i $i$ i=1 $i$

function satisfies regularity, monotonicity, and another

above-mentioned conditions.

Lemma 4.2: Set $\zeta:[0,1] \rightarrow[0,1]$, satisfies regularity, monotonocity, and continuity, also satisfies

$$
\begin{aligned}
& \zeta(\zeta(x))=\zeta^{(x)}, \forall x \in[0,1], \\
& \zeta(x)=a \Lambda_{x}, a=\zeta(1), \Lambda \text { is min operator. }
\end{aligned}
$$


Proof: $\zeta$ is monotonic and continuous $\varepsilon[0, a]$, take $\times \varepsilon$

$[0, a]$, there exists

$y \in[0,1]: x=\zeta(y) \leqslant a$, then

$\zeta(x)=\zeta(\zeta(y))=\zeta(y)=a \Lambda \zeta(y)=a \Lambda x$.

If $a(x \leqslant 1, a=\zeta(\zeta(1))=\zeta(a) \leqslant \zeta(x) \leqslant \zeta(1)=a, \quad \zeta(x)=a \quad k=a$.

Theorem 4.2: Set $f:[0,1]^{m} \rightarrow[0,1]$ satisfies regularity, continuity, and

1. $\left.f\left(z v_{1}{ }_{1}, \ldots, z v_{m} z_{m}^{\prime}\right)=f(z, z, \ldots, z)_{m}\right) v\left(z_{1}{ }^{\prime}, z_{2}{ }^{\prime} \ldots, z_{m}^{\prime}\right)$

2. $f(f(z))=f(z), f(z)=f(0, \ldots, 0, z, 0, \ldots, 0), i \leqslant m$

$\begin{array}{lllllll}i & i & i & i & i & i & i\end{array}$

$g:[0,1]^{m}+[0,1], f\left(z, z_{2}, \ldots, z_{m}\right)=(a \Lambda z) v(a \Lambda z) v . . v$

$(a \Lambda z), a, \ldots, a \varepsilon[0,1]$.

$m$ m $1 \quad m$

Proof: according to regularity,

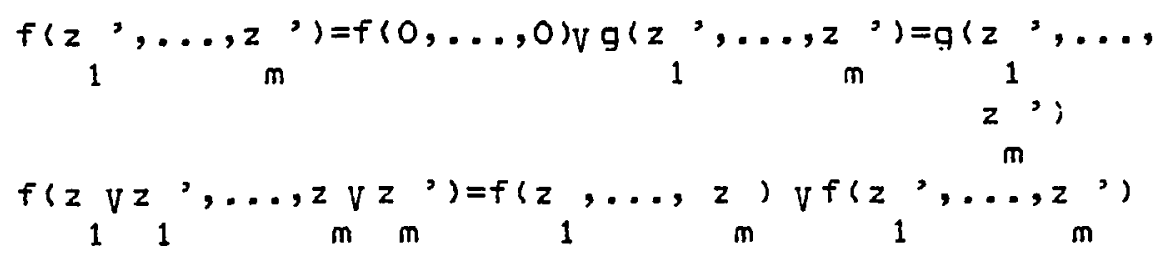

$f$ is monotonic,

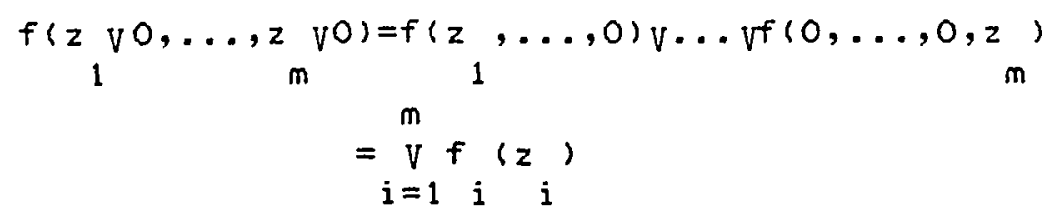

since $f$ satisfies regularity, monotonicity, and continuity, therefore, 


$$
f(z)=a \Lambda z
$$

$$
\left.f\left(z, \ldots, z_{m}\right)=(a \Lambda z)_{1}\right)_{1} \cdots v\left(a{ }_{m} z_{m}\right)
$$

$a_{i}=f(1) \varepsilon[0,1], i \leqslant m$.

For alternative proofs, see [89]. For the Lemma 4.3 and Theorem 4.3 , the results described here are proved by wu $[89]$.

$$
\begin{aligned}
& \text { Lemma 4.3: Set } \zeta:[0,1]+[0,1] \\
& \zeta(x y)=\zeta(x) \zeta(y) \quad \forall x, y \varepsilon[0,1] \\
& \zeta(0)=0, \zeta(1)=1, \quad \zeta^{(x)=x^{a}} \text {, a is positive real }
\end{aligned}
$$

number.

Theorem 4.3: Set $f:[0,1]^{m} \rightarrow[0,1]$, it satisfies regularity, continuity, and the following:

1. $f(z \Lambda z,, \ldots, z \Lambda z$,

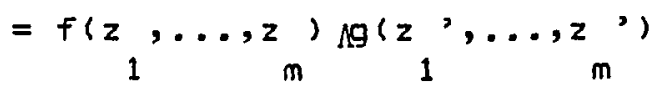

2. Let $\zeta_{i}\left(z_{i}\right)=f\left(1, \ldots, 1, z_{i}, \ldots, 1\right)$

$$
\begin{aligned}
& \zeta_{i}\left(z_{i} z_{i}^{\prime}\right)=\zeta_{i}\left(z_{i}\right)_{i}\left(z_{i}^{\prime}\right) \quad i=1, \ldots, m \\
& \zeta_{i}(0)=0
\end{aligned}
$$

3. $f(1,1, \ldots, 1)=1$ 
Proof: let $z_{1}=z_{2}=\ldots=z_{m}=1$

$$
\begin{aligned}
& f\left(z, \ldots, z_{m}{ }^{\prime}\right)=f(1, \ldots, 1) \wedge q\left(z, \ldots, z_{m}, \ldots\right)=q(z, \ldots, z) \\
& f(z \Lambda z,, \ldots, z \Lambda z, v)=f(z, \ldots, z) \Lambda f(z, \ldots, z,) \\
& \begin{array}{llllllll}
1 & 1 & m & m & 1 & m
\end{array} \\
& f\left(z, \ldots, z_{m}\right)=f(z, 1, \ldots, 1) \Lambda \ldots \Lambda_{1}^{f(1, \ldots, 1, z)} \\
& =\zeta_{1}(z) \Lambda \ldots \Lambda \zeta_{m}(z) \\
& \zeta_{i}(z)=z_{i}^{a} i
\end{aligned}
$$

As Negoita [90, p.125] notes:

The notions of subjective evaluations and of fuzzy sets are not one and the same but rather have the relationship of goal and tool: having precisely manipulatable subjective evaluations is the goal, and fuzzy set theory is a tool to achieve the goal.

Step 4

Systematic search in this step aims to determine a pattern of improving solutions, preferred by the decisionmaker and carried out over objective space.

Since $x \varepsilon x$, the objective space direction defined by i $k$ i $k$ k $c(x)$ and $c(x)$ is denoted by $(c(x), c(x))$. If $c(x)$ is the current solution, the decisionmaker is asked to indicate a preferred, fuzzified, feasible solution $c\left(x^{i+1}\right)$ in the direction of $\left(c\left(x^{i}\right), c\left(x^{k}\right)\right)$. Then the decisionmaker is $i+2$ asked to indicate in turn $c(x)$ in the direction of 
$\left(c\left(x^{i}\right), c\left(x^{k}\right)\right)$. If $c\left(x^{i}\right) \neq c\left(x^{k}\right)$, the pattern of improving solution for whole-subsystems is established. If $c\left(x^{i}\right)=$ $k$ $c(x)$, no pattern of improving solutions has been determined.

Theorem 4.4: If $c(x)$ is an efficient solution, and $j$ $c(x)$ is an efficient solution, there will be a set of efficient solutions inbetween.

Proof: Set $k=0,1, \ldots, n$ as parametric space, then both $i j j$ i $j$ $c(x)$ and $c(x)$ have their $k 1(x)$ and $k 2(x)$ respectively. Because of the convexity of $k=n$, we know that $k 1$ and $k 2$ is contained in the union of all polyhedra which are associated with bounded solutions. Because of a finite covering of $k=n$, we can select a finite sequence of distinct polyhedra $j+1 \quad i+k \quad j+k \quad j$ $\{x, \ldots, x \quad 3$, such that $k(x)=k(x)$ in accordance with $a$ and $b$.

The fuzzified feasible solution in the direction of improving is as follows:

$$
\begin{aligned}
& c\left(x^{x}\right)=c\left(x^{i}\right)+u\left(c\left(x^{k}\right)-c\left(x^{i}\right)\right) \\
& \text { Optimize } u \\
& \text { s.t. } c\left(x^{x}\right)=c\left(x^{i}\right)+u\left(c\left(x^{k}\right)-c\left(x^{i}\right)\right) \\
& x \in X \\
& u \in[0,1]
\end{aligned}
$$


$\left(x^{x}\right)$ would then be the decisionmaker's preferred solution.

The objective function varies with $u$, which is a function of decisionmaker's fuzzy judgment. In this step, the diversification is toward centralization.

Step 5

Let $x^{x}$ be the current optimal solution. When $x^{x}$ is not a basic solution preferred by the decisionmaker, the decisionmaker's preferred solution in the direction of desirable trade-offs among the objectives offered by some non-basic variables at $x$ is determined as follows:

Theorem 4.5: Given a current basic feasible solution, and assuming $\theta \geqslant 0$ for $j \varepsilon \bar{j}$, then, if $z \leqslant 0$, then the basic is inferior ${ }^{j}[88, p .66]$.

Proof: Introducing the jth column into the basis, we ascertain a new adjacent extreme point, for which $\hat{z} \geqslant z$.

Theorem 4.6 : If $z \geqslant 0$, then introducing the $j$ th column into the basis will lead to an inferior solution [88, $p .66]$.

Proot: Introducing the $j$ th column, we find an adjacent

extreme point for which $\hat{z} \leqslant z_{0}$, since $-\theta z \leqslant 0$.

Theorem 4.7 : Given a current basic, feasible solution, if there are two different, nonbasic columns $j$ and $k$, such that

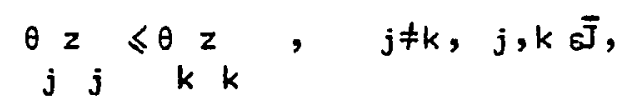


then the solution resulting from introducing the kth column is dominated by the solution resulting from introducing the jth column [8B, 0.67$]$.

Proof: Introducing the kth column, we get $\hat{z}_{0}$; and introducing the $j$ th column, we get $\hat{z}$. Then $\hat{z}=z-\theta_{k} z$ and $\hat{z}=z-\theta_{0} z$. Since $-\theta_{k} z \leqslant-\theta_{j} z$,

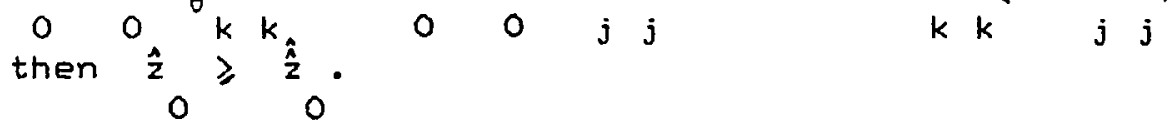
The set of fuzzified feasible solutions in the objective space direction $c\left(a^{j}\right)$ at $c\left(x^{x}\right)$ is as follows:
Optimize $u$ s.t. $\quad c(x)=c\left(x^{x}\right)+u\left(c\left(a^{j}\right)\right)$ $u \varepsilon[0,1]$ $x \varepsilon X$

The $j$ th non-basic variables can be either $x_{j}$ or 5 ." The non-basic 5 at $x$ changes fuzzily in value, solutions generated will lie on the same face of $x$ if no basic variables change values [91].

Step 6

This step explores the possibility that if the current solution is efficient, a fuzzified preferred solution can be determined, too.

This step is a special case for step 4.

Theorem 4.8: When $k\left(x^{i}\right)$ equals $k\left(x^{j}\right)$, the solution reaches its boundary. 
Proof: The proof follows directly from the last theorem. Because of a finite covering of $k=n$, a line segment $\left[k\left(x^{i}\right), k\left(x^{j}\right)\right]$ is contained in the union of all polyhedra associated with the boundary.

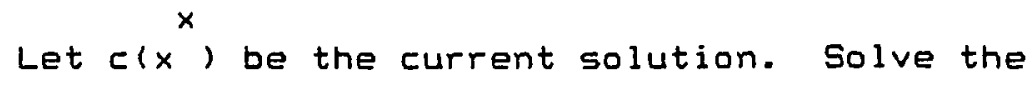

following problem:

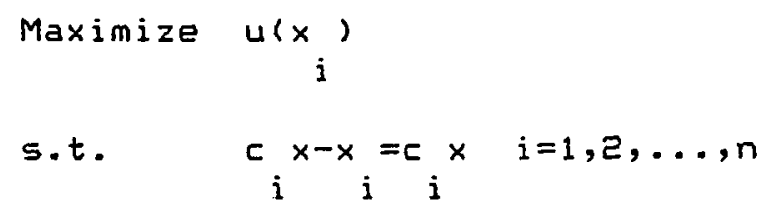

If the solution of the problem equals zero, $u=1$. If the solution $\geqslant 0,0 \leqslant u \leqslant 1$.

Step 7

Systems research, in contrast with applied

mathematics, is problem- rather than tool-oriented [59]. In il1-structured systems, inexact information and value-based judqment are common. In consequence, many sophisticated mathematical analyses, such as the gradient method, often encounter difficulties in measurement, inference, and application [92]. Judgment prevails in place of precise analysis, and approximation instead of exact solutions. In order to discover how effective the various fuzzy alternatives are in achieving the objectives, it is 
necessary to determine a way to measure their effectiveness, again involving fuzzy value judgment.

Broadly, fuzzy integral is appropriate for evaluation [46, P.127]. The systematic evaluation of the object can be summarized as follows: set $U=\{u, U, \ldots, u\}$ be a set of elements or attributes. Let $h:-r][0,1]$,

$$
f h(u) \circ g
$$

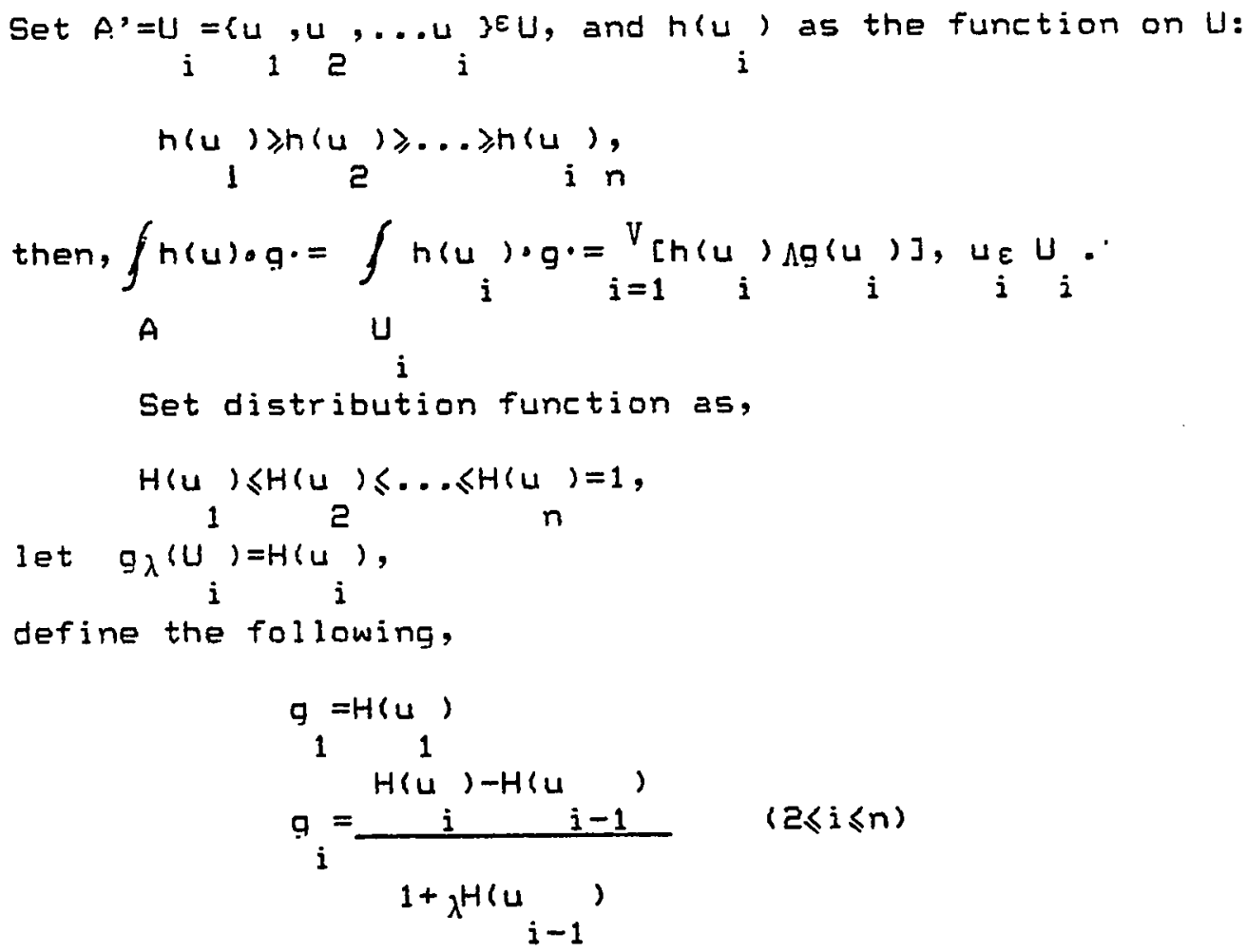

for any UをU,

$$
g_{\lambda}\left(U^{\prime}\right)=\frac{1}{\lambda}\left[\prod_{u \varepsilon^{U^{\prime}}}\left(1+\lambda_{\lambda}{ }_{i}\right)-1\right]
$$

for $U=\{u, u, \ldots, u\}$, 


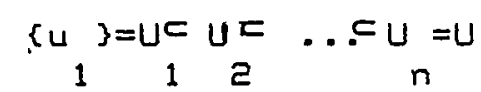

then

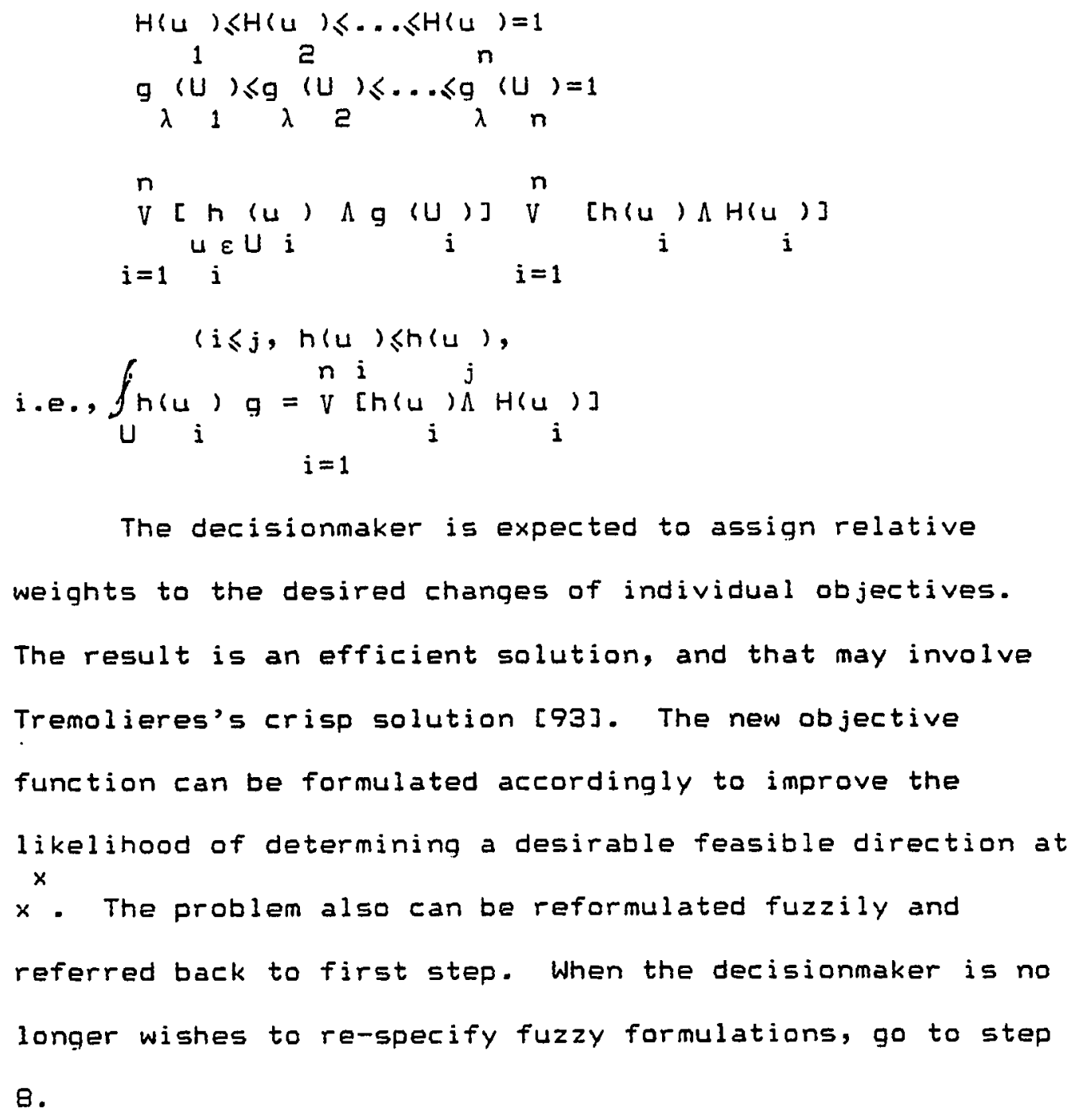




$$
c\left(x^{x+1}\right)=c\left(x^{x}\right)+u\left(c\left(x^{x+1}\right)-c\left(x^{x}\right)\right)
$$

Optimize $u$

$$
\text { s.t. } c\left(x^{x+1}\right)=c\left(x^{x}\right)+u\left(c\left(x^{x+1}\right)-c\left(x^{x}\right)\right)
$$

$x_{E} X$ ue $[0,1]$

Step 9

If the decisionmaker no longer wishes to re-specify fuzzy formulation, or if there exists an efficient satisficing solution dominating the current solution, the solving procedure is terminated. The question of what is satisfactory is largely answered by judgment. The preferred alternative is the one that, in the decisionmaker's value iudgment, yields the greatest positive consequence. At this step, a relative equilibrium has been reached, a state of the system satisficing partial basic consistency conditions that makes it self-perpetuating once attained. As many ill-structured systems methods in applied systems analysis, both the conventional economic systems analysis or current modified economic systems analysis have no stopping rule to tell the decisionmaker where the solution is. There may be an immediate solution, but not an ultimate one. The decision consists of flows, as described in Chapter 3, that only can be described in terms of the instantaneous state of the system. There is no solution but resolution, which relies on judgment. Due to the 
multidimensional perspectives, even the decisionmaker may not really know where the objectives are.

The reason for designing the first and second steps of the algorithm is that whenever multiple objectives are present in a project, there is probably no single course of action that will optimize all objectives simultaneously. In the environment-related projects, more decisionmakers have now been convinced that the pursuit of the perfectly clean, safe environment will involve either unacceptably high costs or intrusive social impacts.

This contradiction may lead to suboptimization, a solution that optimizes subsystem efficiency with inadequate or no regard for system effectiveness. At the first step, the decisionmaker is imperfectly aware of the system, and incompletely describes the economic or other system. The reason for entering step two is the question of what other system will be operated in parallel. The subsystems are parts of the system. Only when the system has been completely defined will there be a real analysis. Then, a reasonable response would be for the decisionmaker to change the model or its parameters to accommodate the observations made. After performing steps one and two, the task is to find an equilibrium between subsystem and system. In other words, the decisionmaker adapts to the variations in the picture of the system perceived, thus arriving at the equilibrium point. 


\begin{abstract}
The system sets ultimate objectives, and the associated subsystems define the multiple strategems required to achieve those objectives. A systems decision selects the overall objective that best utilizes the available resources. The relationship between system and
\end{abstract} subsystems offers constructive insight in Step 3 . The effectiveness of each subsystem is estimated from its effect on system ohjectives. It could happen that a system with lower effectiveness possessed the subsystem with the highest efficiency. Suppose that subsystem $x$ were close to the most efficient subsystem of system I. If it were highest in efficiency, it might be the leading alternative for selection, in its systematic evaluation. $x$ might have high sensitivity, such that it was vulnerable to changes in the system. If it were sensitive on the efficiency scale, a change in either the system or even the wider system could switch the position of the top subsystems, or even the system itself. An insensitive situation might occur, in which all the subsystems for a given system had a higher efficiency than the best subsystem of any other system. The consequence of high sensitivity would be to force a comprehensive estimation to assure the appropriateneis of $x$. A fuzzy analysis could be conducted on projects to explore systems effectiveness. 
4.3.3. An Illustrative Example

A simple numerical example illustrates the approach. Suppose a hydropower administration designs two kinds of dam on given conditions. Dam 1 yjelds a benefit of $\$ 2$ million annually, and dam 2 of \$1 million. Dam 2 , however, improves existing natural scenery, yielding additional yearly recreational revenues of $\$ 2 \mathrm{million}$ dollars, dam 1 has annual neqative environmental impacts of $\$ 1 \mathrm{million}$. Two goals are established: 1. Benefit maximization, and 2. Maximum improvement of the natural environment. The problem can be modeled as follows: $\operatorname{Max}$

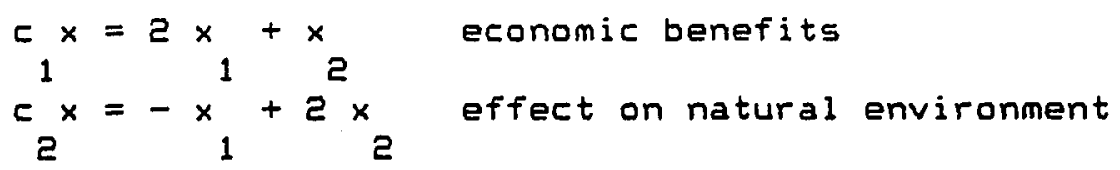

Single Objective Optimization

Economic benefits-maximization solutions:

$$
\begin{aligned}
& x_{1}=27 \\
& z^{1}=54
\end{aligned}
$$

Natural environment-improvement maximization solution:

$$
\begin{aligned}
& x^{2}=7 \\
& z^{2}=14
\end{aligned}
$$


Fuzzy Multiobjective Programming

Step I

The union and intersection can be defined as

follows:

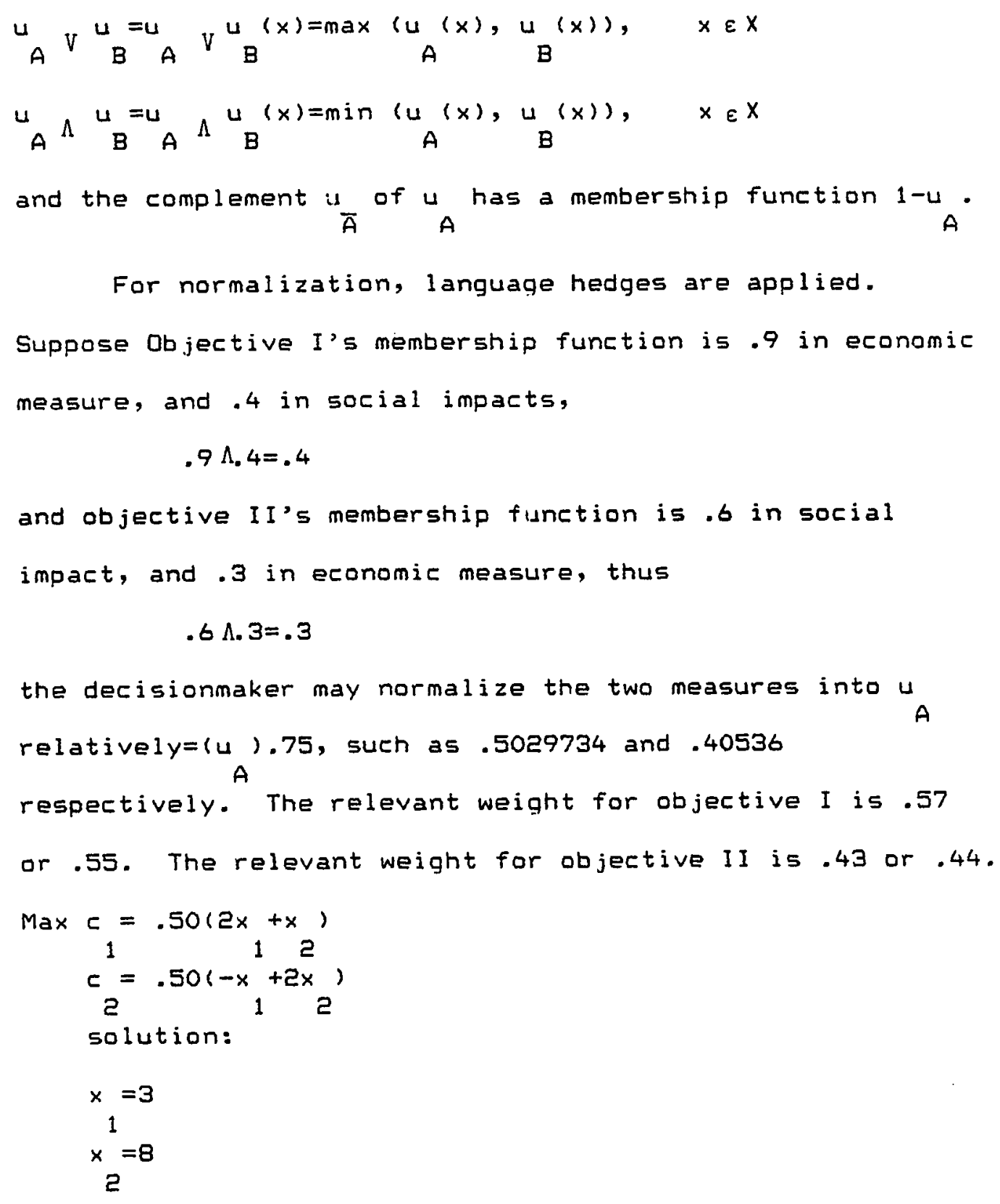


$Z=27$

. .

Step II

$\operatorname{Max} c=.57(2 x+x)$

122

$c=.43(-x+2 x)$

212

solution:

$x=3$

1

$x=8$

ᄅ

$2=23.75$

\section{Step III}

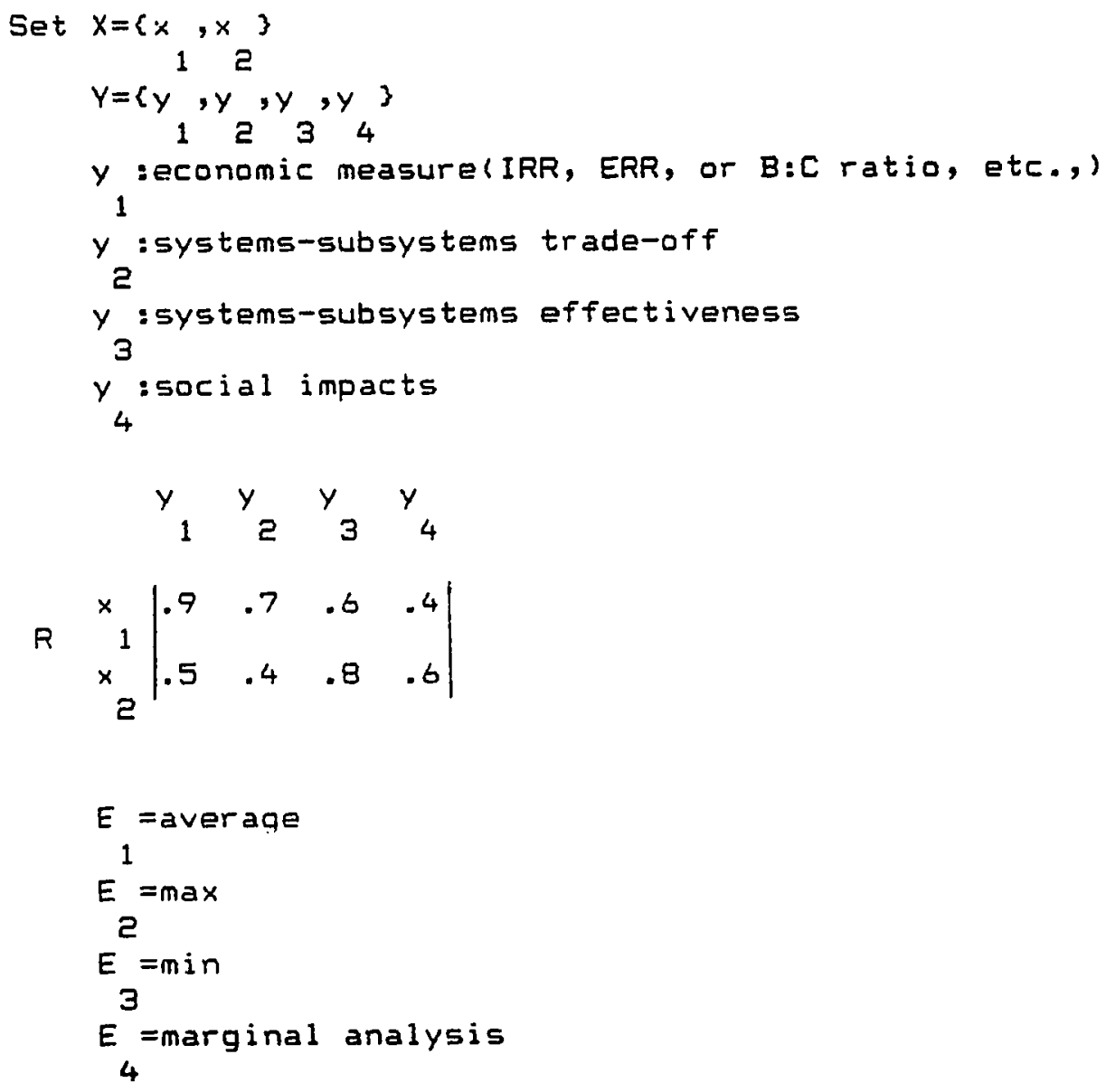




$$
\begin{aligned}
& E_{1} E_{2} E_{3} E_{4}
\end{aligned}
$$

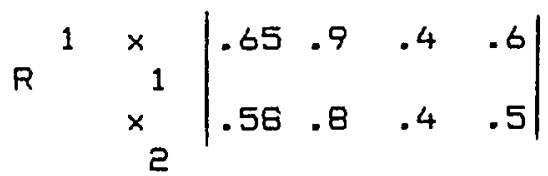

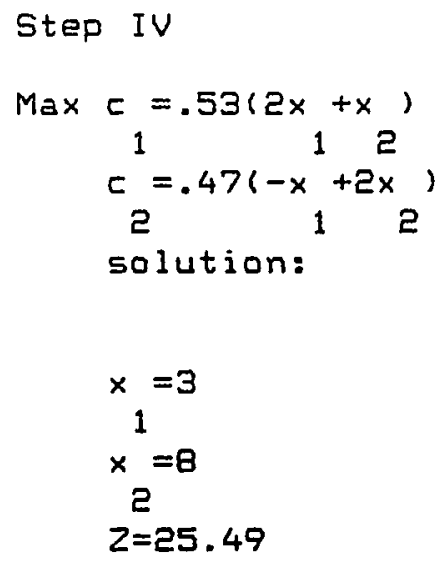

\section{Step VII}

Now we evaluate two kinds of dam again in terms of fuzzy integral. The weight has been changed, and the 
decisionmaker may therefore change the evaluation again.

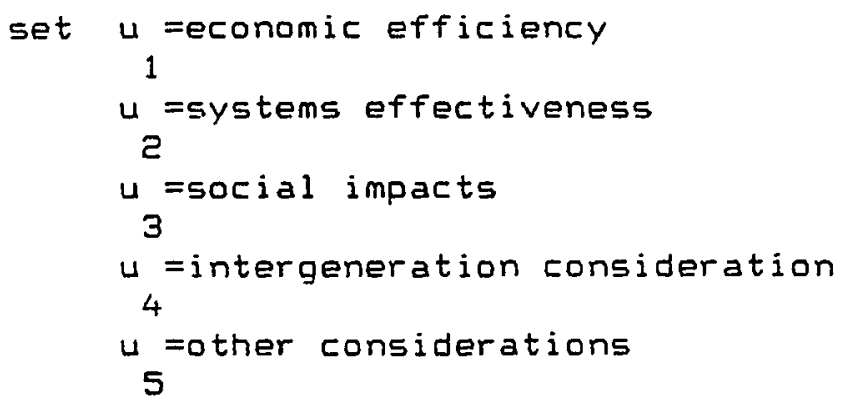


$\begin{array}{lllll}4 & u_{1} & u_{1} & u_{4} & 4 \\ 1 & 2 & 3 & 4 & 5\end{array}$

\begin{tabular}{|c|c|c|c|c|c|c|}
\hline Degree of Satisfaction & $h(u)$ & .8 & .9 & .6 & .3 & .2 \\
\hline Degree of Emphasis & ${ }_{i}(\lambda=0)$ & .5 & .5 & .1 & .1 & .1 \\
\hline Distribution Function & $H\left(u_{i}\right)$ & .5 & .7 & .8 & .9 & 1 \\
\hline Degree of Emphasis & $a_{i}{ }^{\prime}\langle=0)$ & .2 & .1 & .1 & .2 & .4 \\
\hline Distribution Fun & $H^{\prime}(u)$ & .2 & .3 & .4 & .6 & 1 \\
\hline
\end{tabular}

With the systematic evaluation of objective 2 under the degree of satisfaction $h(u)$, degree of emphasis $g_{i}$ is as follows:

$u=(.8 \Lambda .5) V(.9 \Lambda .7) V(.6 \Lambda .8) V(.3 \Lambda .9 N(.2 \Lambda 1)=.7$

With the systematic evaluation of objective 2 under the degree of satisfaction $h^{(L)}{ }_{i}$, degree of emphasis $g_{i}$, is as fallows:

$u=(.8 \Lambda .2) V(.9 \Lambda .3) V(.6 \Lambda .4) V(.3 \Lambda .6) V(.2 \Lambda 1)=.4$

\section{Step VII}

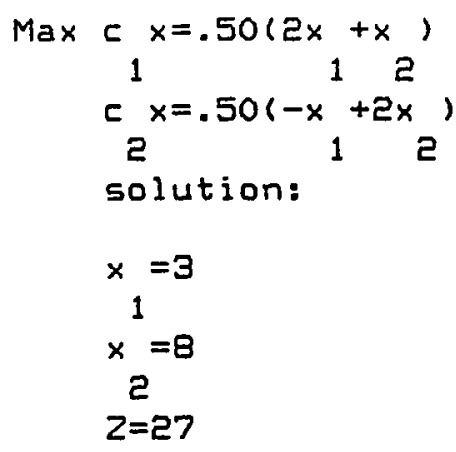


Markov analysis has been applied for finding

membership functions of multiobjectives in terms of a Monte Car lo method.

II. Empirical Data for Initial Distribution of Objective I

\begin{tabular}{ccc}
\hline Importance & Probability & Cumulative Probability \\
\hline $0 \%$ & .00 & .00 \\
$25 \%$ & .25 & .25 \\
$50 \%$ & .55 & .80 \\
$75 \%$ & .10 & .90 \\
$100 \%$ & .10 & 1.00 \\
\hline
\end{tabular}

IV. Simulation Results for Initial Distribution of Objective I

\begin{tabular}{ccc}
\hline Sample & Random Number & Importance \\
\hline 1 & 60 & $50 \%$ \\
2 & 68 & $50 \%$ \\
3 & 8 & $0 \%$ \\
4 & 87 & $75 \%$ \\
5 & 53 & $50 \%$ \\
6 & 67 & $50 \%$ \\
7 & 48 & $50 \%$ \\
8 & 90 & $75 \%$ \\
\hline
\end{tabular}

$E(x)=\sum x \underset{i}{f}(x)$

$=.5$ 
V. Empirical Data for State Transition of objective I

\begin{tabular}{lll}
\hline State 1 & Probability & Cumulative Probability \\
\hline .2 & .00 & .00 \\
.4 & .15 & .15 \\
.6 & .15 & .30 \\
.8 & .60 & .90 \\
1.00 & .10 & 1.00 \\
\hline
\end{tabular}

VI. Simulation Results for State Transition of objective I

\begin{tabular}{lll}
\hline Sample & Random Number & State 1 \\
\hline 1 & 12 & .2 \\
2 & 23 & .6 \\
3 & 75 & .8 \\
4 & 64 & .8 \\
5 & 46 & .8 \\
6 & 41 & .8 \\
7 & 78 & .8 \\
8 & 23 & .6 \\
\hline
\end{tabular}

$E(X)=.675$ 
VII. Empirical Data for State Transition of objective II

\begin{tabular}{ccc}
\hline State 1 & Probability & Cumulative Probability \\
\hline .2 & .00 & .00 \\
.4 & .15 & .15 \\
.6 & .15 & .30 \\
.8 & .60 & .90 \\
1.00 & .10 & 1.00 \\
\hline
\end{tabular}

VIII. Simulation Results for State Transition of Objective II

\begin{tabular}{ccc}
\hline Sample & Random Number & State 1 \\
\hline 1 & 53 & .8 \\
2 & 23 & .6 \\
3 & 33 & .8 \\
4 & 32 & .8 \\
5 & 61 & .8 \\
6 & 75 & .8 \\
7 & 57 & .8 \\
8 & 50 & .8 \\
\hline
\end{tabular}

$E(X)=.775$

The Markov transition process can be expressed as follows: 


$$
\begin{aligned}
& \text { I II }
\end{aligned}
$$

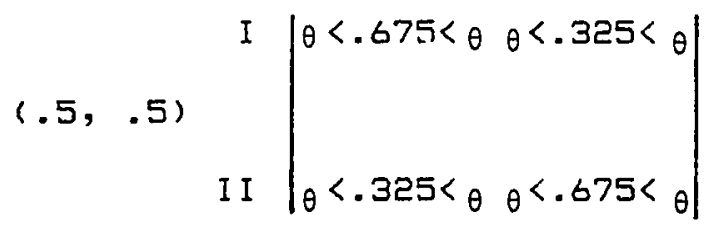

The following two examples provide some information about how the signal is transmitted with noise ffor a further explanation see [17]). They demonstrate that state correspondence matches the concatenation of empirical data supporting probabilistic dynamics as a fundamental causality.

$(.5, .5) \mid \begin{array}{cc}I & \text { II } \\ & =(.5, .49)\end{array}$


I II

$$
\begin{aligned}
(.5, .49) & \left|\begin{array}{ll}
.695 & .302 \\
\text { II } \mid .3 & .689
\end{array}\right| \\
& =(.4945, .48861)
\end{aligned}
$$

Generally speaking, we have a system in which $\sim$ is denoted as stochastic vector,

I

I I

$$
(2, \sim)
$$
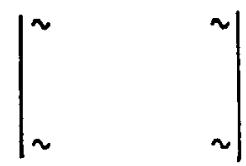

and therefore, the states after infinite steps are always fuzzy. 


\section{CHAPTER 5}

SUMMARY, CONCLUSION, AND SUGGESTIONS

FOR SUBSEQUENT RESEARCH

A model is always an approximation,..., and hopefully an aid to insight.

H. Borko $[94$, P.39]

This final chapter looks backward and forward: back to summarize the previous chapters and to make the major conclusions; ahead to indicate the directions subsequent research might take.

\subsection{Summary}

The introductory chapter scrutinizes classical

economic systems analysis, two schools of economic systems analysis, and the major characteristics of conventional methodology. The chapter also explains the motivation for conducting this study, emphasizing the growing importance of il1-structured systems methodology as the main element of economic systems analysis.

Chapter 2 proposes a synergetic philosophical paradigm to replace the Newtonian-Kantian inquiring system as the foundation of methodology. The chapter concludes with a methodological overview of economic systems analysis, 


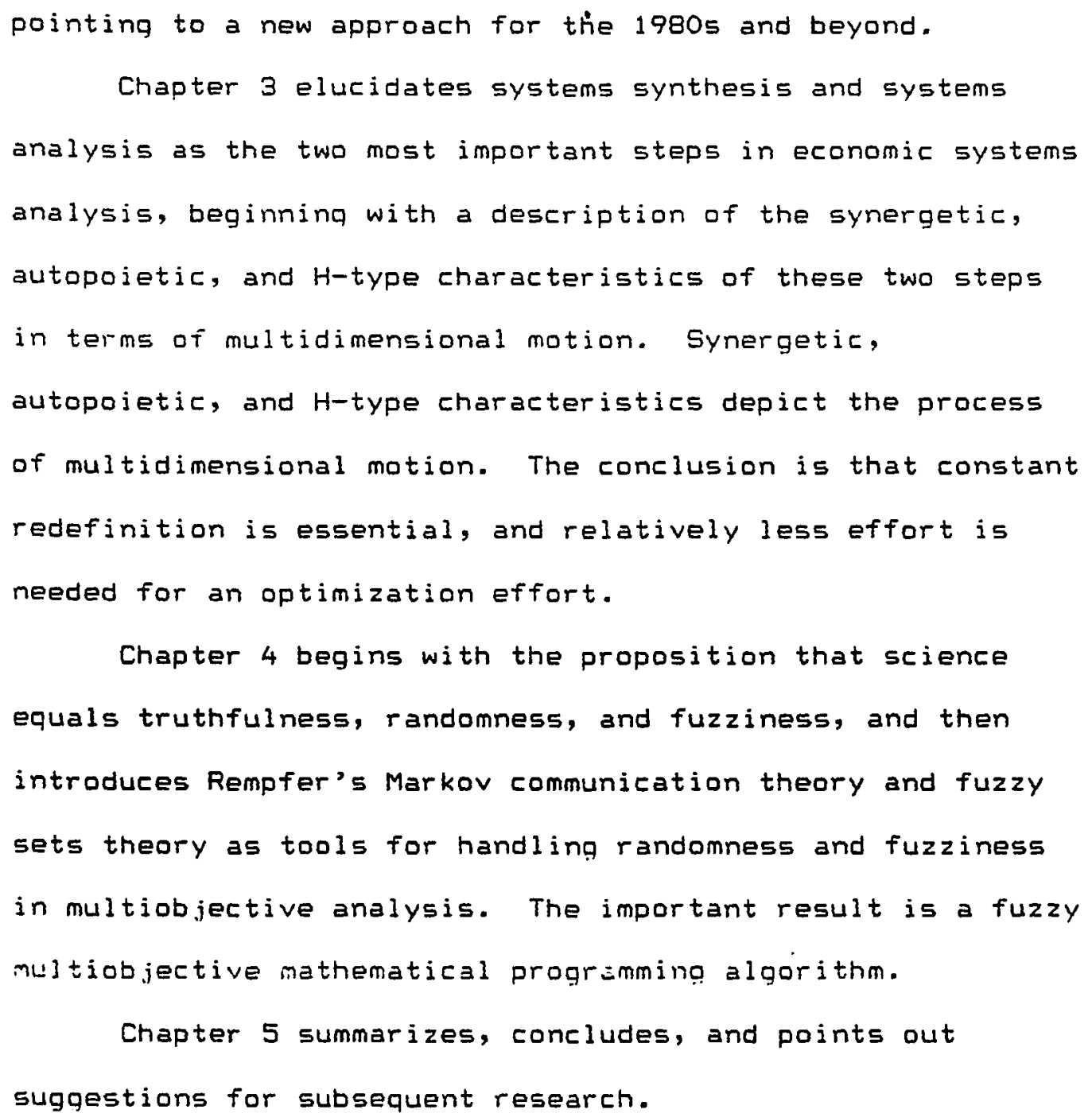

\subsection{Conclusion}

Two decision models have been constructed: a synergetic interaction model for problem formulation and analysis, and a fuzzy multiobjective mathematical programming algorithm for multiobjective analysis. Fuzzy modeling offers a deeper understanding and clear explication of an event's complexities, and a means for incorporating 
subjective inputs and adaptation. Therefore, fuzzy modeling inereases the validity of the systems approach for dealing with ill-structured systems. The method responds to the current trends in economic systems analysis, multiobjective mathematical programming, and systems theory [59, 66].

For economic systems analysis, we improve steps 1,2 , and 5 (see p.3) in terms of fuzzy reasoning, and develop a new fuzzy algorithm for multiobjective programming. For systems theory, general interaction and other relevant coricepts have been developed.

Our initial experience with the algorithm has indicated that,

(1) the method, which is simple and permits easy interaction with the decisionmaker, can provide the required information without significant difficulty. The algorithm, characterized by a progressive articulation of preference, is not difficult for a decisionmaker to understand. Progressive articulation iteratively qives decisionmakers information on the consequences of their value judgments and allows them to modify their choices in an effort to improve the solution.

Generally speaking, the method is appropriate to the problem to which it is applied, to the decisionmakers who will use it, and to the organizational setting in which it will be implemented. The method allows an explicit consideration of external and internal perspectives. 
Therefore, it is appropriate in regard to the types of alternatives it can consider, the value judaments it requests, and the forms of evaluations it yields. It represents an important methodological improvement over Marglin's approach;

(2) The method can provide the room for both systematic and chance observations, and it is closer to reality in comparison with the balance-sheet, goal achievement matrix, and rank-based expected value methods;

(3) Fuzzy evaluation offers an appropriate way to deal with a problem in which many factors must be evaluated simultaneously. The appropriate weighting base on numerous factors makes it possible to approximate reality more closely, as the Rempfer algorjthm proves mathematically [83];

(4) The method is particularly suitable to situations in which a decisionmaker tends to provide linguistic measures in the solution process;

(5) The algorithm establishes a learning process. As Negoita [90, p.126] indicates:"In fuzzy evaluations "the best" is viewed as a new evaluation in the structure of all evaluations, pulling back towards a synthesis." The idea of iteration in a fuzzy environment incorporated in this algorithm has been stated profoundly by Rempfer's algorithm [83] and Negoita's comments.

Basically, the task proposed at Chapter 1 has been 
completed.

5.3. Suggestions For Subsequent Research

This work has not spoken the last word on the application of fuzzy multiobjective programming to economic systems analysis; it is only the beginning.

The following areas would merit further study:

(1) Fuzzy methodology fills many of the gaps left by non-fuzzy methods. However, reduction is still available in the modeling process. Therefore, there is a long way to go toward realizing the proposed paradigm as a solid foundation of the methodology;

(2) A general, fuzzy description for bridging the language gap will be of great value to steps 3 and 4 . The construction of relevant fuzzy functions must be emphasized;

(3) Investigators should consider the extent to which the method may be suitable to allow a multiobjective proqramming solution;

(4) Large-scale Markov analysis using computers should be emphasized;

(5) The effect of H-substance on systems design requires consideration. 
References

[1]. Heisenberg, w. Physies and Philosophy. New York: Harper, 1958.

[2]. Samuelson, P.A. Economics. New York: MeGraw-Hill, 1980.

[3]. Churehman, C.W. "Churchman's Conversation." Systems Research, $1(1986): 1-2$.

[4]. Mekean, Roland N. Efficiency in Government Through Systems Analysis. New York: Wiley, 1958.

[5]. Hitch, C.J., R.N. McKean. The Economics of Defense in the Nuclear Age. Santa Manica, CA: Rand, 1960.

[6]. Quade, E.S., W.I. Boucher. Svstems Analysis and Policy Planning. New York: Elsevier, 1968.

[7]. Seiler, $K$. Introduction to Systems Cost Effectiveness. New York: Wiley, 1969.

[8]. Fisher, G.H. Cost Considerations in Systems Analysis. New York: Elsevier, 1971.

[9]. Stokey, E., R. Zeckhauser. A Primer for Policy Analysis. New York: Norton, 1978.

[10]. Riggs, J.L., T.M. West. Essentials of Engineering Eeonomics. New York: MeGraw-Hill, 1986.

[11]. Sage, A.P. Economic Systems Analysis. New York: NorthHolland, 1983.

[12]. Anderson, L.G., R.F. Settle. Benefit-Cost Analysis: A Practical Guide. Lexington, KY: Lexington, 1977.

[13]. Prest, A.R., R. Turvey. "Cost-Benefit Analysis: A Survey." Economic Journal, 75(1965):683-735.

[14]. Williams, A. "Cost-benefit analysis:Bastard Science? And/or Insidious Poison in the Body Politic?" Journal of Public Economics, 1(1972):199-225.

[15]. Churchman, C.W. The Design of Inquiring Systems. New York: Basic Books, 1971. 
[16]. Marglin, S. "Objectives of Water Resource Development: A General Statement." in A. Maass, (eds.), Design of Water Resource Systems. Cambridqe: Harvard Univ. Press, 1962.

[17]. Rempfer, R.W. "A Communication Model related to Zadeh's F-sets Theory." Presented at the Fuzzy Sets Seminar, Systems Science Institute, Portland State University, Portland, Oregon, May 1973.

[18]. Dies, H. Die Fragmente der Vorsokratiker. (ed.), Walther Kranz, 2(1951): 166 .

[19]. Popper, K. Realism and the Aim of Science. Totowa, NJ : Rowman and Little Field, 1983.

[20] Asefa, S. Economic Decisionmaking, Private and Public Decisions. Ames, IA: Iowa State University, 1985.

[21]. Chadwick, G. A Systems View of Planning. Oxford: Pergamon, 1978.

[22]. Holzer, M., E.D. Rosen. Current Cases in Public Administration. New York: Harper \& Row, 1981.

[23]. Andersen, D.F. Mathematical Models and Decision Making in Bureaucratics: A Case Story Told from Three Points of View. Ph.D. Diss. MIT, 1977.

[24]. Linstone, H.A. Multiple Perspectives for Decision Making. New York: North-Holland, 1984.

[25]. Foerster, H. von. "The Curious Behavior of Complex Systems: Lessons from Biology." in H.A. Linstone and W.H.C. Simmonds, (eds.), Futures Research: New Directions. Reading, Mass.: Addison-Wesley, 1977.

[26]. Boulding, K.E. "Human Knowledqe as a Special System." Behavioral Science, 26(1981):93.

[27]. Kneese, A.V. Measuring the Benefits of Clean Air and Water: Washington, D.C.: Resources for the Futures, Ine., 1984.

[28]. Holling, C.S. "The Curious Behavior of Complex Systems: Lessons from Ecology." in H.A. Linstone and W.H.C. Simmonds, (eds.), Futures Research: New Directions. Reading, Mass.: Addison-Wesley, 1977.

[29]. Rourke, F.E. Bureaucracy, Politics, and Public Policy. Boston: Little, Brown and Co., 1976. 
[30] Dasqupta, P. et al. Guidelines for Project

Evaluation. New York: United Nations, 1972.

[31]. Hoos, I.R. Systems Analysis in Public Policy: A

Critique. Berkeley: University of Caljfornia Press, 1972 .

[32]. Self, P. "Nonsense on Stilts: The Futility of Roskil1." New Society, July 1970:2.

[33]. Peters, T.J., R.H. Waterman. In Search of Excellence. New York: Harper \& Row, 1982.

[34]. Allison, G. Essence of Decision: Explaining the Cuban Missile Crisis. Boston: Little, Brown \& Co., 1978.

[35]. Pierskalla, w. Speech at National TIMS/ORSA Meeting, San Franciseo, 1984.

[36]. Warfield, J.N. Societal Systems. New York: Wiley, 1976.

[37]. Lichfield, N. "Cost-benefit Analysis in Urban Expansion: A Case Study." Reqional Studies, $3(1969): 123-155$.

[38]. Xu, L.D. "The Object and Sphere of Informatics and Partial Space Theory. "Journal of the China Society for Scientific and Technical Information, 2(1983):2,161-164.

[39]. Marx, K., F. Engels. The Complete Works of Marx and Enqels, Vol.xx. Beijing: People's Press, 1965.

[40]. Haimes, Y.Y. "Multiple-Criteria Decisionmaking: A Retrospective Analysis." IEEE Transactions on Systems, Man, and Cybernetics, SMC 15(1985):3.

[41]. Haken, H. Synerqetics. New York: Springer-Ver]aq, 1978.

[42]. Varela, F.G. et al. "Autopoiesis: the Organization of Living Systems, its Characterization and a Model." Bio Systems, $5(1974): 187-196$.

[43]. Mesarovic, M.D. Views on General Systems Theory. New York: John Wiley, 1964.

[44]. Liu, Ying. "Reminiscence of Zhang Wentian." Qutlook Weekly, 33(1985): 45 . 
[45]. Molander, E.A., R.C. Molander. What About the Russians-and Nuclear War? New York: Pocket Books, 1984 .

[46]. Dubois, D.,H. Prade. Fuzzy Sets and Systems: Theory and Applications. New York: Academic Press, 1980.

[47]. Prigogine, I. From Being to Becoming. San Francisco: W.H. Freeman, 1980 .

[48]. Avriel, M. etal. Dptimization and Desian. Englewood Cliffs, NJ: Prentice-Hall, 1973.

[49]. Dixon, J.R. Design Engineering: Inventiveness, Analysis and Decision-Making. New York: McGraw-Hill, 1966.

[50]. Gregory, S.A. The Design Method. London: Butterworth, 1966.

[51]. Krick, E.V. An Introduction to Engineering and Engineering Design. New York: Wiley, 1969.

[52]. Sutherland, J.W. A General Systems Philosophy for the Socjal and Behavioral Sejences. New York: George Braziller, 1973.

[53]. Hal], H.D. A Methodology for Systems Engineering. New York: Van Norstrand, 1972.

[54]. Nadler, G. The Planning and Design Approach. New York: Wiley, 1981 .

[55]. Wilson, W.E. Concepts of Engineering System Design. New York: McGraw-Hill, 1965.

[56]. Mintzberg, H. Operations Research '78. Amsterdam: North Holland, 1979.

[57]. Sage, A.P. "Systems Engineering: Fundamental Limits and Future Prospects." Proceeding of the IEEE, $69(1981): 158-166$.

[58]. Luft, H.S. "Benefit-Cost Analysis and Public Policy Implementation: From Normative to Positive Analysis." Public Policy, 24(4):437-462.

[59]. Cavallo, R.E. Systems Research Movement. New York: The Society for General Systems Research, 1979. 
[60]. Molander, E.A. Responsive Capital ism. New York: MeGraw-Hil1, 1980 .

[61]. Zadeh, L.A. "From Circuit Theory to System Theory." Proceedings of the Institute of Radio Enqineers, $50(1962): 856-865$.

[62]. Zadeh, L.A. "Fuzzy Sets." Information and Control, $8(1965): 338-353$.

[63]. Bellman, R.E., L.A. Zadeh. "Decision-Making in a Fuzzy Environment." Management Science, 17(1970):4.

[64]. Rainville, E.D. Unified Calculus and Analytic Geometry. New York: The Macmillian Co., 1961.

[65]. Cohon, J.L. Multiobjective Programming and Planning. New York: Academic Press, 1978.

[66]. Evans, 6.W. "An Overview of Techniques for Solving. Multiobjective Mathematical Programs." Management Science, $30(1984): 11$.

[67]. Geoffrion, A.M. et al. "An Interactive Approach for Multi-Criterion Optimization, with an Application to the Operation or an Academic Department." Management Science, 19(1972):4.

[68]. Zionts, S., J. Wallenius. "An Interactive Programming Method for Solving the Multiple Criteria Program." Manaoement Science, $22(1976): 6$.

[69]. Zimmermann, H.J. "Fuzzy Programming and Linear Programming with Several Objective Functions." Fuzzy Sets and Systems, $1(1978): 1,45-56$.

[70]. Yager, R.R. "Fuzzy Decision Making Including Unequal Ob jectives." Fuzzy Sets and Systems, 1(1978):2,87-96.

[71]. Takeda, E., T. Nishida. "Multiple Criteria Decision Problems with Fuzzy Domination Structures." Fuzzy Sets and Systems, $3(1980): 2,123-136$.

[72]. Leberling, H. "On Finding Compromise Solutions in Multi-criteria Decision Problems with Fuzzy Minoperator." Fuzzy Sets and Systems, $6(1981): 2,105-118$.

[73]. Hannan, E.L. "Linear Programming with Multiple Fuzzy Goals." Fuzzy Sets and Systems, $6(1981): 3,235-248$. 
[74]. Luhandju]a, M.K. "Compensatory Operators in Fuzzy Linear Programming with Multiple Objectives." Fuzzy Sets and Svstems, $8(1982): 3,245-252$.

[75]. Buckley, J.J. "Fuzzy Programming and the Pareto Optimal Set." Fuzzy Sets and Systems, 10(1983):1,5664.

[76]. Feng, Y.J. "A Method Using Fuzzy Mathematics to Solve Vector Maximum Problem." Fuzzy Sets and Systems, $9(1983): 2,129-136$.

[77]. Hannan, E.L. "On the Efficiency of the Product Operator in Fuzzy Programming with Multiple ob jectives." Fuzzy Sets and Systems, 2(1979):259-262.

[78]. Sakawa, M. "Interactive Fuzzy Decisionmaking for Multiobjective Linear Programming Problems and Its Application." in E. Sanchez, M.M. Gupta, (eds.), Fuzzy Information, Knowledge Representation and Decision Analysis. Oxford: Pergamon Press, 1983.

[79]. Baptistel]a, L.F.B., A. Ollero, "Fuzzy Methodologies for Interactive Multicriteria Optimization." IEEE Trans. Systems Man Cybernet, 10(1980):355-365.

[80]. Fabian, C. et al. "O Metoda Generala Pentru Rezolvarea Problemelor Multicriteriale." Econom. Comp. Econom. Cybernet. Stud. Res. 8(1983):47-55.

[81]. Narasimhan, R. "Goal Programming in a Fuzzy Environment." Decision Science, 11(1980):325-336.

[82]. Slowinski, R. "A Multicriteria Fuzzy Linear Programming Method For Water Supply System Development Planning." Fuzzy Sets and Systems, 19(1986):217-237.

[83]. Rempfer, R.W. "Two Algorithms: Re-aiming and Weighting Approximation." Unpublished paper, 1986.

[84]. Zadeh, L.A. et a1. Fuzzy Sets and their Applications to Cognitive and Decision Processes. New York: Academic Press, 1975.

[85]. Michael, D.N. "Planning's Challenge to the Systems Approach." in H.A. Linstone and W.H.C. Simmonds, (eds.), Futures Research: New Directions. Reading, Mass.: Addison-Wesley, 1977. 
[86]. Wedde, H. "A Formal Method to Deal with Uncertainty in Systems with Concurrent Processes." Proc. of the SGSR, Houston Meeting, 1979.

[87]. Mushkat, M. "Policy Control Through Social Monitoring." Cybernetica, 28(1985):4.

[88]. Zeleny, M. Linear Multiobjective Programming. Berlin: Springer-Verlag, 1974.

[89]. Wu, Wangming, "A Mathematica] Model for Comprehensive Judgment." Journal of Shanghai Normal University, $3(1982): 49-57$.

[90]. Neqoita, C.V. "Structure and Logic in Optimization." Control and Cybernetics, 13(1984):3,121-127.

[91]. Yu, P.L., M. Zeleny. "The Set of All Non-Dominated Solutions in the Linear Case and a Multi-Criteria Simplex Method." J. Math. Anal. Appl., 49(1975):430468 .

[92]. Goedel, K. "Formally Indeterminable Theorems of Principia Mathematica and Related Systems." Monatshaefte fïer Mathematik und Physik, 38(1931):173198.

[93]. Ghassan, K. "New Utilization of Fuzzy Optimization Method." in M.M. Gupta and E. Sanchez, (eds.) Fuzzy Information and Decision Processes. New York: NorthHolland, 1982 .

[94]. Borko, H. Automated Language Processing. New York: John Wiley, 1967. 


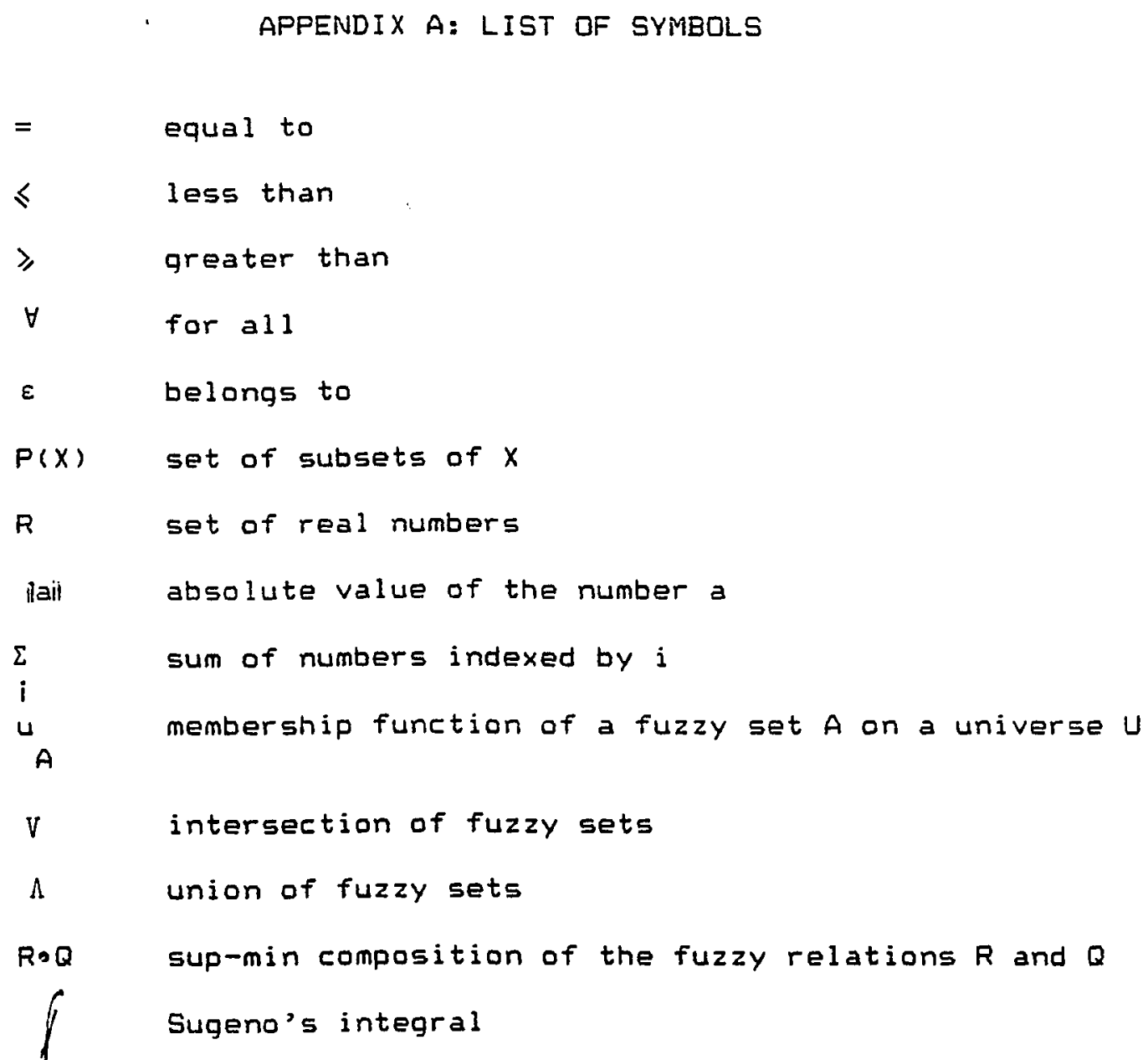

